ORNL/TM-12902

OAK RIDGE

NATIONAL

LABORATORY

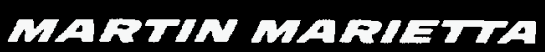

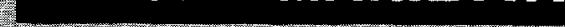
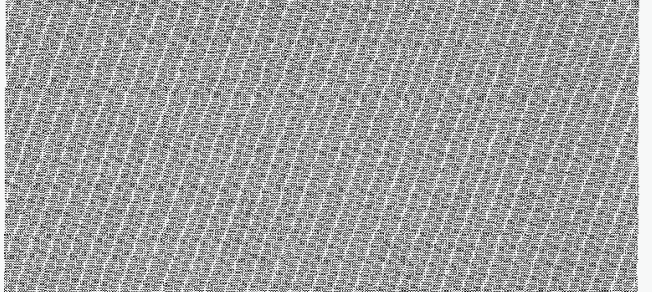

W
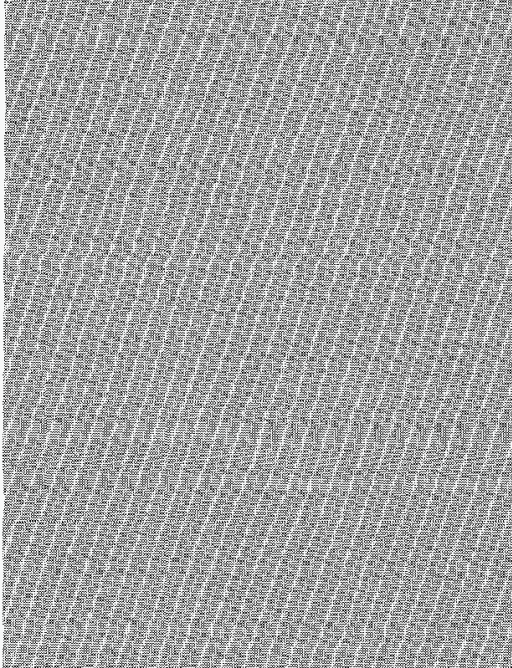

\section{MAMAGED OY}

MARTII MARIETIA ENERGY SYSTEMS, INC. FOR THE UMITED STATES OEPARTIEENT OF ENERGY
High Temperature Materials Laboratory SEVENTH ANNUAL REPORT (October 1993 through September 1994)

\author{
V. J. Tennery \\ P. A. Teague
}


This report has been reproduced directly from the best available copy.

Available to DOE and DOE contractors from the Office of Scientific and Technical Information, P.O. Box 62, Oak Ridge, TN 37831; prices available from (615) 576-8401, FTS 626-8401.

Available to the public from the National Technical Information Service, U.S. Department of Commerce, 5285 Port Royal Rd., Springfield, VA 22161.

This report was prepared as an account of work sponsored by an agency of the United States Government. Neither the United States Government nor any agency thereof, nor any of their employees, makes any warranty, express or implied, or assumes any legal liability or responsibility for the accuracy, completeness, or usefulness of any information, apparatus, product, or process disclosed, or represents that its use would not infringe privately owned rights. Reference herein to any specific commercial product, process, or service by trade name, trademark, manufacturer, or otherwise, does not necessarily constitute or imply its endorsement, recommendation, or favoring by the United States Government or any agency thereof. The views and opinions of authors expressed herein do not necessarily state or reflect those of the United States Government or any agency thereof. 


\section{DISCLAIMER}

Portions of this document may be illegible in electronic image products. Images are produced from the best available original document. 
ORNL/TM-12902

\author{
Metals and Ceramics Division
}

High Temperature Materials Laboratory

\title{
SEVENTH ANNUAL REPORT
}

(OCTOBER 1993 Through SEPTEMBER 1994)

\author{
V.J. Tennery \\ P. A. Teague
}

December 1994

Prepared for:

U.S. Department of Energy

Assistant Secretary for Energy Efficiency and Renewable Energy Office of Transportation Technologies

EE 5104000

Prepared by:

High Temperature Materials Laboratory

OAK RIDGE NATIONAL LABORATORY

Oak Ridge, TN 37831-6062

managed by

MARTIN MARIETTA ENERGY SYSTEMS, INC.

for the

U.S. DEPARTMENT OF ENERGY

under contract DE-AC05-84OR21400 


\section{TABLE OF CONTENTS}

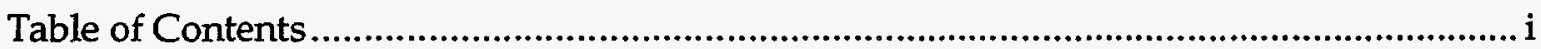

List of Tables and Figures.......................................................................................... iv

List of Research Project Summaries ............................................................................. iv

Abstract.

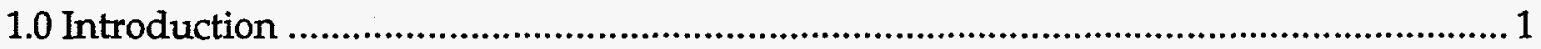

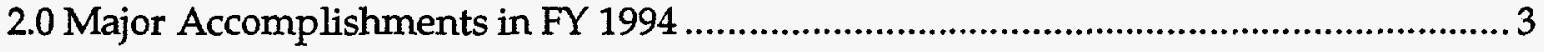

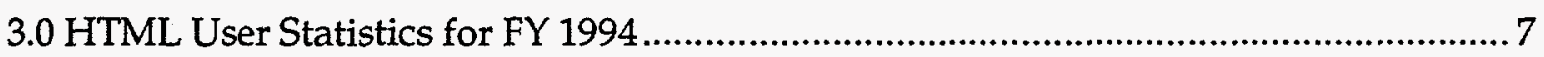

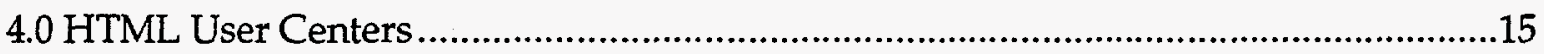

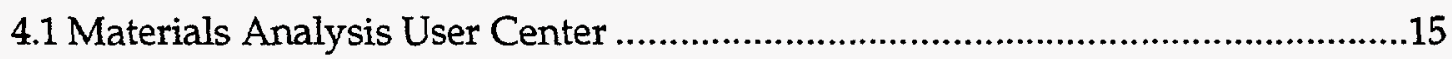

4.1.1 Staff and Current Capabilities...............................................................15

4.1.2 New Capabilities ...................................................................................15

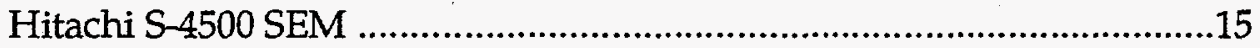

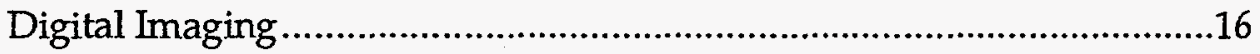

Electron Holography ….....................................................................16

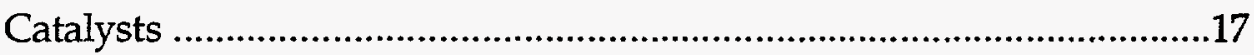

4.2 Mechanical Properties User Center .................................................................17

4.2.1 Staff and Current Capabilities...............................................................17

4.2.2 Major Instruments..........................................................................18

Universal Test Facility ……...............................................................18

Tensile Test Facility …….................................................................19

Environmental Test Facility .............................................................19

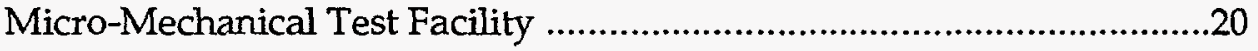

4.2.3 New Capabilities ...............................................................................21

Resonant Ultrasound Spectroscopy Facility ...........................................21

Environmental Tensile Testing Facility ..................................................21

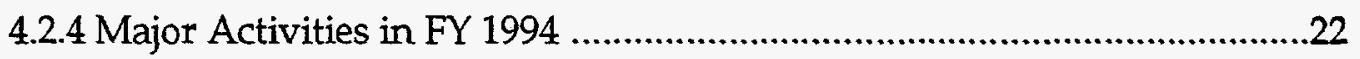

4.3 Physical Properties User Center ......................................................................23

4.3.1 Staff and Current Capabilities....................................................................23

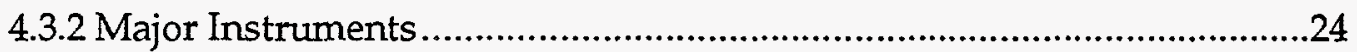

Thermal Analysis...........................................................................24

Thermal Transport...........................................................................24

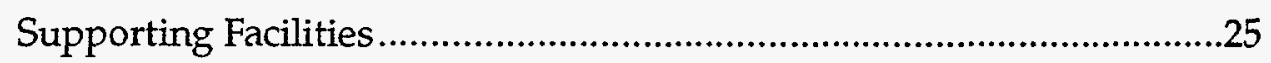

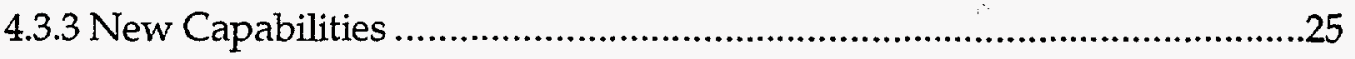




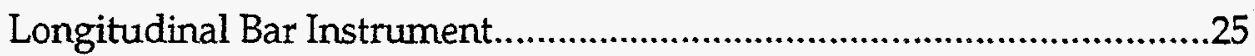

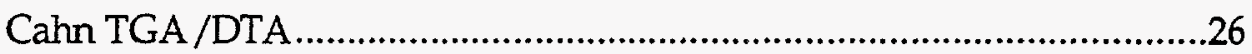

Topometrix Scanning Thermal Conductivity Microscope........................26

Thermal Conductivity of Coatings ...........................................................26

Laser Flash Thermal Diffusivity System ..................................................26

Thermophysical Properties of Molten and Semisolid Metals...................27

4.4 Residual Stress User Center ..............................................................................27

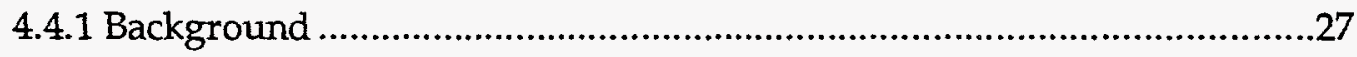

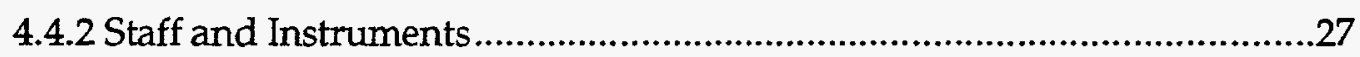

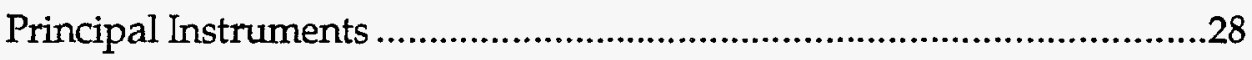

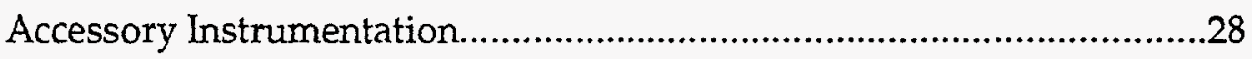

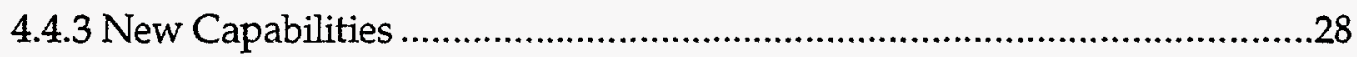

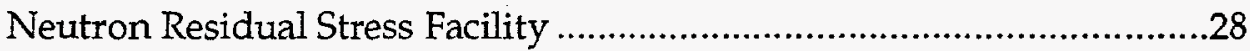

Expansion of the X-Ray Residual Stress Program....................................29

Grazing Incidence X-Ray Diffraction ....................................................29

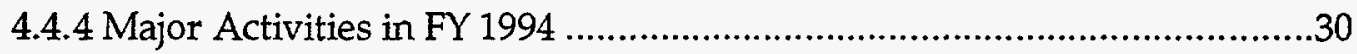

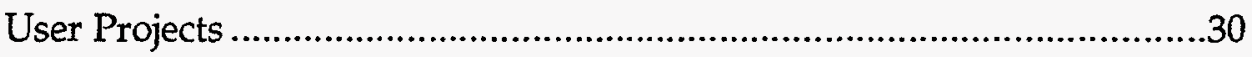

Macro Residual Stress Mapping..........................................................30

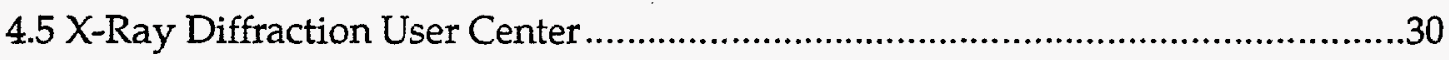

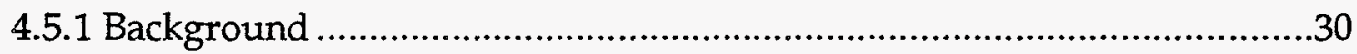

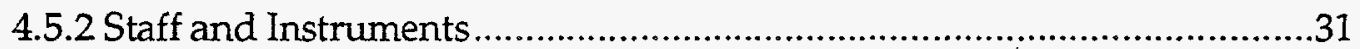

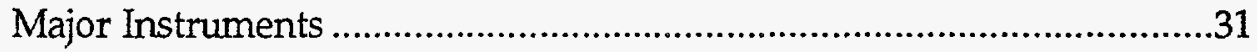

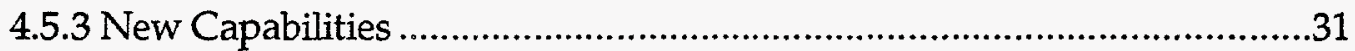

Scanning Position-Sensitive Detector .........................................................31

Rietveld Full-Pattern Refinement Method ...............................................31

Hall-Williamson and Warren-Averback Analysis Package.......................32

Neutron Powder Diffraction ..................................................................

4.6 Ceramic Machining User Center......................................................................32

4.6.1 Staff and Capabilities ..........................................................................32

Major Instruments ..............................................................................33

4.6.2 Major Activities in FY 1994 ................................................................33

4.7 Ceramic Manufacturability Center ……..........................................................33

4.7.1 Staff and Capabilities ..........................................................................

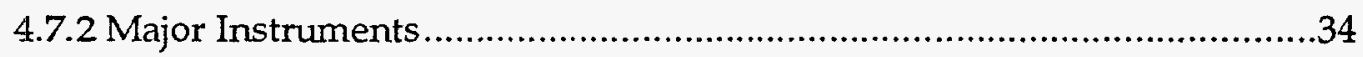

Coordinate Measuring Machine .............................................................34 
Fully Instrumented Creep-Feed Grinder ..................................................34

Cincinnati Milacron Centerless Grinder ..................................................34

5.0 HTML Fellowship Program...........................................................................................35

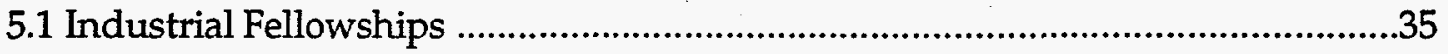

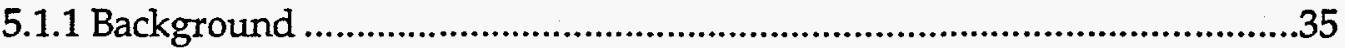

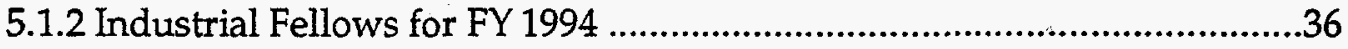

Bangalore A. Nagaraj, G.E. Aircraft Engines ..........................................36

T. Barrett Jackson, LoTEC, Inc...............................................................36

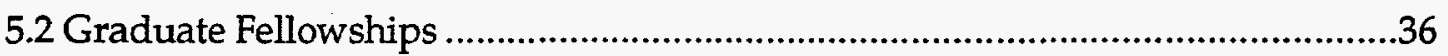

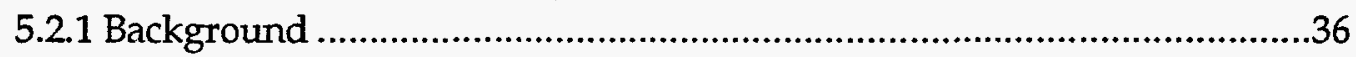

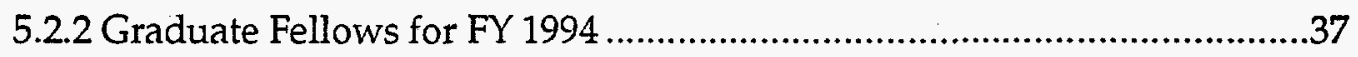

Ron D. Ott, University of Alabama at Birmingham.................................37

J. Allen Haynes, University of Alabama at Birmingham ...........................37

Douglas Taylor, University of Arizona .....................................................38

Alex Cozzi, University of Florida ..........................................................38

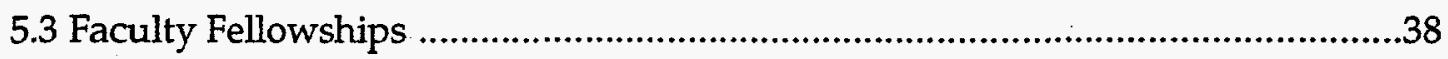

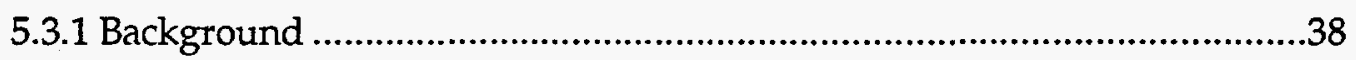

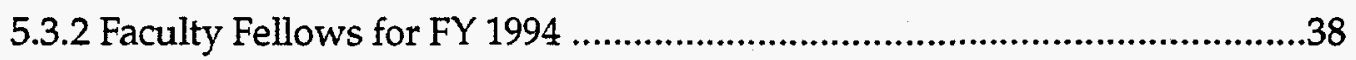

Krishan K. Chawla, New Mexico Tech ..................................................38

Appendix A: FY 1994 Research Project Summaries .........................................................40

A.1 Industrial User Projects (see detailed list below)....................................................41

A.2 University User Projects (see detailed list below) ………....................................54

Appendix B: Publications and Presentations ………......................................................71

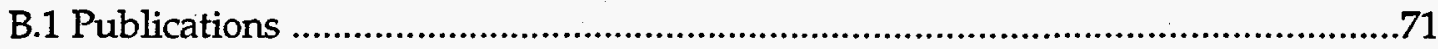

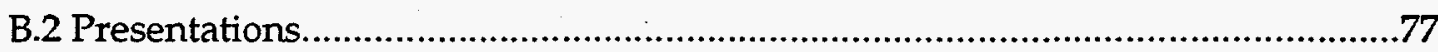

Appendix C: FY 1994 HTML Advisory Committees ......................................................83

Appendix D: Standard Nonproprietary User Agreements In Place...................................85

Appendix E: FY 1994 Nonproprietary Research Proposals ................................................89

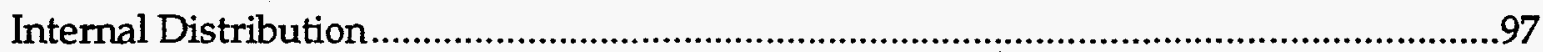

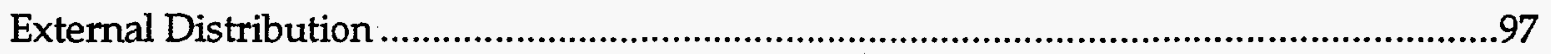




\section{LIST OF TABLES AND FIGURES}

Table 1. FY 1994 HTML User Statistics (Including FY 1993 Statistics for Comparison) ...... 7

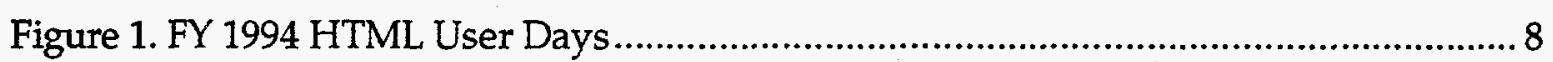

Figure 2. HTML User Days by Quarter Since Third Quarter FY 1987 (Industry and University Only) .............................................................................................................

Figure 3. Total HTML User Days by Quarter Since Third Quarter FY 1987 (Includes ORNL Usage). . .10

Figure 4. Cumulative HTML User Days Since First Quarter of Operation (Industry and University Only). . .11

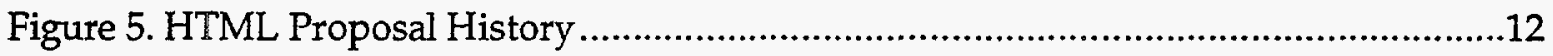

Table 2. HTML User Proposal Statistics for FY 1994 (Including Cumulative Totals).........13

Figure 6. Map Showing Location and Type of HTML User...............................................8

\section{LIST OF RESEARCH PROJECT SUMMARIES}

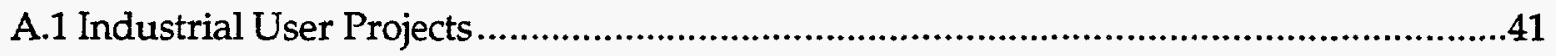

Advanced Refractory Technologies, Inc. ...............................................................41

AlliedSignal, Inc. .........................................................................................

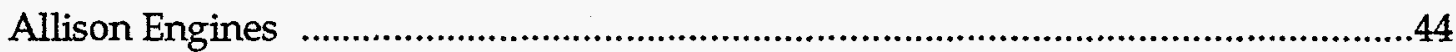

American Superconductor ...........................................................................44

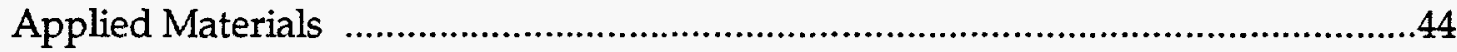

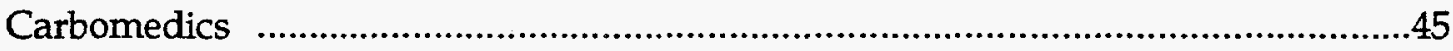

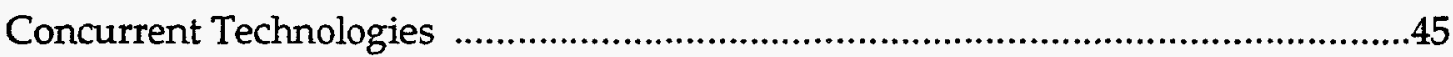

Coors Electronic Package Company …………..................................................45

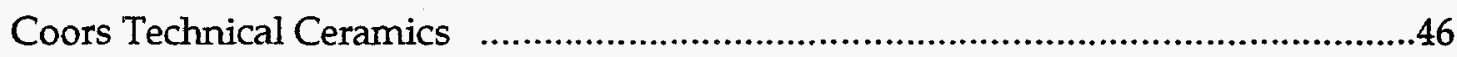

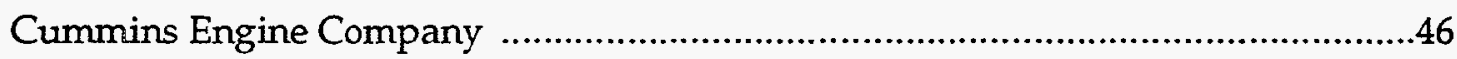

Delco Remy Division of General Motors Corporation.............................................47

Dow Corning Corporation ..............................................................................48

Florida Tile Industries

Ford Research Laboratory ..............................................................................48

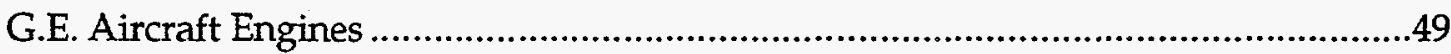

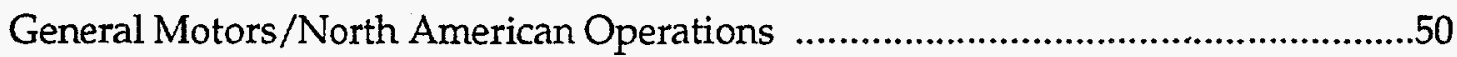

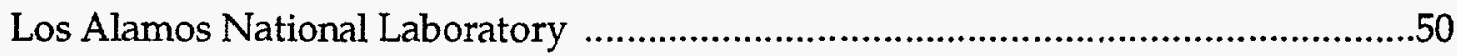

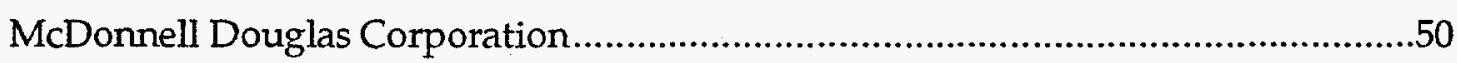

Northrop Corporation ..................................................................................51 
Saint Gobain/Norton Industrial Ceramics ............................................................51

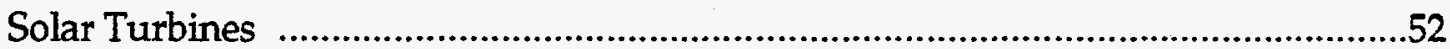

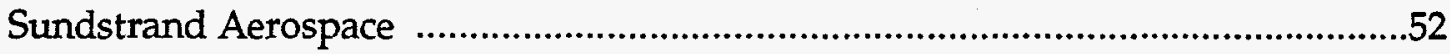

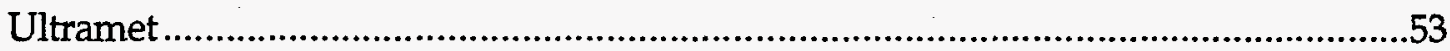

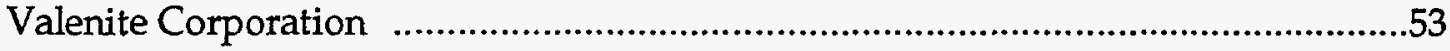

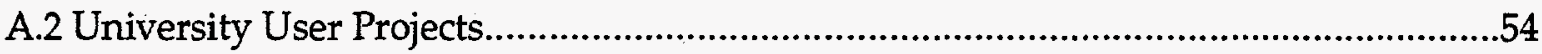

Alabama A\&M University ...................................................................................54

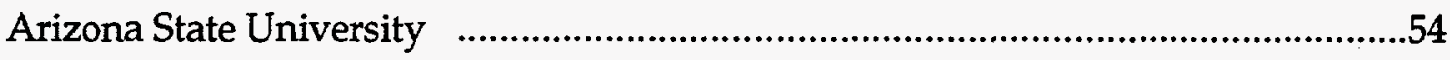

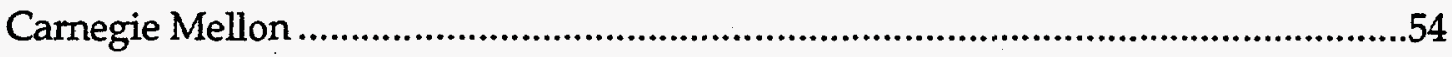

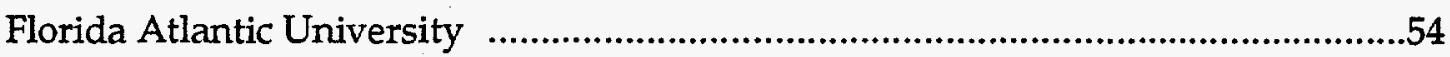

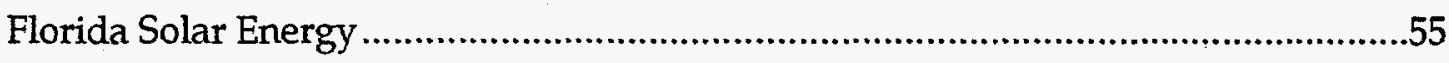

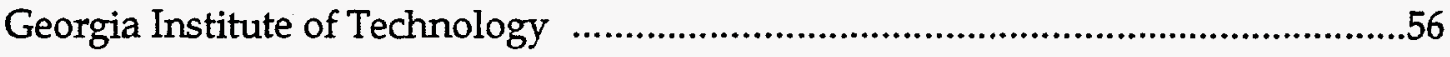

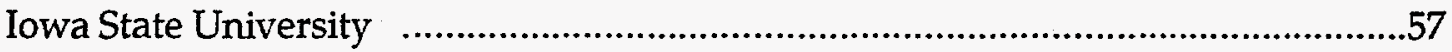

Massachusetts Institute of Technology ...............................................................57

New Mexico Institute of Mining and Technology ….............................................58

North Carolina State University ........................................................................58

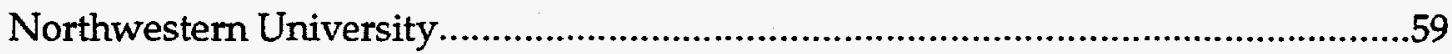

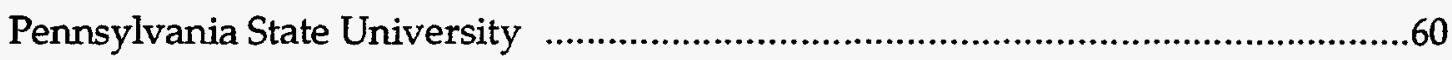

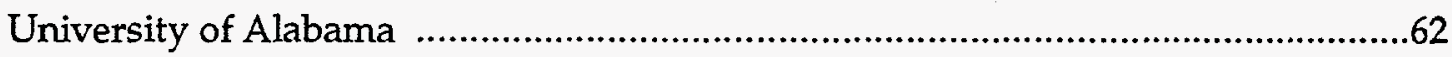

University of Alabama /Birmingham ....................................................................63

University of Dayton .....................................................................................63

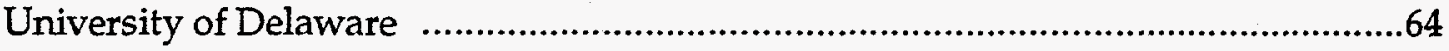

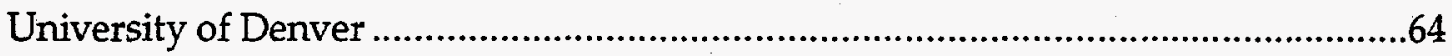

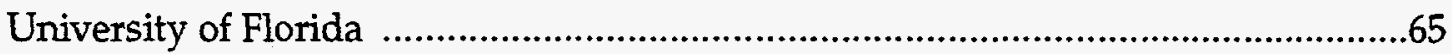

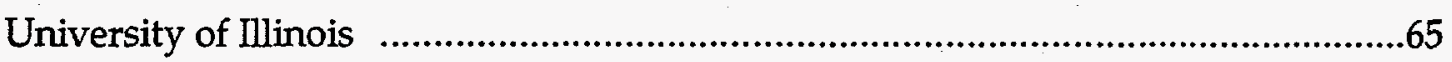

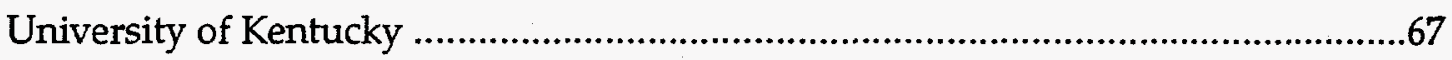

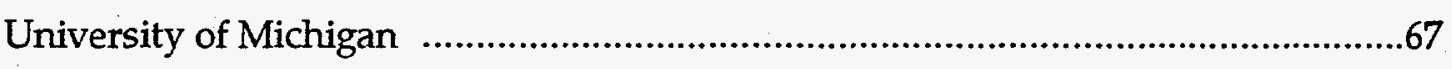

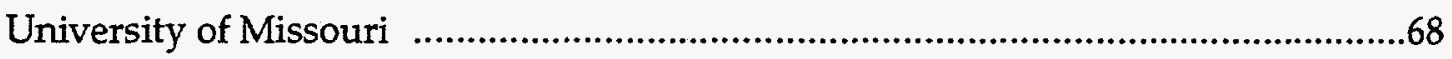

University of New Mexico ............................................................................68

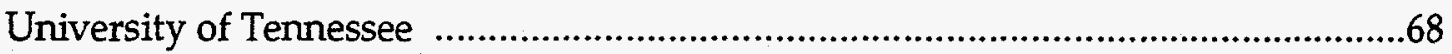

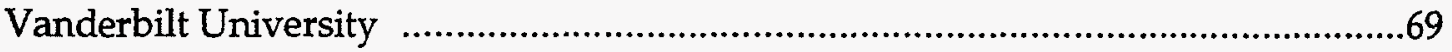

Virginia Polytechnic Institute and State University ……........................................70

West Virginia University .....................................................................................70 


\begin{abstract}
The High Temperature Materials Laboratory (HTML) has completed its seventh year of operation as a designated Department of Energy User Facility at the Oak Ridge National Laboratory. Growth of the User Program has been demonstrated by the number of institutions executing user agreements since the HTML began operation in 1987. A total of 193 nonproprietary agreements ( 91 industry and 102 university) and 41 proprietary agreements (39 industry and two university) are now in effect. This represents an increase of 21 nonproprietary user agreements during FY 1994. (Appendix D lists these nonproprietary user agreements.) Forty-one states are represented by these users.

During FY 1994, the HTML User Program evaluated 106 nonproprietary proposals (46 from industry, 52 from universities, and 8 from other government facilities) and 8 proprietary proposals. Appendix $E$ lists the nonproprietary proposals received during FY 1994. The HTML User Advisory Committee approved about ninety-five percent of those evaluated proposals, sometimes after the prospective user revised the proposal based on comments from the Committee.

This annual report discusses FY 1994 activities in the individual user centers, as well as plans for the future. It also gives statistics about users and their proposals and FY 1994 publications, and summarizes nonproprietary research projects active in FY 1994.
\end{abstract}

\title{
1.0 INTRODUCTION
}

The High Temperature Materials Laboratory (HTML) is a modern research facility that houses a unique collection of instruments for characterizing materials. The instruments in the six HTML User Centers provide a comprehensive set of tools for performing state-ofthe-art determination of the structure and properties of solids and some liquids at high temperatures. A dedicated staff trains and guides the user in conducting the research.

Highly computerized instrumentation is used to improve the efficiency of the data collection and interpretation process. Research projects start as submitted proposals that, when approved, provide the user access to any of the HTML instruments needed to perform the work. User projects typically include research* to relate materials properties to structure or to manufacturing processes, or to train users and provide them access to the equipment necessary to perform their own materials research. Two advisory committees assist in the successful operation of the HTML User Program. Appendix C lists the functions of these committees and their current members.

Early in the User Program, user agreements were developed that established the intellectual property and liability rights of the user institution and Martin Marietta 
Energy Systems, Inc. The first user agreement was signed on July 15, 1987; since that time, more than 190 agreements have been executed.

Two types of standard agreements are used: a "Nonproprietary Agreement" and a "Proprietary Agreement." The nonproprietary user agreement requires that users along with HTML technical staff - jointly publish the results of their research within six months of completing the user project. Proprietary agreements do not require users to publish with HTML staff but do require payment on a full-cost-recovery basis.

*Research sponsored by the Department of Energy, Assistant Secretary for Energy Efficiency and Renewable Energy, Office of Transportation Technologies, as part of the High Temperature Materials Laboratory User Program and the High Temperature Materials Laboratory Fellowship Program, under contract DE-AC05-84OR211400 with Martin Marietta Energy Systems, Inc. 


\subsection{MAJOR ACCOMPLISHMENTS IN FY 1994}

During FY 1994, the HTML experienced steady growth both in the number of users performing research and in the number of proposals received. The User Centers undertook activities in new areas and expanded their existing expertise and capabilities. Following is a list of many HTML accomplishments during FY 1994:

- Received over 100 new requests from university and industrial researchers to use HTML capabilities.

- Initiated beneficial operation of the new Hitachi $S-4500$ high-resolution scanning electron microscope.

- Initiated work on two industrial and two university HTML user proposals in the area of catalyst characterization.

- Completed user project with a major American decorative ceramic tile manufacturer, Florida Tile Industries, which identified the sources of tile imperfections and resulted in substantially improved production.

- Held an International Workshop on Electron Holography. This meeting was a highly successful gathering of nearly 30 invited speakers (20 from Europe and Japan) and approximately 70 other researchers from around the world. The workshop highlighted materials characterization using electron holography.

- Negotiated and signed a book contract with Plenum Press, to edit Introduction to Electron Holography, which will be the first complete text in the field. Publication is expected in late 1995.

- Used an atomic force microscope to confirm the experimental procedures traditionally applied to the calibration of the shape of nanometer-size indentations.

- Examined the role of oxidation in the time-dependent creep failure of advanced ceramics.

- Installed a unique environmental tensile testing capability that permits hightemperature static, dynamic, or tension-tension testing in vacuum or inert environments with extensometry. Using this facility, researchers in the Mechanical Properties User Center (MPUC) performed unique creep-rupture tests in inert environments on a commercially available silicon nitride to examine the effect of mechanical damage in the absence of oxidation-damage effects. Because the masking effects of oxidation are greatly reduced in such testing, the MPUC is now able to study the evolution of creep damage that causes failure.

- Developed specimen grips and procedures required to measure the tensile strength (both at room and high temperatures) of porous or reticulated ceramic foams, a new class of thermal insulator.

- Generated the first high-temperature compressive strength data on reticulated ceramic foams being commercialized by a small ceramic company (Ultramet). 
- Completed numerous creep tests on a developmental nickel-based superalloy; the superalloy is the first to be mechanically characterized in the HTML.

- Completed a high-temperature dynamic fatigue study on a silicon nitride where the acquired engineering data will be used in a gas-turbine engine manufacturer's lifetime prediction code (Allison Engine Co.).

- Performed c-ring and flexure strength tests on a silicon nitride material; the manufacturer (AlliedSignal) is further developing it for commercialization.

- Established a Neutron Residual Stress User Facility (joint project between DOE Energy Efficiency and Renewable Energy, DOE Office of Transportation Technologies, and DOE Energy Research/Basic Energy Sciences; this facility will be operated as part of the HTML Residual Stress User Center. Nondestructive mapping of macro residual stresses through the thickness of a component will - for the first time - enable industry and university users to determine these important stresses. Results will improve life prediction and be used to guide development of process modeling.

This facility has been anxiously awaited by industry and universities, and by automotive, aerospace, and chemical industries. Shortly after initiation of this facility, the HTML received more than 15 proposals requesting over four months of measurement effort. Since the initial announcement, interest in this capability remains high. The HTML has also received requests for proprietary measurements from automotive, heavy duty transport, aluminum processing, and aerospace firms.

- Installed the world's first commercial scanning thermal conductivity microscope in the HTML. This instrument, the first of its kind, can detect differences in thermal conductivity on a submicrometer scale. Microscopic thermal conductivity information is valuable for understanding bulk properties of composites and in studying microscopic structures such as fibers, particles, coatings, and grain boundaries.

- Completed full instrumentation of a very high stiffness creep-feed grinder to collect and present machining data in real time.

- Installed and made operational a $10,900 \mathrm{~kg}$. centerless grinder obtained through a cooperative research and development agreement (CRADA) with Cincinnati Milacron. This grinder, which is being fully instrumented by the industrial partner, will be the only instrumented centerless grinder in the United States.

- Conducted an instrumented transverse grinding study on fracture statistics of a leading U.S. silicon nitride. Results showed unusual strengths and Weibull parameters under selected grinding conditions.

- Prepared test specimens that will be used in an International Energy Agency task, with Germany, Sweden, Belgium, Japan, and the United States as participants.

- Specified and procured a new instrumented cylindrical grinder.

- Participated in a national work shop on cost-effective manufacturing of structural ceramics, held in Oak Ridge on August 23, 24, and 25; the workshop included group 
tours and orientations for HTML User Centers.

- Conducted approximately 70 briefings and tours of HTML facilities during this fiscal year, including the following:

- Secretary of Energy

- Director, Office of Energy Research, DOE

- Assistant Secretary of Energy Efficiency and Renewable Energy, DOE

- Examiner from the Office of Management and Budget

- C4 Committee of the Partnership for a New Generation of Vehicle (PNGV)

- Numerous other committees of the PNGV and Clean Car organizations

- Galvin Commission 



\subsection{HTML USER STATISTICS FOR FY 1994}

This section shows graphs and tables that summarize HTML User Program statistics, including user "demographics" and proposal history. Table 1 shows the types of users and number of user days accumulated in this the seventh year of HTML operation. FY 1993 numbers are included for comparison.

\begin{tabular}{|l|cc|cc|cc|}
\cline { 2 - 7 } \multicolumn{1}{c|}{} & \multicolumn{2}{c|}{$\begin{array}{c}\text { Number of } \\
\text { User Institutions }\end{array}$} & \multicolumn{2}{c|}{$\begin{array}{c}\text { Number of } \\
\text { Individual Users }\end{array}$} & \multicolumn{2}{c|}{ User Days } \\
\hline $\begin{array}{c}\text { Type of } \\
\text { User }\end{array}$ & FY 1993 & FY 1994 & FY 1993 & FY 1994 & FY 1993 & FY 1994 \\
\hline Industry & 30 & 36 & 46 & 67 & 2,695 & 4,719 \\
University & 20 & 32 & 47 & 72 & 1,353 & 2,163 \\
ORNL* & - & - & 101 & 103 & 9,666 & 7,301 \\
\hline Totals & 50 & 68 & 194 & 242 & 13,714 & 14,183 \\
\hline
\end{tabular}

*Internal use by other ORNL programs

Table 1. FY 1994 HTML User Statistics (Including FY 1993 Statistics for Comparison) 
Figure 1 shows the number of eight-hour user days logged per quarter during FY 1994. The user days are divided among industrial, university, and ORNL users. During the four quarters, the number of industrial user days ranged from 1021 to 1500; university user days ranged from 282 to 694 per quarter. Additionally, researchers from other ORNL programs logged user days ranging from 1224 to 2522 per quarter.

FY 1994 HTML User History (Including ORNL Users)

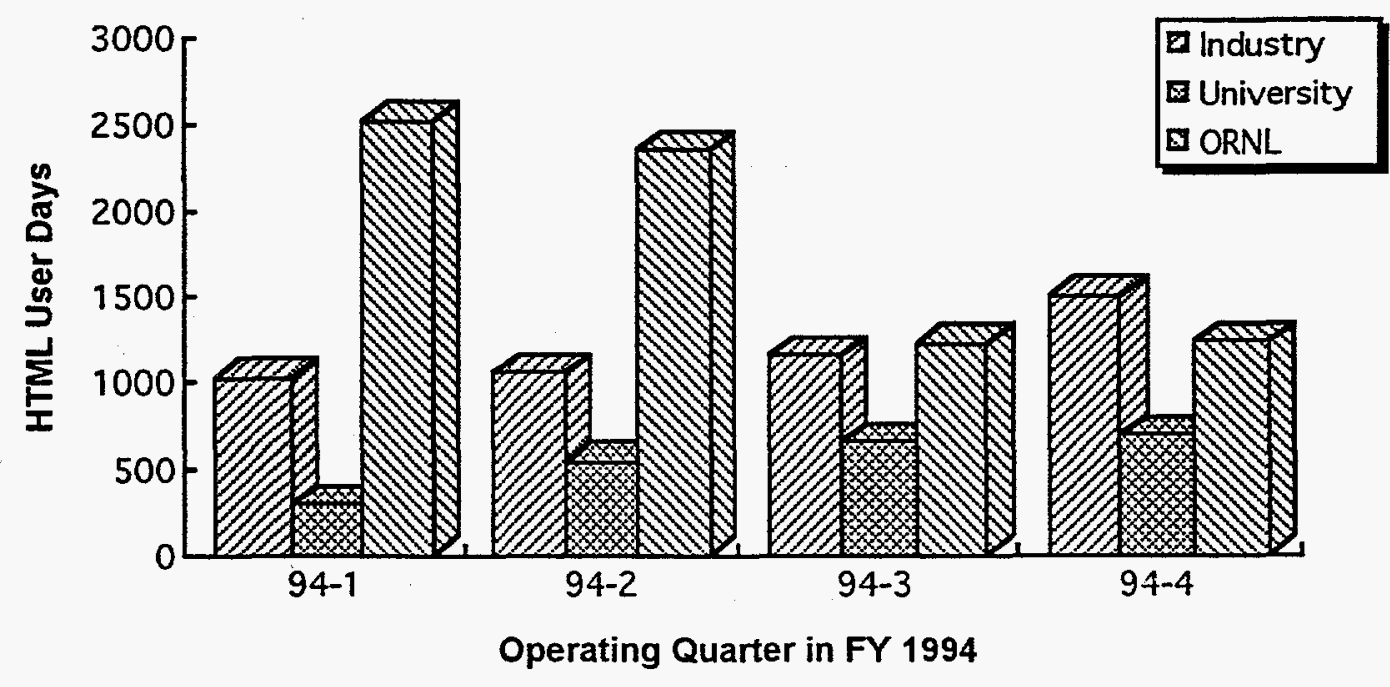

Figure 1. FY 1994 HTML User Days 
Figure 2 is a summary of HTML user activity by quarter since the beginning of the HTML User Program (in the third quarter of FY 1987). The user days are divided into industrial and university user days (ORNL usage is not included in these totals). The graph clearly shows the strong growth trend experienced in the past four quarters (quarters 27 through 30 represent FY 1994).

\section{HTML User Days by Quarter of Operation}

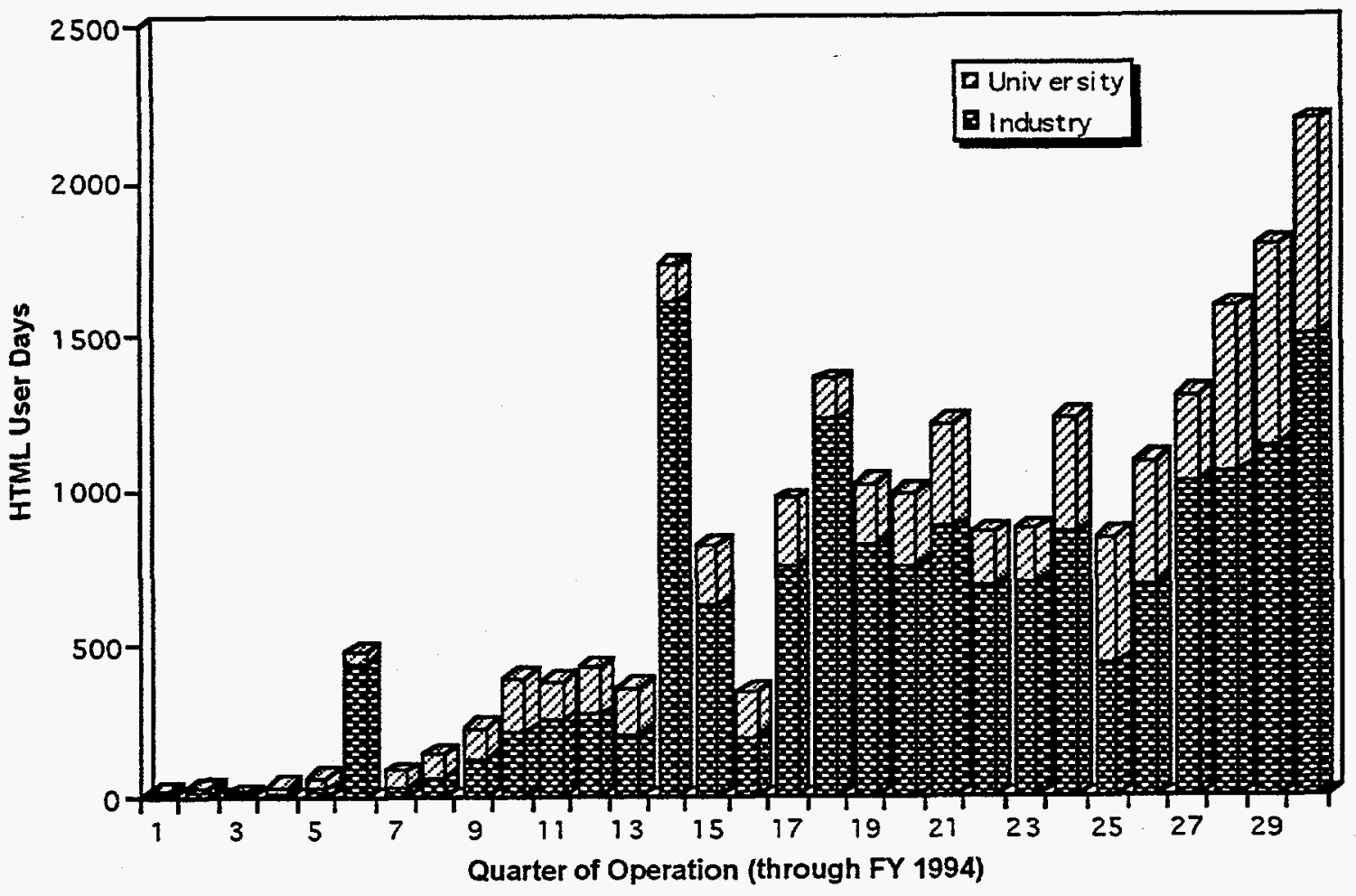

Figure 2. HTML User Days by Quarter Since Third Quarter FY 1987 (Industry and University Only) 
For comparison, Figure 3 shows total HTML user days by quarter since the first quarter of operation; internal (ORNL) usage is included in the graph.

Total HTML User Days by Quarter of Operation (Includes ORNL Usage)

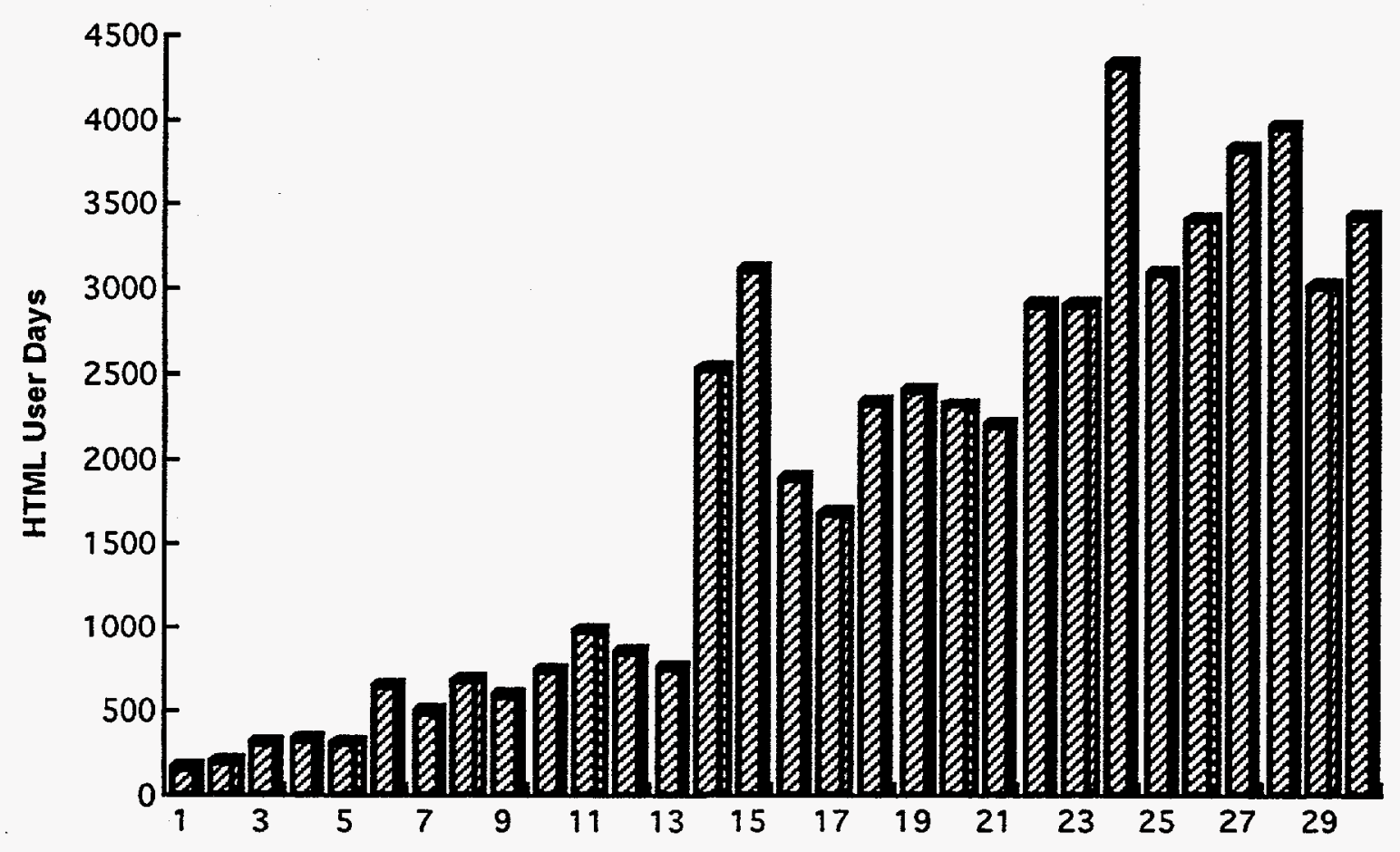

Figure 3. Total HTML User Days by Quarter Since Third Quarter FY 1987 (Includes ORNL Usage) 
Figure 4 shows cumulative user days for all thirty quarters of operation. ORNL usage is not included.

Cumulative HTML User Days by Quarter of Operation

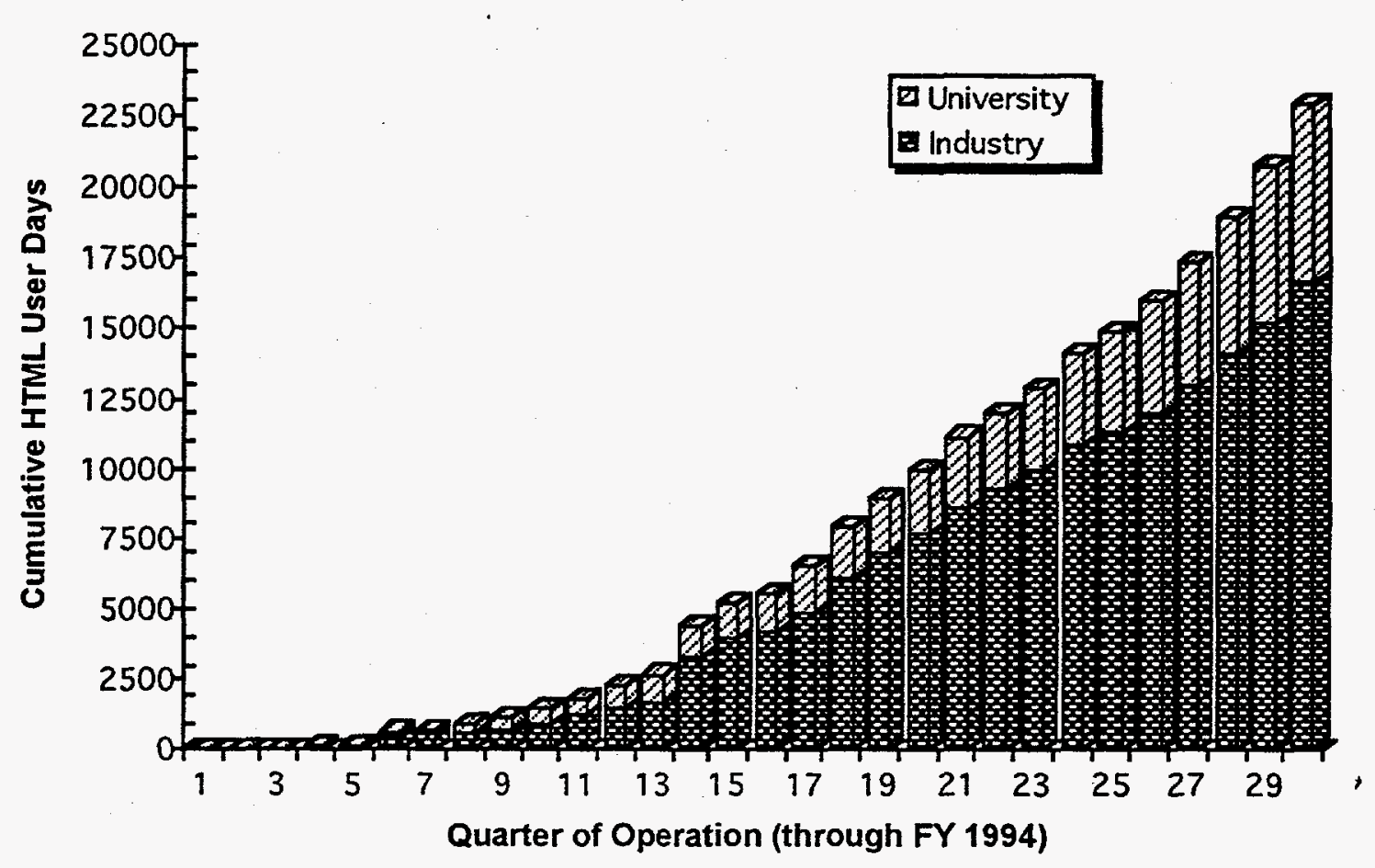

Figure 4. Cumulative HTML User Days Since First Quarter of Operation (Industry and University Only) 
Figure 5 shows the proposal activity in the program over its history. The data show that the industrial proposal level increased from 54 in FY 1993 to 60 in FY 1994, an increase of about twelve percent. The number of university proposals increased from 50 to 52 . Thus, for FY 1994, the HTML User Program processed and approved a total of 112 proposals. About five percent of the proposals submitted could not be accommodated.

HTML Proposal History by Fiscal Year (Industry and University Proposals)

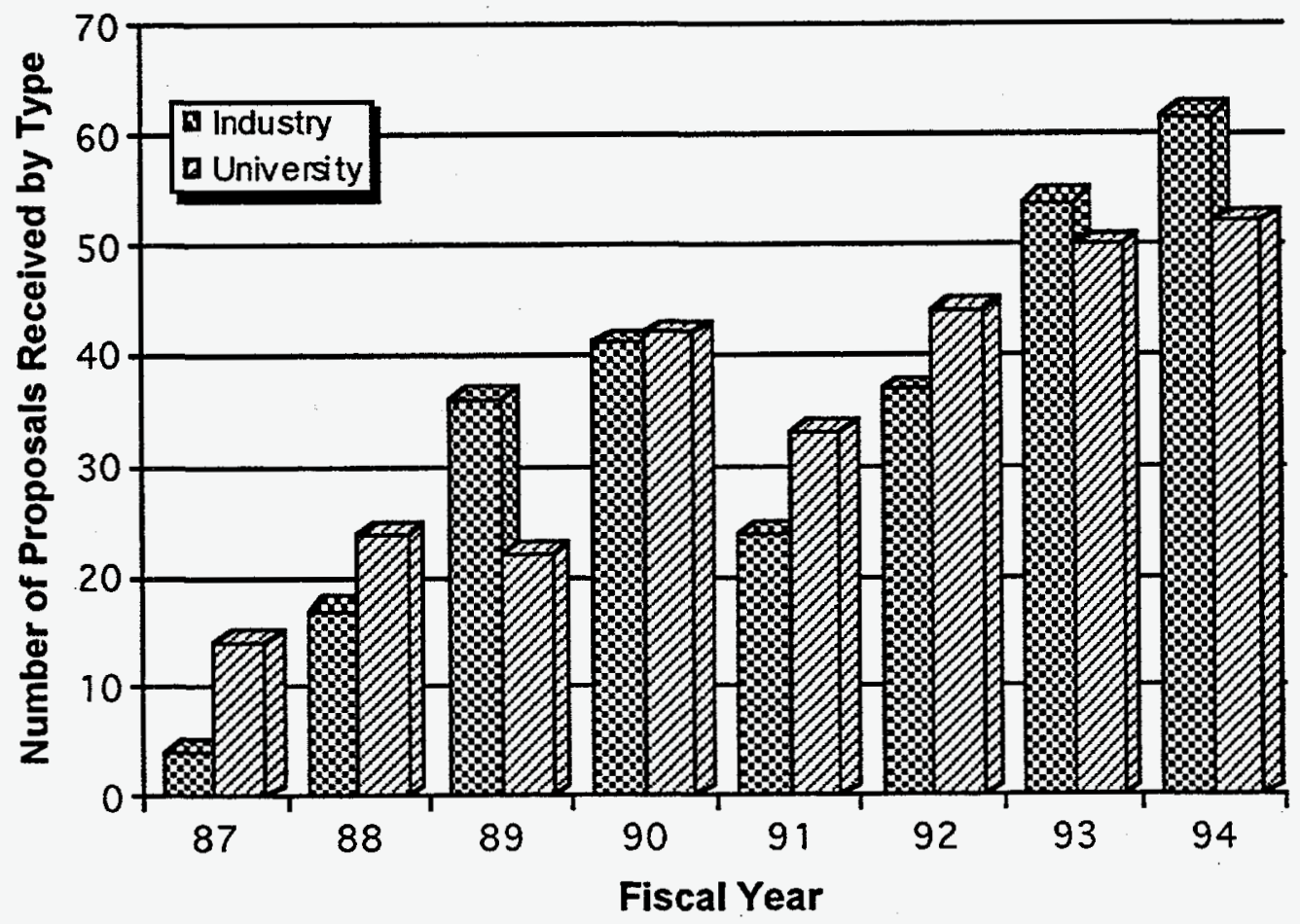

Figure 5. HTML Proposal History 
Table 2 shows the categories and total number of proposals received in the HTML.

\begin{tabular}{|c|c|c|c|}
\hline \multirow[b]{2}{*}{ Type of User } & \multicolumn{2}{|c|}{ HTML Research Proposals Received } & \multirow[b]{2}{*}{$\begin{array}{l}\text { Cumulative } \\
\text { through FY } 1994\end{array}$} \\
\hline & $\begin{array}{l}\text { Cumulative } \\
\text { through FY } 1993\end{array}$ & FY 1994 & \\
\hline Industry & 173 & 46 & 219 \\
\hline University & 221 & 52 & 273 \\
\hline $\begin{array}{l}\text { Other Government } \\
\text { Organizations }\end{array}$ & 8 & 8 & 16 \\
\hline Total Nonproprietary & 402 & 106 & 508 \\
\hline Proprietary & 37 & 8 & 45 \\
\hline Grand Totals & 439 & 114 & 553 \\
\hline
\end{tabular}

Table 2. HTML User Proposal Statistics for FY 1994 (Including Cumulative Totals) 



\subsection{HTML USER CENTERS}

\subsection{MATERIALS ANALYSIS USER CENTER}

\subsubsection{STAFF AND CURRENT CAPABILITIES}

The Materials Analysis User Center (MAUC) uses electron microscopy and surface chemical analysis techniques to characterize the structure and chemistry of advanced structural materials. The information obtained from these characterizations is used to elucidate the mechanisms that control material performance.

Mr. T. A. (Ted) Nolan is Group Leader of the MAUC. Additional MAUC staff members are listed below, along with the instruments for which they have primary operating responsibility:

- Dr. L. F. (Larry) Allard - Hitachi HF-2000 Field Emission Gun Transmission Electron Microscope

- Mr. D. N. (Dave) Braski - PHI 660 Scanning Auger Microprobe and Topometrix Scanning Probe Microscope

- Ms. D. W. (Dorothy) Coffey - Hitachi S-800 Field Emission Gun Scanning Electron Microscope and S-4500 800 Field Emission Gun Scanning Electron Microscope

- Dr. D. L. (Debra) Joslin - JEOL 4000EX High-Resolution Transmission Electron Microscope and 2000FX Analytical Electron Microscope

- Dr. K. L. (Karren) More - JEOL 4000EX 4000EX High-Resolution Transmission Electron Microscope and 2000FX Analytical Electron Microscope

- Ms. C. L. Smite - Group administrative support

- Dr. E. (Edgar) Völkl - (post-doctoral appointee) Electron Holography

\subsubsection{NEW CAPABILITIES}

\section{Hitachi S-4500 SEM}

The MAUC added an important new instrument to its suite of instruments in the past year. The new Hitachi S-4500 ultra-high resolution SEM achieved beneficial operation in January 1994. This instrument provides the MAUC with world-class capability for imaging the surfaces of specimens with diameters of up to 15 centimeters at a resolution of one nanometer or better at medium voltage, and 3.5 nanometers or better at very low voltage on the specimen. Thus, it is ideal for studying fine surface details on large ceramic components such as high-temperature tensile fatigue-tested Si3N4 specimens.

The instrument is equipped with an energy-dispersive $X$-ray detector and new software from National Institute of Standards and Technology that permits quantitative analysis of chemical compositions. It also allows researchers to generate $X$-ray maps that image the distribution of elements over the specimen surface. This software runs on the Macintosh simultaneously with the digital imaging software, making the acquisition of data from the microscope very facile and easy to learn. 


\section{Digital Imaging}

The MAUC took the final steps toward becoming a complete digital imaging laboratory by adding digital control systems for the Hitachi S-800 and S-4500 scanning electron microscopes, installing a new digital camera system for the JEOL 4000EX high-resolution transmission electron microscope, and placing the order for a digital camera for the JEOL 2000FX transmission electron microscope. Eliminating the need to record images on film has resulted in our decommissioning both the enlarging darkroom and the plate developing darkroom in the MAUC laboratory suite.

These rooms have been converted to better uses. For example, the enlarging darkroom now houses several of our specimen preparation instruments, including a new ion beam sputter coater. This instrument is used to deposit ultra-fine grained coatings in the 1 nanometer thickness range for high-resolution scanning electron microscope imaging of non-conductive specimen surfaces. A major advantage of achieving a complete digital imaging capability was eliminating the chemical waste stream associated with film processing. Members of the MAUC staff won the ORNL 1994 Pollution Prevention Award for these efforts.

In addition, users now have the option of transporting their analyzed and annotated images and spectra to their home institution on optical disc or on magnetic media. We are also instituting the use of Internet communications to transport user data. The MAUC is a national leader in the area of digital microscopy and has been asked by the Microscopy Society of America to conduct a national workshop on this subject.

\section{Electron Holography}

The electron holography project, funded by an award from the Laboratory Director's Research and Development, was successfully concluded; our laboratory co-hosted the International Workshop on Electron Holography August 29-31, in Knoxville, Tennessee. This workshop was strongly supported by funds from the Japan Research and Development Corporation, which supports the Tonomura Electron Wavefront Project through the Exploratory Research and Technology Program in Japan.

Dr. Tonomura, of the Hitachi Advanced Research Laboratory, felt that a meeting in the United States would best showcase the results of his program. Ultimately, international recognition of the MAUC's successful project in this exciting, newly developing field of electron microscopy led to Knoxville, Tennessee being chosen as the meeting site.

As a result of our electron holography capabilities (see individual project descriptions), we have generated a number of new user projects; several of these new research areas are particularly promising for development into future projects. Additionally, Dr. Edgar Völkl, a post-doctoral scholar working in the MAUC, wrote and copyrighted a sophisticated software package - HoloWorks - for processing and analyzing holograms. ORNL has licensed HoloWorks to Gatan Co. in Pleasanton, California.

This suite of programs provides a capability for more extensive processing of digital data associated with electron holography than any other such program currently available in the world; it is already in high demand by all of the major laboratories that are equipped with field emission electron microscopes. HoloWorks is proving to be quite valuable in our user environment since it greatly simplifies the steps necessary to realize useful 
information from holograms. Thus, it facilitates holography-based user projects involving researchers who are not experts in electron microscopy.

As in digital imaging, the MAUC is also the national leader - and one of the three top laboratories in the world - in electron holography. For example, the May 1994 issue of the Microscopy Society of America Bulletin was a special issue devoted to "Coherent Beam Imaging and Digital Microscopy"; the MAUC's Larry Allard was Guest Editor of this issue. Larry is also the principal editor for the first comprehensive book on methods of electron holography.

\section{Catalysts}

With increased emphasis on supporting the automotive and diesel engine industry in the United States, we have begun a program that emphasizes the relationship of the microstructure of catalyst materials to catalyst performance. The MAUC is uniquely positioned to assume this task. The combination of capabilities such as ultra-high spatial resolution elemental analysis, atomic-level structure imaging, and small particle morphology determination using electron holography presently exist only in our laboratory.

The MAUC staff has considerable expertise in materials research on emission reduction catalysts and fine particle analysis in general. We are currently involved in cooperative research and development agreement (CRADA) activities in this area and have begun several HTML User Program activities with both industrial and university partners. The first HTML faculty fellow, Professor Abhaya Datye of the University of New Mexico, studied catalyst materials during the summer of 1993 (his work was reported in the FY 1993 HTML annual report).

The principal emphasis of his research was to elucidate microstructure in real catalyst systems as opposed to model systems that typically use large single crystals and esoteric surface chemical analytical techniques. We have determined that a majority of the research in catalysis uses model systems; there is a major need for research that bridges the gap between model systems and the real world of multi-constituent, multi-phase catalysts used to reduce automotive emissions.

\subsection{MECHANICAL PROPERTIES USER CENTER}

\subsubsection{STAFF AND CURRENT CAPABILITIES}

The Mechanical Properties User Center (MPUC) is dedicated to the study of the mechanical performance of high-temperature materials. The Group Leader of the MPUC is Dr. M. K. Ferber. Other staff and their areas of expertise are as follows:

- Dr. Hongda Cai - Assessment of R-curve and strength behavior, contact damage and fatigue, and damage characterizations using novel techniques

- Ms. D. Green - Group administrative support

- Mr. T. P. Kirkland - Measurement of mechanical properties of structural materials

- Dr. E. Lara-Curzio - Characterization of macro- and micro-mechanical behavior of ceramic composites, fiber testing, and modeling of the constitutive equations for 
mechanical performance in ceramic composites

- Ms. L. Riester - Indentation and flexure testing

- Dr. A. A. Wereszczak - Characterization of the tensile creep/fatigue behavior of structural ceramics, fracture toughness testing, and evaluation of interfacial properties in fiber-reinforced ceramic composites

\subsubsection{MAJOR INSTRUMENTS}

The development of advanced materials for heat engine applications has been a major thrust area of research and development programs in the United States for over ten years. The two primary drivers for these research activities have been increased fuel efficiency and lower emissions. In addition to DOE-sponsored programs, the industrial sector (diesel engine, automotive, gas turbine manufacturers, and materials suppliers) has committed substantial resources to developing new and improved materials for a number of heat engine applications.

In the case of high-temperature structural materials, several mechanical performance issues must be resolved before engine components fabricated from these materials are commercialized. For newly developed materials, short-term mechanical property data (strength, fracture toughness, hardness) are required for process optimization and verification. For relatively mature material systems, an extensive database describing mechanical performance as a function of time (creep, stress rupture, cyclic fatigue) is necessary for the design of engine components having an acceptable lifetime.

Such data are also critical to the development and verification of life prediction models. Finally, the implementation of cost-effective manufacturing technologies for component fabrication generally relies on mechanical property data to ensure that the mechanical performance of the component is comparable to that established during initial development of the material.

A major barrier to measuring these mechanical performance data has been the limited availability of state-of-the-art facilities. This has been particularly true for advanced ceramics and ceramic and metal matrix composites, which require specialized hardware for high-temperature property measurements. To address this problem, the MPUC makes such facilities available to U.S. industries and universities through the HTML User Program. Current capabilities include a universal test facility, a world-class tensile test facility, an environmental test facility, and a micro-mechanical test facility.

\section{Universal Test Facility}

The universal test facility currently consists of six pneumatic test frames, each having the capability of loading three flexure samples, and a universal (electromechanical) test machine equipped with a high-temperature furnace. Users are able to conduct a number of standard mechanical property tests, including static fatigue (time to failure measured as a function of static stress), dynamic fatigue (fracture stress measured as a function of loading rate), cyclic fatigue (cycles to failure measured as a function of cyclic stress), fast fracture tensile and compressive strength, and shear strength.

Process engineers have used data generated from this facility to optimize and verify the mechanical performance of their materials. In addition, studies involving flexure (and 
c-ring) testing have focused on measuring the cyclic fatigue behavior of silicon nitride ceramics at room temperature, the effect of processing on the high-temperature behavior of aluminum nitride ceramics, and the evaluation of the time-dependent strength of $\mathrm{SiC}$ $\mathrm{SiC}$ ceramic composites.

\section{Tensile Test Facility}

The tensile test facility consists of ten electromechanical test machines equipped with passive couplers and grips for accommodating either button-head tensile specimens or flat specimens, one electromechanical test machine fitted with fixed wedge-grips for flat composite specimens, and a servohydraulic test machine capable of tension-tension and tension-compression loading of button-head specimens.

The operation of all test machines is controlled with integral, electronic load controllers and function generators, which allow three principal test modes: ramp at a controlled rate, ramp and hold at a constant load, and tension-tension cyclic loading. All machines are also equipped with short $(100 \mathrm{~mm})$, resistance-heated furnaces capable of $1600^{\circ} \mathrm{C}$ maximum temperature or $1500^{\circ} \mathrm{C}$ for sustained testing in ambient air. Six machines are equipped with contacting, capacitance extensometers that have resolutions of $\sim 0.1 \mu \mathrm{m}$ at room temperature and $\sim 0.5 \mu \mathrm{m}$ at $1500^{\circ} \mathrm{C}$.

During FY 1994, the MPUC conducted extensive studies of the strength, creep, and fatigue behavior of silicon nitride button-head specimens at temperatures in the range of $900^{\circ}$ to $1400^{\circ} \mathrm{C}$. A major objective of these studies was to measure the temperature and stress sensitivities of the dominant failure mechanisms and then compare the resulting experimental data to model predictions. A major finding from these tests was that when failure was controlled by creep damage generation and accumulation, the fatigue life was uniquely determined by the steady-state creep rate (i.e., Monkman-Grant behavior). A second objective was to verify the expected improvements in creep and fatigue resistance of a HIPed silicon nitride that resulted from processing modifications to the intergranular phase.

\section{Environmental Test Facility}

The MPUC has used the environmental test facility to study the effects of environment on mechanical performance. This instrument consists of two electromechanical test machines fitted with vacuum chambers. The first environmental test facility, which has a high-temperature clamshell furnace and ceramic retort, allows researchers to conduct both compression and flexure tests in air, inert gas, or vacuum to temperatures up to $1500^{\circ} \mathrm{C}$. The second environmental test facility is equipped with a vacuum chamber, $a$ diffusion pump, a regenerative gettering furnace, and a temperature controller.

The vacuum chamber accommodates passive couplers for minimizing bending, and has a sidecar attachment that houses a strain-measuring, contact extensometer. The mechanical and diffusion pumps together can readily achieve a vacuum less than $10^{-5}$ torr. The regenerative gettering furnace is used to purify inert gases to less than $1 \mathrm{ppm} \mathrm{O}_{2}$ its regenerative capability allows for a long-term, continuous gas supply without requiring the replacement of spent gettering media. A graphite hot zone is used, which achieves $1600^{\circ} \mathrm{C}$ with a temperature gradient of less than $\pm 5^{\circ} \mathrm{C}$ across the $35 \mathrm{~mm}$ gage length of a standard button-head specimen. 


\section{Micro-Mechanical Test Facility}

The micro-mechanical test facility has been instrumental in studying the mechanical behavior of thin films, thermal barrier coatings, polymers, and fiber/matrix interfaces in composites. This facility consists of the mechanical properties microprobe (or the nanoindenter) and the interfacial test system. The mechanical properties microprobe is a special microhardness tester capable of operating at loads in the microgram range $(0-20$ $\mathrm{mN}$; a high-load range $(0-120 \mathrm{mN})$ is also available.

Unlike conventional hardness testers, the micro-mechanical test facility does not require researchers to determine the area of an indent optically in order to calculate hardness. Instead, the height of the indenter relative to the surface of the specimen is constantly monitored with a sensitive capacitance gage, thus allowing the depth of an indent to be determined. The unique feature of the mechanical properties microprobe is its ability to measure indent depths to \pm 0.2 nanometers. The area of the indent is then calculated from a knowledge of the geometry of the tip of the diamond indenter.

The load is also constantly monitored, with the result that hardness is reported as a function of displacement. Measurements of sample stiffness from unloading data permit a separation of the plastic and elastic components of displacement; the projected areas for indents can then be calculated on the basis of the plastic depth of the indents. The elastic moduli of samples can also be estimated from stiffness data.

Motion of the specimen stage in the $x-y$ plane is also precisely controlled. The indenter can be positioned within $2 \mu \mathrm{m}$ of any chosen point on the specimen, and a series of indents, separated by steps as small as $0.1 \mu \mathrm{m}$, may be made in any geometrical pattern. The entire operation of the system is computer controlled; one or several series of indents may be specified and carried out without further operator intervention.

The characterization of the micromechanical behavior of continuous fiber ceramic composites often relies on the use of mechanical properties microprobe-based indentation techniques for the measurement of interfacial properties (including debond stress, interfacial shear stress, and residual stress). These techniques typically involve generating a load-displacement curve associated with sliding of individual fibers. The corresponding instrumentation is currently limited by its inability to test fibers exhibiting a wide range of diameters (5 to $100 \mu \mathrm{m}$ ). This limitation arises from insufficient load capability, low spatial resolution of stages used to position the fiber with respect to the indenter, and insufficient resolution of the transducers used to measure fiber displacement.

The development of the interfacial test system represents a major effort to address these limitations. The interfacial test system is capable of measuring the load and displacement associated with both fiber push-in and push-through tests. The fibers are positioned using an $x-y$ table capable of precise movement to greater than $0.5 \mu \mathrm{m}$. An optical microscope is used to locate fibers for indentation loading. A large-screen monitor connected to the microscope camera is used for easy viewing of the fibers.

The indenter and load cell are mounted on a separate bracket adjacent to the stages. This bracket is designed to accommodate load cells covering a range of load capabilities. The indenter holder also accommodates several WC- and diamond flat-bottomed probes, as 
well as a standard Vickers indenter. The specimen is loaded into the indenter using a zstage, which is mounted on top of the $x-y$ table. During testing, the displacement is measured to $0.1 \mu \mathrm{m}$ using an encoder mounted on the shaft of the z-stage. A personal computer controls the operation of the entire system, including data storage and analysis.

\subsubsection{NEW CAPABILITIES}

\section{Resonant Ultrasound Spectroscopy Facility}

A resonant ultrasound spectroscopy facility (NDI-502 by Quatrosonics) has been installed and tested in the HTML for characterizing and inspecting the mechanical integrity of ceramic specimens and components. Resonant ultrasound spectroscopy is based on the principle that the mechanical resonance of a component, which depends on its shape, density, elastic moduli, and defects, is sufficiently complex that measuring the resonant frequencies provides a signature unique to the component.

Changes in the shape, density or elastic moduli, or introduction of defects lead to a variation of this signature. The resonant ultrasound spectroscopy system consists of a controller, a signal generator, two or more transducers, and a receiver. The resonance spectrum is generated by sweeping the frequency of an ultrasound signal applied to the component and by detecting the resonance frequencies of the component.

A major advantage of the resonant ultrasound spectroscopy technique is its high sensitivity. Deviations as small as a few parts per million can be detected. Furthermore, the test is very fast, requiring as little time as a few seconds. The resonant ultrasound spectroscopy technique can be applied to determining the full elastic constants of isotropic and anisotropic materials (such as single crystals, textured polycrystals, and composites) to a high accuracy. Because of the high sensitivity of this method, it is potentially suitable for characterizing and inspecting the mechanical integrity of ceramic specimens and components. The HTML is presently evaluating the resonant ultrasound spectroscopy technique for characterizing creep damage in silicon nitride and other ceramic materials.

\section{Environmental Tensile Testing Facility}

The HTML recently designed and installed a new environmental tensile testing facility. Using this facility, researchers can conduct high-temperature static, tension-tension cyclic, or dynamic loading in vacuum or inert environments up to $1600^{\circ} \mathrm{C}$ using the button-head tensile specimen geometry. The environmental tensile testing facility is a vacuum chamber mounted on an Instron 1380 testing machine (screw-driven), a mechanical pump, a diffusion pump, a regenerative gettering furnace, and a temperature controller. The vacuum chamber accommodates Instron's Supergrip couplers for bending minimization and has a sidecar attachment that houses a strain-measuring, contact extensometer. The Instron 1380 may be operated in load or displacement control and may be used for static loading, tension-tension cyclic loading ( $1 \mathrm{~Hz}$ maximum), and dynamic loading up to $35 \mathrm{kN}$.

The following question may be posed: If a material or component is mechanically stressed at high temperatures in an ambient environment, how / why can mechanical testing in vacuum or inert environments at high temperatures provide any representative or useful data or information? Mechanically stressing a material or component at 
elevated temperatures in an ambient environment frequently generates two different types of damage: that resulting from the applied stress (e.g., creep damage, cavitation, etc.) and that resulting from oxidation-associated corrosion (e.g., surface cracking).

By conducting tests in both an ambient environment and a non-oxidizing environment, the damage contribution from mechanical stressing and oxidation can be decoupled, thus providing insight into the evolution of each type of damage. This information is not attainable by testing only in air. Using this same methodology, the MPUC staff currently is examining the evolution of creep damage and oxidation-associated damage in silicon nitride.

\subsubsection{MAJOR ACTIVITIES IN FY 1994}

Norton Advanced Ceramics, in collaboration with the HTML, examined the role of oxidation on Norton's NCX-5102 silicon nitride. Comparative creep-rupture tests in air and inert environments provided insight into how the damage mechanisms evolve in this material as a function of crystallization treatment, creep, and oxidation.

In an HTML project, we used the scanning force microprobe to measure in three dimensions the residual nanometer-sized impressions made by the mechanical properties microprobe. Data generated to date have shown that consistent variations in the impression geometry can arise from the non-ideal shape of the diamond indenter. We are further using these results to calibrate the mechanical properties microprobe, which will improve the accuracy of the data generated by our users.

Working with a user from Ultramet, MPUC researchers were able to generate hightemperature engineering compressive strength data on $\mathrm{SiC}$ - and C-reticulated ceramic foams. These carbon foams had to be tested in an inert environment at elevated temperatures. The resulting data, which are the first of their kind, are being used to guide the development of this important material class, which is being considered for use as insulation for reentry vehicles.

Alabama A\&M University and Teledyne Allvac conducted high-temperature creep tests on a developmental nickel-based superalloy. Engineering creep data were needed to survey its development and for potential marketing purposes.

AlliedSignal is using HTML capabilities to develop a relatively low-cost silicon nitride material to be used for structural applications at elevated temperatures. Researchers studied properties of the material, including creep rupture. The results of these studies were introduced back into the AlliedSignal development cycle.

Advanced Refractory Technologies (ART) conducted flexure strength studies to track the development of an AIN material that they hope to commercialize at a production level. The facilities provided by the MPUC successfully accommodated the company.

Dow Corning initiated a long-term collaboration effort through the HTML User Program to determine the effects of temperature, loading rate, and matrix additives on the tensile strength of continuous fiber-reinforced ceramic matrix composites currently under development at Dow Corning. Also investigated were the effects of temperature, stress, and matrix additives on the fatigue resistance of these materials. These materials are being considered for use in heat exchangers and combustion liners and in several parts of 
chemical pumps.

We complemented these Dow Corning studies with interlaminar shear strength measurements and with single-fiber interfacial measurements. The latter tests were aimed at determining the bond strength and the sliding resistance of the reinforcing fibers and the evolution of these properties during typical service conditions. The Federal Business Development Director at Dow Corning recently commended the MPUC staff for our efforts on this project.

AlliedSignal studied the effect of different modes of machining on the tensile strength of continuous fiber-reinforced Blackglas ${ }^{\mathrm{TM}}$ composites. (Blackglas ${ }^{\mathrm{TM}}$ is a polymer-derived ceramic developed by AlliedSignal.) The results of this study indicated that there was not a significant difference in the strength of this material after being machined in the green or the after-pyrolysis states using abrasive water jet cutting or diamond grinding. These results are significant because abrasive water jet machining is cheaper and has a shorter turnaround time than diamond grinding.

Northrop conducted a study to determine the effects of thermal treatments on the interfacial and mechanical properties of continuous fiber-reinforced Blackglas ${ }^{\mathrm{TM}}$ composites. Of interest was the effect of exposure to aqueous environments on the composite interfacial properties. Using single-fiber push-out tests on the interfacial test system developed at the HTML, MPUC researchers determined that some of the boronbased fiber coatings investigated were unstable after combined exposure to air and steam at elevated temperatures.

One of the merits of this type of study is that it is possible to predict the macroscopic response of ceramic matrix composites by knowing the interfacial properties of the material. Therefore, it suffices to conduct single-fiber interfacial tests using samples about $1 \mathrm{~cm}$ long, $0.5 \mathrm{~cm}$ wide, and $1 \mathrm{~mm}$ thick as a screen test to determine the true potential of the material before conducting more extensive (and expensive) tests such as tensile testing.

\subsection{PHYSICAL PROPERTIES USER CENTER}

\subsubsection{STAFF AND CURRENT CAPABILITIES}

The Physical Properties User Center (PPUC) is dedicated to measuring thermophysical properties as a function of temperature and correlating these properties with the processing, microstructure, and performance of materials. Specifically, the PPUC staff works with users to determine thermophysical properties such as thermal diffusivity, thermal conductivity, specific heat, and thermal expansion and to characterize the thermal stability, high-temperature reactions and compatibility, high-temperature oxidation, and corrosion properties of materials. The materials studied include structural ceramics, superalloys, ceramic and metal matrix composites, superconducting materials, ceramic precursors, carbon materials, and carbon fiber composites.

The Group Leader of the PPUC is Dr. C. R. (Cam) Hubbard. Other members of the Diffraction and Thermophysical Properties Group with prime responsibilities include the following:

- Dr. S. C. (Steve) Beecher (post-doctoral appointee) - Thermal transport 
- Mr. Tim Corrigan - Co-op student

- Dr. R. B. (Ralph) Dinwiddie - Thermal transport

- Ms. J. (Joy) Kilroy - Group administrative support

- Mr. W. D. (Wally) Porter - Thermal analysis

\subsubsection{MAJOR INSTRUMENTS}

The major facilities of the PPUC are divided into two areas: thermal analysis and thermal transport.

Thermal Analysis

The thermal analysis laboratory instruments include a simultaneous thermal analyzer (STA = DTA + TGA + MS) and a differential scanning calorimeter, both capable of operation to $1500^{\circ} \mathrm{C}$ in inert or oxidizing atmospheres. The thermal analysis laboratory also contains a dual push rod dilatometer for bulk thermal expansion measurements to $1500^{\circ} \mathrm{C}$.

A large-mass, high-temperature, high-sensitivity Cahn TGA with DTA attachment provides measurement capability to $1700^{\circ} \mathrm{C}$ for samples having masses to $100 \mathrm{~g}$. This unit permits measurements in vacuum, inert, oxidizing, and corrosive atmospheres, and thus considerably extends the PPUC's capabilities in thermal analysis.

- Stanton Redcroft STA1500 Simultaneous Thermal Analyzer

- Differential thermal analysis (DTA)

- Thermogravimetry (TG)

- Evolved gas analysis (EGA)

- Stanton Redcroft DSC1500 Differential Scanning Calorimeter

- Theta Dual Push Rod Dilatometer

- Cahn Thermogravimetry (TGA) with concurrent Differential Thermal Analysis (DTA)

\section{Thermal Transport}

The thermal transport instruments include the following:

- Holometrix Laser Flash Thermal Diffusivity System

- Xenon Flash and Step-Heat Thermal Diffusivity System

- Longitudinal Bar Thermal Conductivity System

- Topometrix Scanning Thermal Conductivity Microscope

The laser flash and xenon flash systems determine thermal diffusivity of materials under a variety of conditions. With the laser flash system (discussed in more detail in Section 4.3.3, "New Capabilities"), researchers can make measurements as a function of 
temperature to $2000^{\circ} \mathrm{C}$. The xenon flash system, optimized for room-temperature thermal diffusivity measurements, has recently been modified to permit measurement by the "step heat flux" method, which measures thermal diffusivity of heterogeneous materials, including laminar composites.

The step heat modification permits us to measure low thermal conductivity materials. In addition, the xenon flash software has been modified to determine the thermal diffusivity of coatings on substrates of known thermal conductivity. A major U.S. aircraft turbine manufacturer is currently using the system to study the effect of thermal aging on thermal barrier coatings for turbine engine components.

A scanning thermal conductivity microscope, currently under development, will map the thermal conductivity on a micrometer scale. A new laser flash thermal diffusivity system, scheduled to be delivered in the late 1994, will allow - for the first time - measurement of thermal diffusivity of molten metals, as well as 2-and 3-layer samples. This system is discussed in more detail in Section 4.3.3, "New Capabilities."

\section{Supporting Facilities}

- Five-cell helium pycnometer

- Sample preparation facilities, including the following:

- Diamond core drill

- Low-speed diamond cutoff saw

- Diamond band saw

- Vacuum deposition chamber

- Polisher

- MicroVAX 4200 file server connected by Ethernet to each instrument's computer

\subsubsection{NEW CAPABILITIES}

\section{Longitudinal Bar Instrument}

The longitudinal bar thermal conductivity system provides for steady-state measurement of thermal conductivity from $80^{\circ} \mathrm{K}$ to $500^{\circ} \mathrm{K}$. These measurements, coupled with the elevated temperature measurements, are important in modeling thermal conductivity in solids (in terms of grain size, impurities, and crystal defects). Projects currently scheduled to employ this system include self-reinforced silicon nitride, silicon nitride/molybdenum composites, and aluminum nitride.

This system, which has just become operational and is in the final test phase prior to beneficial use, takes rod- or bar-shaped samples approximately 25 to $60 \mathrm{~mm}$ long. This makes the sample preparation and quantity particularly convenient to users. Data from this system are essential for modeling the sources of thermal resistivity. Such fundamental knowledge is essential when thermal conductivity property improvements are desired. 


\section{Cahn TGA/DTA}

The PPUC procured and installed two new instruments in 1994. The Cahn TGA/DTA system provides for measurement to $1700^{\circ} \mathrm{C}$, which is $200^{\circ}$ higher than the Stanton Redcroft STA unit. The Cahn TGA also is very sensitive ( 1 ppm) to weight change, while at the same time capable of measurement on large specimens (to $100 \mathrm{~g}$ ). The Cahn TGA allows researchers to test oxidizing, inert, reducing, and corrosive atmospheres; this is a capability that will benefit industry in studying the stability of a material in various environments. The first studies scheduled to be conducted on this instrument involve studies of growth of alumina layers between a metallic bond coat and zirconia thermal barrier coatings with General Electric Aircraft and Mr. Allen Haynes, HTML Fellow.

\section{Topometrix Scanning Thermal Conductivity Microscope}

The Topometrix Scanning thermal conductivity microscope, which is the first instrument of its kind in the world, can detect differences in thermal conductivity on a submicrometer scale. It was built by Topometrix to specifications and using concepts developed at the HTML. The system simultaneously operates as a conventional atomic force microscope with topographic imaging capabilities and measures thermal conductivity contrast. Factors that influence the performance of the instrument were studied. The most important include probe force, scan speed, surface moisture, and extraneous heat sources. Cooperative efforts with Topometrix are underway to improve the sensitivity and to develop quantitative thermal conductivity mapping with submicrometer resolution.

Microscopic thermal conductivity information is valuable in the understanding of bulk properties of composites, as well as in the study of microscopic structures such as fibers, particles, coatings, and grain boundaries. The system has been successfully used in several user projects. Development and application of this system is also sponsored by the DOE Office of Energy Efficiency and Renewable Energy Continuous Fiber Ceramic Composite program.

\section{Thermal Conductivity of Coatings}

PPUC researchers also developed software to determine thermal diffusivity of coatings. Coatings are being widely used to increase the performance life of gas turbine engine hot-section components, with a future goal of increasing operating temperatures and, hence, fuel efficiency. This new capability enhances the HTML's ability to study the effects of processing conditions, thermal history, and microstructure on the thermal conductivity of high-performance coatings.

The software was tested using a plasma-sprayed zirconia-coated René 142 specimen and a free-standing, plasma-sprayed zirconia coating supplied by G.E. Aircraft Engines. The results from the bi-layer analysis are in excellent agreement with the thermal diffusivity

of the free-standing coating. The method is being applied by G.E. Aircraft to develop the database of property data needed for predicting the life of the thermal barrier coating.

\section{Laser Flash Thermal Diffusivity System}

The PPUC is obtaining a new laser flash thermal diffusivity system, which will significantly expand our thermal transport measurement capabilities and replace the 
aging, unreliable laser flash system. This system will operate from $-50^{\circ} \mathrm{C}$ up to $2400^{\circ} \mathrm{C}$ in vacuum or inert gas. Tests may be made in oxidizing or reducing atmospheres from $25^{\circ} \mathrm{C}$ to $1700^{\circ} \mathrm{C}$. A six-sample carousel will greatly increase the number of tests that can be made in a single day. In addition to standard disc-shaped samples, the new system will also measure square plates, powders, molten metals, and coatings.

Thermophysical Properties of Molten and Semisolid Metals

After carefully assessing industry's current and future needs for knowledge of thermophysical properties, the PPUC expanded its focus to include measuring the properties of molten and semisolid metals. These data have recently become very valuable in the national efforts to model materials processes such as welding, casting, quenching, and hot forging or rolling. The PPUC received several user proposals and inquiries for such data in this past year. The new laser flash thermal diffusivity system can determine the thermal diffusivity of these difficult-to-measure materials. The PPUC is also researching methods for determining the density of molten metals; current plans include testing one method based on our existing dilatometer.

\subsection{RESIDUAL STRESS USER CENTER}

\subsubsection{BACKGROUND}

User projects and DOE programs are increasingly concerned with life prediction and failure analysis. In many of these cases, knowledge of residual stress gradients (sign and magnitude) as a function of location at both the surface and within a component is vital information. The Residual Stress User Center (RSUC) was established three years ago to meet this need and to provide a facility for research into controlling residual stresses, either through modifying the forming and finishing processes or the design, or through stress-relief procedures. RSUC activities, which continue to expand, now include both the $X$-ray residual stress facility and the neutron residual stress facility (discussed in detail in Section 4.4.3) for measuring macro (long-range) and micro (short-range) residual stresses in polycrystalline materials.

\subsubsection{STAFF AND INSTRUMENTS}

The neutron residual stress facility (NRSF) is operated in a team mode, with members of the Metals and Ceramics (M\&C), Solid State (SSD), and Instrument and Controls (I\&C) Divisions participating. Unless otherwise noted, the following staff members are from the Metals and Ceramics Division. Dr. C. R. (Cam) Hubbard is the Program Leader; other team members include the following:

- Mr. Sean Agnew (co-op student) - Neutron diffraction data analysis

- Mr. Alex Chediak (co-op student) - X-ray residual stress

- Dr. K. J. (Kris) Kozaczek - X-ray texture and residual stress - alloys

- Ms. J. (Joy) Kilroy - Group administrative support

- Mr. David Schenk (co-op student) - Neutron diffraction instrumentation

- Dr. S. (Steve) Spooner (SSD) - Residual stress mapping by neutron diffraction (Support staff from High Flux Isotope Reactor [HFIR], SSD): operation and 
instrumentation support in HFIR

- Dr. X.-L. (Xun-Li) Wang - Micro and macro residual stress by neutron diffraction

- Dr. T. R. (Tom) Watkins - X-ray residual stress and high temperature X-ray diffraction

- Dr. Michael Wright (I\&C) - Instrumentation design for NRSF

Principal Instruments

- Scintag PTS 4-axis goniometer with 18-kW rotating-anode generator

- Scintag PTS 4-axis goniometer with 2-kW sealed-tube generator

- HB-2 spectrometer with XYZ mapping system for macro residual stress mapping

- HB-4 spectrometer for micro residual stress analysis

Accessory Instrumentation

- Position-sensitive and Peltier Si(Li) X-ray detectors

- Laser position sensor for X-ray PTS units

- Grazing incidence optics

- Strain gauge capabilities

- Tensile load frame for use on the neutron diffraction mapping facility

- Huber full-circle goniometer for use on the neutron diffraction mapping facility

\subsubsection{NEW CAPABILITIES}

\section{Neutron Residual Stress Facility}

A cooperative joint effort - signed in April 1994 between DOE Office of Energy Efficiency and Renewable Energy, DOE Office of Transportation Technologies; and DOE Energy Research/Basic Energy Sciences, Division of Material Sciences - established a new user facility: the Neutron Residual Stress Facility (NRSF). This joint program is a direct result of a multiyear Laboratory Director's Research and Development project proposed and lead by HTML staff at the ORNL High Flux Isotope Reactor.

The Neutron Residual Stress Facility is operated by a team consisting of staff from the HTML in the M\&C Division and the Neutron Scattering Group in the Solid State Division at ORNL. The goal of the joint program is to establish and operate a user facility for macro and micro residual stress analysis in conjunction with the existing $X$-ray facilities of the RSUC in HTML. We currently are meeting this goal by using a portion of the beam time on a Solid State Division spectrometer. Another goal is to develop a dedicated instrument at HFIR optimized for macro residual stress analysis, and thus to greatly expand both the capabilities and speed of measurement. This instrument is currently scheduled for completion in FY 1996. 


\section{Expansion of the X-Ray Residual Stress Program}

In the last year, besides establishing the Neutron Residual Stress Facility, the RSUC expanded the $X$-ray residual stress program to meet the industrial and academic demand through user proposals. For example, users had begun requesting texture measurements for correlating anisotropic materials properties with materials performance. To meet the demand for both residual stress measurement and texture measurement, the RSUC purchased and installed a second Scintag PTS unit in January 1994. Subsequent user projects on this instrument have been about equally split between texture and residual stress characterization. Having this second instrument also enables us to focus the use of the high flux system on problems where the additional flux is necessary. This has been particularly valuable in our development of the grazing incidence $X$-ray diffraction method (discussed below).

To further enhance the X-ray facilities, the RSUC purchased two accessories. The first, a laser-positioning sensor, allows researchers to place the specimen at the correct height quickly and reproducibly. This is particularly valuable for determining the stress gradient as a function of depth below the surface in studies involving multiple electropolishing steps in metal specimens.

The second, a position-sensitive detector for the high flux system, is now available to speed data collection by a factor of five. This enables users to collect more accurate data faster and to study more samples. The position-sensitive detector works best when there is low fluorescence radiation and relatively sharp diffraction peaks. When these two conditions are not met, we use the Peltier-cooled Si(Li) solid state detector to step scan over the diffraction peak.

\section{Grazing Incidence X-Ray Diffraction}

One of the exciting developments in the $X$-ray residual stress area was demonstrating grazing incidence $X$-ray diffraction methods for depth profiling residual stresses over a very shallow, near-surface region of specimens. grazing incidence $X$-ray diffraction employs low angles of $X$-ray incidence and thereby reduces the depth of $X$-ray penetration. By approaching the angle of total external reflection, the depth of sampling can range from tens of angstroms to a few micrometers. With this technique, diffraction information about phase content, texture, and residual stress can be obtained as a function of sampling depth.

In a project with the University of Denver, RSUC researchers used grazing incidence $X$-ray diffraction to study the residual stresses in Mo thin films deposited on glass substrates. Tests with stress-free specimens showed the instrument was free of aberrations. For the Mo films, we observed changes in interplanar spacing as the grazing incidence angle was changed, revealing a change in residual stress with depth. The application of this technique to nondestructive characterization of grinding damage in ceramics appears particularly promising due to the range of depth profiling and the location of subsurface damage. The RSUC is currently pursuing projects to support further development of this technique. 


\title{
4.4.4 MAJOR ACTIVITIES IN FY 1994
}

\author{
User Projects
}

In the last year, the residual stress facilities have also been used on a number of DOE projects, including stresses in clad boiler tubes, weld overlays, thermal barrier coatings, and depth profiling of stresses by neutron and $\mathrm{X}$-ray methods in carburized and quenched automotive gears. These projects have universally led to additional nonproprietary user projects, as well as proprietary projects from industrial users. The neutron residual stress facility was used in three proprietary projects during the fiscal year; the staff is currently working with candidate users in conducting research and developing additional proposals.

\section{Macro Residual Stress Mapping}

The demand for macro residual stress mapping by neutron diffraction currently exceeds the time available. For example, in September there were user projects and DOE projects with industrial users needing over 60 instrument days. Since the program receives only 10 to 15 days of neutron beam time per month, the backlog is substantial.

To meet this demand as soon as practical, we have broken the new instrument development task down into several components. The first component involves expanding the number of detectors from one to seven. We have placed the orders for these special position-sensitive neutron detectors, and final designs are being developed for mounting them on the existing spectrometer. This will increase our measurement capability by about fivefold at least a year before the dedicated instrument is available.

The next phase will be to improve the alignment process. Our goal is to eliminate about six hours of neutron measurement for every sample currently used for alignment and replace it with optical alignment and three-point mounting. Subsequent phases of developing the dedicated instrument include developing the neutron monochromator, possibly implementing some focusing optics, and designing the sample positioner and data acquisition system.

\subsection{X-RAY DIFFRACTION USER CENTER}

\subsubsection{BACKGROUND}

The X-Ray Diffraction User Center (XRDUC) uses room- and high-temperature diffraction methods to characterize the phase(s) and stability of advanced structural ceramics, alloys, catalysts, and other industrially relevant materials. The data - obtained individually as a function of temperature and / or in conjunction with data from thermal analysis or electron microscopy - are used to relate phase composition, thermal expansion behavior, and phase stability with materials performance.

Besides supporting users' diffraction needs, the X-ray diffraction facilities are widely used by qualified staff in the $M \& C$ Division, who are conducting a wide variety of ceramic and alloy research and development efforts. The XRDUC also provides technical expertise in diffraction in support of a number of DOE-funded projects. 


\subsubsection{STAFF AND INSTRUMENTS}

Dr. C. R. (Cam) Hubbard is the XRDUC Group Leader and has expertise in hightemperature $X$-ray diffraction and nonstandard analysis. Other members who had prime responsibilities for activities in this user center during FY 1994 include the following:

- Mr. O. B. (Burl) Cavin - Consultant

- Ms. J. (Joy) Kilroy - Group administrative support

- Dr. Nick Packan - Phase analysis and instrument operation

- Dr. T. R. (Tom) Watkins (post-doctoral appointee from the RSUC) - hightemperature $\mathrm{X}$-ray diffraction

In October 1993, Dr. Packan filled Mr. Burl Cavin's position. Mr. Cavin, who retired at the end of September 1993, had been with the XRDUC since the beginning of the HTML and has proved difficult to replace. Dr. Packan transferred to another position in May 1994 , leaving the group substantially understaffed. Dr. Watkins, whose primary focus is the Residual Stress User Center, helped fill the gap in X-ray diffraction. After considerable effort to locate a suitable replacement, we are pleased to announce that $\mathrm{Dr}$. Scott Misture, a graduate of Alfred University with extensive experience in HTXRD, joined the group in November 1994.

Major Instruments

- Scintag 6-20 PAD V goniometer with liquid $\mathrm{N}_{2}$-cooled Ge detector

- Scintag $\theta-\theta$ PAD X goniometer with Buehler high-temperature stage

- MicroVAX 4200 minicomputer

- Scanning position-sensitive detector

\subsubsection{NEW CAPABILITIES}

\section{Scanning Position-Sensitive Detector}

The addition of the scanning position-sensitive detector to the high-temperature $X$-ray diffraction system significantly enhanced our $X$-ray diffraction facilities. This detector collects approximately a five-degree $2 \theta$ portion of the diffraction pattern simultaneously and can scan over a large $2 \theta$ range quickly. Coupling the diffraction angle information to the detector electronics allows the "windows" to be added together, giving a complete pattern. As such, detectors provide a five- to tenfold increase in data collection rate. We can now examine the kinetics of solid state reactions and crystallization while at temperature. We will continue developing and optimizing this system in FY 1995.

\section{Rietveld Full-Pattern Refinement Method}

The Rietveld full-pattern refinement method demonstrated previously has become a frequently requested data analysis method. The Rietveld method refines instrumental aberrations, the lattice parameters, profile shape function, atomic coordinates, and thermal motion parameters. With this tool, users are able to accurately determine lattice parameters without use of an internal standard, thus avoiding possible chemical 
interactions between the standard and the sample.

Simultaneously, the user can obtain information on the volume fraction of each phase in a mixture and the atomic coordinates for each phase and can calculate bond distances and angles from the atomic coordinates. An example of this approach is the work on $\mathrm{BaZP}$, a low thermal expansion ceramic, where high-temperature $X$-ray diffraction was used to characterize the type of phase transition, the anisotropic thermal expansion, and the structural changes as a function of temperature.

Hall-Williamson and Warren-Averback Analysis Package

Use of the room-temperature diffraction facilities to characterize the coherent domain size (crystallite size) and root mean square micro residual stresses increased last year based on implementation of a Hall-Williamson and Warren-Averback analysis package, written by Dr. James Stewart and Dr. C. R. Hubbard. To date, three user projects have used or are scheduled to use this capability.

\section{Neutron Powder Diffraction}

The neutron powder diffraction capabilities of the Neutron Scattering Group in the Solid State Division are now available to HTML users. This became possible by developing a cooperative understanding and referral process. When an HTML project would benefit from a small amount of neutron powder diffraction, users can include this request in the HTML proposal; members of the XRDUC team then will help the user obtain the necessary additional review by the Solid State Division's neutron powder diffraction staff. When the HTML staff receives a request for extensive neutron powder diffraction research, they forward this request to the neutron powder diffraction staff for consideration under the Basic Energy Sciences Neutron Scattering Program.

A cooperative effort begun two years ago to acquire a high-temperature furnace for neutron powder diffraction measurements recently has been completed with the procurement and delivery of a vacuum furnace designed for use at the neutron powder diffraction facilities at the ORNL's High Flux Isotope Reactor. We plan to jointly test and demonstrate this furnace facility in FY 1995 and to make it available to HTML and Neutron Scattering Group users at HFIR.

\subsection{CERAMIC MACHINING USER CENTER}

The Ceramic Machining User Center (CMUC) provides basic facilities for investigation of grinding processes for high-performance ceramic materials, design and fabrication of mechanical property test specimens, and dimensional characterization of test specimens and ceramic and metal components, including roughness, form, orientation, and subsurface structure.

\subsubsection{STAFF AND CAPABILITIES}

Mr. H. L. (Howard) Gerth is the Group Leader of the CMUC. Following are the other staff members in the CMUC and the equipment for which they have primary operating responsibility:

- Mr. Tyler Jenkins - Harig surface grinders, Weldon cylindrical grinder 
- Mr. Randy Parten - Mahrs form tool, Taylor-Hobson profilometer, Rodenstock non-contact profilometer

- Mr. Earl Shelton - Weldon cylindrical grinder

\section{Major Instruments}

The major focus of this center is on ceramic machining research using instrumented machine tools along with the following dimensional and surface characterization tools:

- Fully instrumented computer numerical control (CNC) surface grinder

- CNC cylindrical grinder (soon to be fully instrumented and have high-speed grinding capability)

- Computer-controlled profilometer and a non-contact laser topography system

- Form measuring instrument (cylindricity)

- Resonant ultrasound spectroscopy system

- Computer workstation with design, analysis, and programming software

\subsubsection{MAJOR ACTIVITIES IN FY 1994}

Researchers used the instrumented Harig surface grinder to grind a series of modulus of rupture (MOR) bars. These data were then included in an International Energy Agency study for comparison of grinding and strength studies conducted on an international scale. Studies on this same grinder in cooperation with AlliedSignal illustrated the potential for obtaining high Weibull values in transverse grinding of specimens. In addition, Chand Kare Technical Ceramics used the instrumented Harig in a user program study of grinding parameter effects on mechanical properties of ceramic materials.

The CMUC obtained a new, much stiffer CNC cylindrical grinder to replace an older grinder. This grinder was procured with piezo-electric force washers built in so that the machine base becomes a dynamometer body for directly measuring grinding forces in three directions. This is a capability not found on any other known cylindrical grinder. The machine will also be retrofitted with a high-speed grinding spindle, which will give it the capability to operate at a grinding speed of 25,000 surface feet per minute.

\subsection{CERAMIC MANUFACTURABILITY CENTER}

The Ceramic Manufacturability Center (CMC) was created in 1992 as a partnership between DOE's Office of Transportation Technologies, Defense Programs, and Energy Research. Its purpose is to investigate and determine cost-effective machining processes for structural ceramic materials. To accomplish this goal, the CMC obtained and installed state-of-the-art instrumented grinding equipment and dimensional characterization equipment in the HTML close to the existing user centers. As a result, users can take full advantage of these facilities in characterizing their materials.

\subsubsection{STAFF AND CAPABILITIES}

Mr. H. L. (Howard) Gerth is the Group Leader of the CMC. Following are the other staff 
members in the CMC and the equipment for which they have primary operating responsibility:

- Mr. Earl Shelton - Cincinnati Milacron RK centerless grinder, NICCO Ccreep-feed grinder

- Mr. Randy Parten - Leitz coordinate measuring machine

- Mr. Lawrence O'Rourke - NICCO creep-feed grinder

\subsubsection{MAJOR INSTRUMENTS}

\section{Coordinate Measuring Machine}

A Cooperative Research And Development Agreement (CRADA) with Brown and Sharpe placed a Leitz coordinate measuring machine in the CMC. This agreement will terminate at the end of the calendar year. Following termination of this CRADA, the $\mathrm{CMC}$ - using Defense Program funds - will procure a smaller coordinate measuring machine for permanent installation in the center.

A statistical study on the effects of eccentric loading of the coordinate measuring machine worktable on machine accuracy determined that off-center loading had negligible effect on the machine's accuracy. Rapid scanning tests on complex geometries such as engine blocks determined that researchers could make reasonably accurate dimensional measurements on complex geometries in much shorter times than normally required for coordinate measuring machine measurements.

\section{Fully Instrumented Creep-Feed Grinder}

Grinding studies on silicon nitride using a fully instrumented creep-feed grinder determined that stock removal rates can be significantly increased compared to conventional grinding.

\section{Cincinnati Milacron Centerless Grinder}

A CRADA with Cincinnati Milacron provided a state-of-the-art centerless grinder for the CMC during this year. This machine has a granite/epoxy base for improved dampening capability and CNC grinding wheel truing and dressing capability. This machine, which is being used to develop cost-effective grinding processes for heat engine components such as valves, rings, and fuel injector components, will be fully instrumented for collecting grinding data.

Other plans for this machine extend to areas outside of the CRADA efforts. Industry has expressed a strong interest in using this grinder within the framework of the HTML User Program. A major study (supported through DOE Office of Energy Research funds) with this machine sought to determine the environmental impact of selected grinding fluids in this machine. This included evaluating a new class of instrument developed by Cincinnati Milacron. 


\subsection{HTML FELLOWSHIP PROGRAM}

In FY 1992, the HTML Fellowship Program was started for the purpose of providing research opportunities, primarily in the HTML, for industrial and university researchers. This program is administered for the HTML by the Oak Ridge Institute for Science and Education. Research conducted in this program must be focused within one or more of the following 10 technical areas that are of direct importance to the DOE Transportation Technology Program:

- Mechanical properties of ceramics at high temperatures

- Physical and electrical properties of ceramics at high temperatures

- Tensor mechanics of solids

- Processing of ceramics

- Finite element computation methods for stress analysis

- Tribology of solid surfaces at elevated temperatures

- High-temperature gas phase reactions with solids

- Heat transfer through solids and gases

- Corrosion of ceramics at high temperatures

- Structure and properties of ceramics and alloys

Initiation of a fellowship is a relatively simple process and generally can be done within two to three months of submission of the application to the Director of the HTML.

\subsection{INDUSTRIAL FELLOWSHIPS}

\subsubsection{BACKGROUND}

Just as in HTML user research, industrial researchers propose a research problem (approved by the researcher's management) and submit the application to the HTML Director. However, most HTML user projects are limited to about two weeks of hands-on time at the HTML. The industrial fellowship provides industrial researchers the opportunity to work on a problem in depth and for a much longer period.

With the concurrence of the user center leaders who will be involved in the proposed research (and if sufficient resources are available at the time), the fellowship is approved for start at the industrial researcher's convenience. Generally, it is better for industrial researchers to perform research in the HTML during extended visits. When this is not possible because of job responsibilities, researchers can use a multiple visit schedule; this approach, however, makes continuity difficult to maintain.

Industrial fellowships, which typically cover a period up to six months, provide funds to assist in travel and housing relocation. In addition, funds are provided for the Fellow to conduct research while in the HTML. Two additional industrial fellowships are currently 
in negotiation.

\subsubsection{INDUSTRIAL FELLOWS FOR FY 1994}

\section{Bangalore A. Nagaraj, G.E. Aircraft Engines}

The objective of Mr. Nagaraj's research is to develop advanced thermal barrier coatings for superalloy components in advanced aircraft turbine engines. This Fellowship, which started on April 1, 1994, is currently scheduled to be completed at the end of April 1995.

His research involves evaluating the thermal conductivity of thermal barrier coatings that were tested at G.E. in a special facility capable of producing steep thermal gradients in the coatings similar to those present in an operating gas turbine engine. These results are being correlated with microstructural characterization of the tested coatings done via SEM, TEM, and other techniques. It is anticipated that observed changes in the coating thermal conductivity can be correlated to observed microstructural changes. If this is successful, it will be the first time that such a correlation in these very important coating systems has been demonstrated.

\section{T. Barrett Jackson, LoTEC, Inc.}

Dr. Jackson studied the thermophysical properties of [NZP]-type ceramics. His fellowship started in January 1994 and was completed in August 1994. From the research he conducted as part of an HTML Industrial Fellowship, Dr. Jackson concluded the following:

1. The NZP compositions tested in this study $\left(\mathrm{Ba}_{1+\times} \mathrm{Zr}_{4} \mathrm{P}_{6-2 x} \mathrm{Si}_{2 x} \mathrm{O}_{24}\right.$ and $\left.\mathrm{Ca}_{1} \mathrm{Sr}_{x} \mathrm{Zr}_{4} \mathrm{P}_{6} \mathrm{O}_{24}\right)$ are stable when subjected to repeated thermal cycles. Isotropic compositions have stable bulk thermal expansion characteristics, and the anisotropic compositions are stable after removing the microcrack opening effects of moisture.

2. The anisotropic - and thus microcracked - compositions have lower flexural strength than the isotropic compositions. Both isotropic and anisotropic compositions retain their original flexural strength after repeated thermal cycles.

3. The changes in the microstructure of the anisotropic compositions (formation of voids or cavities) do not lead to lower mechanical strength. Strength is controlled by the severity of the microcracks present.

4. Anisotropic compositions are susceptible to moisture-induced microcrack opening. After being heated and cooled in an inert atmosphere or a vacuum, the ceramic component can experience catastrophic failure as a result of exposure to moisture. Isotropic compositions are unaffected by moisture.

\subsection{GRADUATE FELLOWSHIPS}

\subsubsection{BACKGROUND}

For graduate students the following criteria are applicable:

- The student must be a U.S. citizen and be studying in an engineering department having $\mathrm{ABET}$ accreditation of the undergraduate program. 
- The candidate can be working in either an Master of Science or Doctor of Philosophy program, but must be prepared to conduct a substantial part of the thesis research in the HTML.

- The candidate must have an undergraduate grade point average of at least 3.5 in a 4.0 system.

- The university must execute an HTML nonproprietary user agreement.

- The HTML Fellowship Selection Committee, which has members from both industry and universities, evaluates applications to the fellowship program.

The student's thesis research progress is evaluated yearly to determine if support should be continued. An HTML staff member is assigned lead responsibility for each student and normally serves on the student's formal graduate committee at the home university. Monthly stipends up to about $\$ 2000$ per month are paid during the course of the thesis research in the HTML. These fellowships can be for as long as two years.

With the budget for FY 1995 for the HTML graduate fellowship program, we initiated a national solicitation for at least three graduate fellows. The solicitation went to 56 major materials departments in the United States that have ABET-accredited undergraduate programs.

\subsubsection{GRADUATE FELLOWS FOR FY 1994}

Ron D. Ott, University of Alabama at Birmingham

Mr. Ott's research problem involves determining the influence of selected machining parameters (grit size, table speed, wheel surface speed, etc.) on grinding forces for selected silicon nitride ceramics and the relationship of these parameters to fracture statistics - such as strength and Weibull modulus - as a function of the grinding forces and resulting surface damage. Mr. Ott started his research in the HTML in August 1994. The fellowship appointment, which began on January 3,1994, is currently scheduled to be completed at the end of May 1996.

Recently, he has been learning different techniques for establishing and analyzing experimental designs. The first step involves varying five machining parameters and evaluating their relationship to the resulting grinding forces. Depending on the amount of information to be obtained, this step may require as many as 32 experiments. He is currently being trained on the different grinding machines and other equipemnt that will be involved in his research.

\section{J. Allen Haynes, University of Alabama at Birmingham}

Mr. Haynes's research problem is a study of thermal barrier coatings for superalloys used in gas turbines, specifically, the effects of bond coating oxidation on the degradation and failure mechanisms of thermal barrier coating systems. His fellowship started on November 1, 1993; Mr. Haynes has now completed all of his coursework. The fellowship is currently scheduled to be completed at the end of May 1996.

He is still in the development stage of this project. He recently has visited two companies, Plasma Systems and United Technology Research Center, regarding recommendations 
for state-of-the-art coatings for this study and assistance in obtaining these very proprietary and expensive coating specimens for the fellowship research. He is now in the process of procuring samples. At the HTML, we have begun developing a new, nondestructive technique called resonant ultrasound spectroscopy, which $\mathrm{Mr}$. Haynes will use to evaluate coatings and assess the possibility of microscopic techniques for characterizing the critical interfaces in these complex multiphase systems.

\section{Douglas Taylor, University of Arizona}

Mr. Taylor's research problem is to determine relationships between sol gel coating parameters and electrochromic behavior of several coating systems when applied to glasses. The major goal of the research is to tailor the microstructure of sol gel-derived tungsten oxide coatings by laser firing to enhance the electrochromic behavior. These coatings are of major commercial interest for thermal control systems.

He has prepared several laser-fired sol gel-derived tungsten oxide coatings with different laser fluences and translation speeds and measured their electrochromic behavior in an electrochemical test cell. He has also studied these films with $X$-ray diffraction and analytical electron microscopy to determine the microstructure of the laser-fired coatings. His fellowship, which began on December 6, 1993, is scheduled to be completed early in 1995.

\section{Alex Cozzi, University of Florida}

Mr. Cozzi's research goal is to determine how to form strong joints in aluminum oxide ceramics using microwave techniques. He selected alumina as a model ceramic material; the major joining process being studied uses sol-gel interlayers. His fellowship, which began on February 1, 1993, is scheduled to be completed at the end of February 1995.

A load frame has been designed and constructed for applying pressure to specimens inside a microwave oven. The alumina and the special high-temperature microwaveshielded thermocouples have been received, and the critical experiments are in progress. The focus of this research is to determine how to synthesize strong joints in aluminum oxide using microwave fields, which could be used to more economically fabricate complex geometry ceramic components than can be done using conventional ceramic fabrication techniques.

\subsection{FACULTY FELLOWSHIPS}

\subsubsection{BACKGROUND}

These fellowships are intended for faculty of ABET-accredited departments to conduct special research problems in the HTML for periods generally not to exceed three months. The research problem must be from within the ten technical areas defined for the fellowship program. For this fellowship, a proposal is submitted to the Director, reviewed by the user center leaders and, with full concurrence, the fellowship is started.

\subsubsection{FACULTY FELLOWS FOR FY 1994}

\section{Krishan K. Chawla, New Mexico Tech}

Dr. Chawla's research goal is to determine fundamentals necessary for interface 
engineering in oxide fiber-reinforced oxide matrix composites. His fellowship is scheduled to cover two periods of research in the HTML: June 13-August 31, 1994 (completed), and November 1-December 20, 1994.

His work included preparing samples of oxide fiber/oxide matrix composites for characterizing interfaces and mechanical properties. Nextel oxide fibers (610 and 550) are being coated with tin dioxide and boron nitride, respectively, for use in glass and mullite matrix composites. Large plates are being prepared by the slurry impregnation process at the Y-12 Plant in a large hot press. These plates will provide samples large enough for tensile strength specimens and flexure strength specimens. He will use these samples to evaluate the role of processing variables on the mechanical properties. 



\section{APPENDIX A: FY 1994 RESEARCH PROJECT SUMMARIES}

\section{A.1 INDUSTRIAL USER PROJECTS}

ADVANCED REFRACTORY TECHNOLOGIES, INC.

PPUC

HTML No. 93-043, "High-Temperature Thermal Conductivity of Aluminum Nitride," Thomas J. Mroz

Recent developments at ART have made it possible to obtain stable composites of aluminum nitride containing silicon carbide whiskers $(\mathrm{SiCw})$. These composites are of interest because of their potential use as heat exchanger materials. The AIN matrix provides greater thermal conductivity, corrosion resistance, and thermal shock resistance compared to previously investigated matrices.

Researchers from ART fabricated monolithic AlN and AlN/SiCw composites. The goal of the research at HTML was to develop a thorough understanding of the effects of each variable on the thermal conductivity of the composite. The laser flash and DSC facilities of the HTML were used to determine the thermal diffusivity and specific heat capacity of the ART monolithic and composite materials up to $1200^{\circ} \mathrm{C}$. Thermal conductivity as a function of temperature was calculated using the diffusivity, specific heat capacity, and density of the samples.

The results are aiding ART in optimizing the mechanical and thermal transport properties of the composite, and thus in competing in the international marketplace. ART investigated the effects of oxidation on the thermal conductivity of aluminum nitride at various temperatures in an oxidizing atmosphere. They found that the thermal conductivity of AIN decreased with increasing temperatures. Aluminum nitride is being studied as a potential high-conductivity additive for ceramic matrix composites intended for high-temperature applications.

HTML No. 93-091, "Mechanical Properties of AlN-SiCw Composites Exposed to a Corrosive Environment," Thomas J. Mroz

Advanced Refractory Technologies conducted flexure strength studies to track the development of an AIN material that they hope to commercialize at a production level. They were particularly interested in the effects of $\mathrm{SiC}$ whisker reinforcement on hightemperature mechanical performance. Results obtained to date suggest that the whiskers may have a beneficial influence on high-temperature creep and corrosion resistance.

HTML No. 93-016, "Comparison of Creep Rupture in HIPed and In Situ Reinforced Silicon Nitrides," John P. Pollinger and Doug J. Twait

AlliedSignal, in collaboration with the MPUC, is developing an in situ reinforced silicon nitride material to be used for structural applications at elevated temperatures. Creep- 
rupture tests are currently being used to track the progress of its development including the influence of post-processing thermal treatments.

\section{ALLIEDSIGNAL CONTROLS AND ACCESSORIES}

MPUC

HTML No. 93-045, "Nanohardness and Surface Topography of Hard Anodized Aluminum," Richard G. Rateick, Jr.

Hardness variations in anodized coatings were examined with the mechanical properties microprobe. The effect of coating thickness on this hardness profile was also measured. Following indentation, the surface topography was studied using the atomic force microscope. The hardness of the thicker coating exhibited a minimum at its center, while the hardness of the thinner coating was relatively independent of position. Reasons for this behavior are currently under investigation.

\section{ALLIEDSIGNAL ENGINES}

MPUC

HTML No. 92-042, "Influence of Surface Condition on Creep Rupture of NT-154 Silicon Nitride," M. Nanu Menon, Ho T. Fang, and David C. Wu

Many ceramic components in advanced turbine and other heat engines are most likely to be used in the as-densified condition without any machining; some will have transverse machined surfaces, which are known to have lower fast fracture strength. Therefore, it is important to obtain an estimate of the difference in strength between the as-densified or transverse machined surfaces versus longitudinally machined surfaces whose strength is typically what is measured in mechanical property data generation programs.

Work on this project will begin in the latter part of FY 1995. The objective of this research will be to investigate the influence of surface condition on creep and rupture behavior of NT-154 silicon nitride. Three surface conditions will be investigated: (1) as-densified, (2) longitudinally machined, and (3) transverse machined. The same lot material will be employed for all three. A difference is therefore expected only in the surface flaw populations among the three conditions. Researchers will use tensile testing to generate the required data. This will be important in determining if the strength (population) difference influences the creep and creep rupture behavior.

ALLIEDSIGNAL ENGINES

MPUC

HTML No. 93-093, "Effect of Surface Condition, Machined versus As-Densified Surface, in Flexural Cyclic Fatigue of NT-154 Silicon Nitride," M. Nanu Menon, Ho T. Fang, and David C. Wu

Many ceramic components in advanced turbine and other heat engines are most likely to be used in the as-densified condition without any machining; therefore, it is important to obtain an estimate of the difference in strength between the as-densified surface and the as-machined surface whose strength is typically what is measured in mechanical property data generation programs.

Work on this project will begin in the latter part of FY 1995. The objective of the research 
will be to investigate the differences in cyclic fatigue life when failures initiate from asdensified versus machined surface for NT-154 silicon nitride. The as-densified surface is expected to have a different flaw population from a machined surface. Flexural testing will be used, since flat rectangular specimens are easier to make with an as-densified surface than cylindrical specimens.

ALLIEDSIGNAL, INC.

PPUC

HTML No. 93-067, "Pyrolysis Process Control for CMC Fabrication: A Baseline PropertyParameter Study," S. Gonzy and R. Leung

AlliedSignal used the facilities in the HTML Physical Properties User Center to study the effect of oxidation on the thermal diffusivity of carbon-coated Nicalon ${ }^{\mathrm{TM}}$-reinforced Blackglas $^{\mathrm{TM}}$ composites. Blackglas $^{\mathrm{TM}}$ is being developed by Allied Signal as a low-cost, easily formed, high-performance composite. The composites were heat treated in air at temperatures between $500^{\circ} \mathrm{C}$ and $800^{\circ} \mathrm{C}$ for 20 hours.

The thermal diffusivity values are unaffected for treatment at $500^{\circ} \mathrm{C}$. However, for treatments at $600^{\circ} \mathrm{C}$ and above, the thermal diffusivity perpendicular to the fibers dropped by approximately $12 \%$. This is due to the oxidation of the carbon coating on the fibers and indicates the need for an oxidation-resistant coating material. Possible coatings under investigation include BN.

AlliedSignal researchers investigated the pyrolysis of the polymer precursor used in

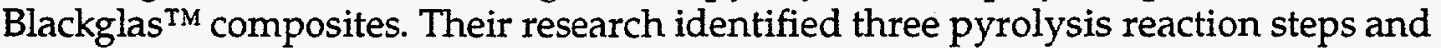
characterized the gases evolved during each of the reaction steps. A better understanding of the pyrolysis process will allow Allied Signal to optimize the polymer curing stage of composite fabrication.

ALLIEDSIGNAL RESEARCH AND TECHNOLOGY

MPUC

HTML No. 93-011, "Design of Tubular Ceramic Components Containing Radial Holes," Philip J. Whalen, Richard G. Rateick, Jr., and Steven Sund

In this project, Weibull scaling relationships were applied to the description of failure of tubular ceramic components containing radial holes. The component geometry was simulated using a c-ring specimen containing a single radial hole at the specimen midspan. A finite element analysis (FEA) program was used to calculate the stress distribution within this specimen as a function of applied tensile load. We then introduced the output into the Cares Life Program to estimate the probability of failure as a function of applied tensile load.

The estimates of the Weibull distribution parameters required for this analysis were generated from either four-point flexure or c-ring (having no hole) fast fracture tests. We then compared the predicted probability of failure versus load curve with actual experimental data. In general, the predicted curve underestimated the failure probability associated with a given load. The inability of Weibull statistics to adequately describe the 
failure of the c-ring containing a radial hole was attributed to high stress concentration associated with the hole.

ALLIEDSIGNAL RESEARCH AND TECHNOLOGY

MPUC

HTML No. 93-068, "Low-Cost Water Jet Cutting of Ceramic Matrix Composites: A Study of Tensile Property Effects," Stephen T. Gonczy

AlliedSignal studied the effect of different modes of machining on the tensile strength of continuous fiber-reinforced Blackglas ${ }^{\mathrm{TM}}$ composites. (Blackglas ${ }^{\mathrm{TM}}$ is a polymer-derived ceramic developed by AlliedSignal.) The results of this study indicated that there was not a significant difference in the strength of this material after being machined in the green or the after-pyrolysis states using abrasive water jet cutting or diamond grinding. These results are significant since abrasive water jet machining is cheaper and has a shorter turnaround time than diamond grinding.

\section{ALLISON ENGINES}

MAUC

HTML No. 93-036, "Evaluation of the Effect of Filler Metal Composition on Joint Microstructure for Ti Alloys Brazed with Ti-Cu-Ni Materials," J. Chang

Commercially available brazing alloys derived from the $\mathrm{Ti}-\mathrm{Cu}-\mathrm{Ni}$ ternary system provide high-integrity braze joints for advanced titanium alloys. It has been found that subtle changes in filler metal composition can produce a wide variation in some mechanical properties. Three different brazing compositions have been characterized using analytical electron microscopy to determine microstructural differences.

\section{AMERICAN SUPERCONDUCTOR}

MPUC

HTML No. 92-075, "Mechanical Properties of Oxide Superconductors," G. N. Riley

In this user project, researchers measured the elastic modulus and hardness differences of c-axis aligned, silver-sheathed superconductor tapes, both along as well as perpendicular to the c-axis. The observed elastic anisotropy was a reflection of the anisotropy of the layered crystal structures of the superconductors.

\section{APPLIED MATERIALS}

MPUC

HTML No. 93-046, "Characterization of Long-Term Creep Behavior of Aluminum Alloys at High Temperature as a Function of Anodization Thickness," Sam Shamouilian

The goal of this project was to extend the creep database for an aluminum alloy that currently is used as a susceptor in a chemical vapor deposition facility. During FY 1994, the MPUC modified one tensile test machine to accommodate the aluminum tensile specimen. The major modification involved fabricating new high-temperature grips so that water cooling was not required. This, in turn, greatly reduced the temperature gradients in the specimen. Additional modifications, to be done in FY 1995, will involve replacing the existing two-zone slot furnace with a clamshell furnace having better 
temperature stability at lower temperatures.

CARBOMEDICS

PPUC

HTML No. 93-030 , "Oxidation of Pyrolytic Carbon," D. James

In this project, researchers studied the weight change and evolved gases as a function of increasing temperature (in air) on two materials: silicon-alloyed pyrolytic carbon and Poco AXF-5Q graphite. The graphite was a reference material used to provide baseline data. The pyrolytic carbon was studied using three different, but known, silicon concentrations. Silicon is present within the carbon matrix in the form of beta silicon carbide (crystal size $\sim 1000-2000 \AA$ ). Two surface conditions of pyrolytic carbon were used in the study: a polished surface (surface roughness $<0.2 \mu \mathrm{m}$ ) and an as-deposited surface.

\section{CONCURRENT TECHNOLOGIES}

XRDUC

HTML No. 93-070, "Phase Identification and Volume Fraction of Various Phases for Thixocast Al-Si Alloys at High Temperatures," P. Kahn

Semi-solid metalworking (SSM) technology holds significant potential for near-net shape forming of lightweight materials. In SSM, a nondendritic thixotropic material is induction heated to a temperature between its solidus and liquidus temperatures and introduced into dies to make near-net shaped parts. This research will determine the volume fractions of the crystalline and liquid phases as a function of temperature for use in modeling of the die forming process and in validating on-line non-destructive testing.

The initial assessment measurements from this work, which has just begun, indicate that the materials are appropriate for characterization by $X$-ray powder diffraction.

Development of Rietveld phase refinement tools to support this project has been completed. HTXRD measurements should commence in FY 1995.

\section{COORS ELECTRONIC PACKAGE COMPANY}

XRDUC, MAUC

HTML No. 93-098, "Characterization of Gold Microstructure to Limit Nickel Diffusion and Improve Functional Performance," W. K. Baxter, E. D. Winters, and C. T. Johnson

Researchers studied the effect of various electroplating conditions on the functional performance of ceramic integrated circuit (IC) packages. The ceramic IC package consists of an $\mathrm{Al}_{2} \mathrm{O}_{3}$ substrate with $\mathrm{W}, \mathrm{Ni}$, and finally $\mathrm{Au}$ layers electroplated on top. A reduction of the grain boundary diffusion of the underlayer elements (viz., Ni) through the $\mathrm{Au}$ plating during heat exposure is sought.

A general correlation was found among observed Au grain size, Au X-ray peak breadths, and $\mathrm{Ni}$ diffusion; that is, as the observed grain size increased, the $\mathrm{X}$-ray peak breadths, and detected $\mathrm{Ni}$ on the Au surface decreased. This suggests that as the grains become larger, the number of grain boundaries available for diffusion decreases. Also, Ni grain boundary diffusion may be dependent on crystallographic direction. The effects of adding various "brighteners" to the Au are still being investigated. 
In addition, AES and AFM were used to characterize the plated-gold coatings on the seal ring sections of ceramic electronic packages. The coatings with large faceted Au grains exhibited less $\mathrm{Ni}$ on the surface than those with small grains; diffusion of the $\mathrm{Ni}$ to the coating surface was presumed to be controlled by grain boundary diffusion. Auger maps showed that the Ni on the surface was in the form of nickel oxide and that it surrounded the small islands of $\mathrm{Au}$.

The impact of this work, once it is complete, should be an increased understanding of the plating and diffusion processes, which will in turn allow Coors to reduce manufacturing defects. Also, routine X-ray diffraction can be used to inspect for this type of problem.

\section{COORS TECHNICAL CERAMICS}

MAUC

HTML No. 93-026, "An Investigation of the Differences in Alumina Rings Used in Semiconductor Plasma Etch Equipment," J. Ghinazzi

By characterizing a variety of alumina rings, esearchers examined the surfaces of several alumina-insulating rings used in plasma etch equipment for semiconductor (Si wafer) processing. Specifically, this included examining a "bad" ring that was in the system for a relatively short period of time and may have caused surface deposits on the Si wafer, and a "good" ring that was in place within the system for an extended period of time and was not associated with any surface deposits.

\section{CUMMINS ENGINE COMPANY}

MAUC, MPUC

HTML No. 93-089, "Characterization of the Oil Balls and Their Influence on Premature Overlay Removal of Diesel Engine Bearings," M. Patel

The objective of this experimental research was to determine chemical composition and hardness of oil balls embedded in the tri-metallic bearing overlay layers found in the connecting rods and main bearings of diesel engines. Oil balls are discrete spherical particles that embed in the bearing overlay; the elemental composition of oil balls included calcium, phosphorus, zinc, and barium. These elements are also present in diesel engine oil additives.

Diesel engine manufacturers have observed a high incidence of premature overlay removal in connecting rods and main bearings; the analysis indicated that the bearings overlay was removed prematurely due to fatigue, aggravated by corrosion. The oil balls embedded in the bearing overlay are considered to be one of the contributing factors in the premature overlay removal, although their exact formation, chemical composition, hardness, and embedding mechanisms are not well understood. In addition, researchers determined the elastic properties and hardness of these inclusions, as well as the regions surrounding them, using the mechanical properties microprobe. 
HTML No. 94-029, "Microstructural Characterization of Electrochemical Cells," S. Rajaduri

The aim of this proposed research was to perform a detailed study of the structure and chemistry of electrochemical cells used for NOx reduction in diesel engines. These microstructural observations will be related to performance of the cell and correlated with fundamental properties that control the effectiveness of the cell activity. These studies will include phase identification, surface structure, chemical composition, valence states and distribution, and characterization of interfaces between constituents. This study will include the evaluation of "good" and "bad" cells, as well as cells subjected to bench-scale reactor testing and engine testing.

CUMMINS ENGINE COMPANY

MPUC, XRDUC

HTML No. 94-030, "Microstructural Characterization of Oxidation Catalysts," Suzanne Raebel

Hardness gradients from surface to the matrix in chromium-plated plungers that had been nitrided were determined using the nanoindenter. Samples that have shown good wear characteristics were selected for this study.

\section{DELCO REMY DIVISION OF GENERAL MOTORS CORPORATION}

PPUC, RSUC

HTML No. 93-066, "Thermal Properties of Magnequench," J. Herchenroeder and M. Nguyen

Two staff members from Delco Remy Division of General Motors Corporation used the HTML facilities to obtain thermophysical property data essential for modeling deformation processing of their Magnequench permanent magnets. The goal is to improve hot workability of this inherently brittle compound. The highly oriented Magnequench magnets are the strongest known permanent magnets and are potentially useful in many applications, including alternators.

Commercialization of the highly oriented alloy has been hindered by the poor ductility of the material. Thermal diffusivity, thermal expansion, and specific heat were measured from room temperature to $850^{\circ} \mathrm{C}$ for samples with a random orientation of crystalline grains and for others with highly oriented crystalline grains. A subsequent visit will use facilities in the RSUC to characterize the degree of orientation of grains in the samples. The data will be used to improve processing of the Magnequench alloy, which will lead to lightweight alternators for automobiles.

The highest energy permanent magnets, Magnequench MQ3, are manufactured by developing an anisotropic crystal texture through controlled hot deformation of an isotropic precursor, $M Q 2$. Texture analysis on $\mathrm{MQ} 2$ and sixty percent upset $\mathrm{MQ3}$ materials was used to explain the deformation mechanisms during upsetting and the 
observed anisotropic remenance of the deformed samples. The texture measurements will also assist in developing a finite element model of the deformation process.

HTML No. 93-015, "Mechanical Property Evaluation of Polymer-Derived Ceramic Matrix Composites," Ronald Boisvert

Dow Corning initiated a long-term collaboration effort through the HTML User Program to determine the effects of temperature, loading rate, and matrix additives on the tensile strength of continuous fiber-reinforced ceramic matrix composites currently under development at Dow Corning. Also investigated were the effects of temperature, stress, and matrix additives on the fatigue resistance of these materials. These materials are being considered for use in heat exchangers, combustion liners, and in several parts of chemical pumps.

These studies have been complemented by interlaminar shear strength measurements and by single-fiber interfacial measurements. The latter tests were aimed at determining the bond strength and the sliding resistance of the reinforcing fibers and the evolution of these properties during typical service conditions. Efforts on this project by our staff were recently commended by the Federal Business Development Director at Dow Corning.

FLORIDA TILE INDUSTRIES

MAUC

HTML No. 93-022, "Improve Ceramic Tile Manufacturing Yield by Identification of Major Defects," M.S. Love

Two types of defects - "dents," which are characterized by a depression in the tile glaze, and "pinholes," which are characterized by a series of small holes grouped together have been characterized in an attempt not only to identify the defect, but also to identify the defect source. Excess scrap tile has been generated as a result of these particular defects, and improvements in manufacturing yields are expected as a result of the identification of the source of the defects. Thus far, both types of defects have been associated with excess aluminum and silicon within the tile body. The aluminum and silicon are possible contaminants in the raw material.

FORD RESEARCH LABORATORY

PPUC

HTML No. 94-009, "Effect of Thermal Cycling on the Thermal Conduction of HCCMMCs (High-Ceramic Content Metal Matrix Composites)," G. Crosbie

Ford Research Laboratory initiated use of the facilities and expertise of the staff of the PPUC with the goal of developing high thermal conductivity composites for thermal management in electronic modules. The composites under study are metal matrix, typically aluminum or copper, loaded with high thermal conductivity particles, either $\mathrm{SiC}$ or diamond.

Calculations published by the PPUC staff indicate the need for large particles in this approach. Ford is testing this theory by varying the particle size as well as studying the 
effect of these large particles on thermal and mechanical stability under the thermal cycling conditions typically associated with automotive electronic applications.

\section{G.E. AIRCRAFT ENGINES}

PPUC, XRDUC

HTML No. 92-025,"Thermal Conductivity of Physical Vapor Deposited Thermal Barrier Coatings," B. Nagaraj

G.E. Aircraft Engines is using the electron beam-assisted, physical vapor deposition (EBPVD) process and plasma spraying to deposit thin thermal barrier coatings (TBCs) on turbine engine components. These low thermal conductivity coatings extend the life expectancy of components in the hot section of turbine engines. A goal of turbine engine manufacturers is to increase engine operating temperatures by $150^{\circ} \mathrm{C}$, which will improve engine performance and fuel efficiency, and will lower NOx pollutants.

G.E. Aircraft Engines is studying the feasibility of increasing engine temperatures by using aluminide alloys protected by partially stabilized zirconia TBCs. As part of their HTML user project, G.E. used the xenon flash diffusivity system to investigate the effect of temperature and time at temperature on the thermal conductivity of partially stabilized zirconia TBCs. The EB-PVD coatings are less susceptible than plasma-sprayed coatings to increases in thermal conductivity due to thermal aging.

After 1000 hours at $1035^{\circ} \mathrm{C}$, the EB-PVD coatings have thermal conductivities that are lower than the plasma-sprayed coatings. The exposure temperatures and times have been incorporated into a Larson-Miller type relationship in order to predict and model the increases in thermal conductivity. These models developed at HTML permit engineers to predict the performance of coatings for turbine engine applications.

HTML No. 93-086, "Measurement of Residual Stresses in Metal Matrix Composites by Neutron Diffraction," P. K. Wright

Metal matrix composites (MMCs) are being developed as potential high-strength, highstiffness, and reduced-weight materials for aircraft turbine engine components such as frame, fan blades, and disks. Due to the radically different nature of these materials compared to the metals they would replace, and due to their high cost, the strength and life performance must be carefully understood so that accurate component life predictions can be made.

These component life predictions will depend, in part, on the nature and level of residual stresses within the MMC. Such residual stresses arise from the thermal expansion mismatch of the fibers and matrix as well as from component processing. Since neutrons penetrate deep into the material and provide data from both the fiber and the matrix, neutron diffraction is especially suitable for measuring such stresses in MMCs.

MMC samples from both $\mathrm{SiC} / \mathrm{TiAl}$ and sapphire/ $\mathrm{NiAl}$ systems are being investigated. Measurements of residual stress, which have been partially completed in the SiC/TiAl system, show levels approximately equal to those estimated from analytical models. Results were highly reproducible for the same samples measured at different times. No 
significant effect of thermal cycling on reducing stress was observed. Experiments on sapphire $/ \mathrm{NiAl}$ have recently been completed and will be analyzed for the effects of consolidation practice and thermal cycling.

GENERAL MOTORS NORTH AMERICAN OPERATIONS

MAUC

HTML No. 93-100, "TEM Investigation of Precipitation in Metal Matrix Composites," R. K. Mishra and V. Franetovich

General Motors is investigating precipitation in metal matrix composites (MMCs) that have potential elevated temperature structural applications. The matrix material is a precipitation-strengthened $\mathrm{Al}$ alloy containing $\mathrm{Si}$ and $\mathrm{Cu}$. Fibers of $\mathrm{Al}_{2} \mathrm{O}_{3}-\mathrm{SiO}_{2}$ are used to make the composite. It is known that the mechanical properties of the $\mathrm{Al}$ alloy without any fibers are significantly different from those of the matrix material in the fiberreinforced composite, even when the overall composition of the matrix alloy is the same.

The fibers are believed to affect the precipitation-strengthening process due to chemical partitioning and changes in the thermodynamics and kinetics of the phase transformation in the presence of $\mathrm{Al}_{2} \mathrm{O}_{3}-\mathrm{SiO}_{2}$ fibers. TEM has been used effectively in studying the precipitate structure and composition, distribution of chemical species in the balance of the matrix, and coherency of the precipitates, all of which influence the mechanical properties of the matrix.

\section{LOS ALAMOS NATIONAL LABORATORY RSUC}

HTML No. 93-083, "Preliminary Assessment of Residual Stress in Quenched Heat Treated and Carburized Automobile Parts," M. Bourke

Neutron and X-ray diffraction residual stress mapping of stress gradients was demonstrated at HTML for use in studies of heat treatment and carborization of automotive gears. Applications include projects with the National Center for Manufacturing Sciences (NCMS), which is working with DOE under a multi-laboratory CRADA to develop process model codes for predicting distortions and properties of gear steels.

The validation of the codes will depend on accurate, comprehensive residual stress and retained austenite measurements. The Neutron Residual Stress Facility at HTML/ORNL has demonstrated the capability to nondestructively map the stress and phase content with a sampling volume down to $1 \mathrm{~mm}^{3}$. Based on the successful demonstration, subsequent proprietary measurements have been performed.

MCDONNELL DOUGLAS CORPORATION

PPUC, XRDUC

HTML No. 91-046, "Thermal Conductivity of Various Carbon Fibers," J. Sapp and D. Bowers

McDonnell Douglas Aerospace investigated the thermal conductivity and thermal expansion of carbon/carbon composites for plasma-facing components in fusion energy devices. The results of this study illustrate several techniques that are being successfully 
employed to fabricate high thermal conductivity 1-D carbon composites. In particular, the vapor growing process has improved density and conductivity from $1.46 \mathrm{~g} / \mathrm{cm}^{3}$ and $650 \mathrm{~W} / \mathrm{mK}$ in 1992 to the current values of $1.9 \mathrm{~g} / \mathrm{cm}^{3}$ and $850 \mathrm{~W} / \mathrm{mK}$.

\section{NORTHROP CORPORATION}

MPUC

HTML No. 93-048, “Fiber /Matrix Interfacial Properties of a Blackglas ${ }^{\text {TM Matrix }}$ Composite," Robert Carter

Northrop conducted a study to determine the effects of thermal treatments on the interfacial and mechanical properties of continuous fiber-reinforced Blackglas ${ }^{\mathrm{TM}}$ composites. Of interest was the effect of exposure to aqueous environments on the composite interfacial properties. It was determined by means of single-fiber push-out tests using the interfacial test system, developed at the HTML, that some of the boronbased fiber coatings investigated were unstable after combined exposure to air and steam at elevated temperatures.

One of the merits of this type of study is that it is possible to predict the macroscopic response of ceramic matrix composites by knowing the interfacial properties of the material. Therefore, it suffices to conduct single-fiber interfacial tests using samples about $1 \mathrm{~cm}$ long, $0.5 \mathrm{~cm}$ wide, and $1 \mathrm{~mm}$ thick as a screen test to determine the true potential of the material before conducting more extensive (and expensive) tests (e. g., tensile testing).

SAINT GOBAINNORTON INDUSTRIAL CERAMICS

RSUC

HTML No. 92-011, "Residual Stress Analysis of $\mathrm{Si}_{3} \mathrm{~N}_{4}$ Cylindrical Tensile Specimens," M. R. Foley

The objective of this study was to determine the effect of machining-induced residual stresses (damage) on strength of tensile rods made of $4 \% \mathrm{Y}_{2} \mathrm{O}_{3}$-doped $\mathrm{Si}_{3} \mathrm{~N}_{4}$ (viz., NCX5102) and thereby increase Norton's understanding of their grinding procedures. Asmachined and machined/heat-treated samples were examined. The grinding direction in the gage section for all rods was parallel to the axis of the rod.

Three of the four tensile rods examined have essentially the same residual stress state, considering the standard deviations. In general, all stresses in the gage section of these three rods are zero except the axial and hoop stresses, which were, on average, -60 and $180 \mathrm{MPa}$, respectively. This stress anisotropy is consistent with the literature; that is, the stress in the direction perpendicular to the grinding direction is greater than the stress in the direction parallel to the grinding direction.

The fourth tensile bar, which was oxidized and crystallized, exhibited lower residual stresses than the other tensile bars. We note, however, that these stress results conflict with earlier work done by Snoha and Foley on similar samples. Consequently, some of the same samples Snoha and Foley examined will soon be reexamined at the HTML.

From this work Norton can apply the characterized stress state due to grinding to similar samples and correct/account for the influence of grinding stresses on the fracture 
behavior. Such understanding is needed for proper design and life prediction based on tensile testing results.

\section{SAINT GOBAINNORTON INDUSTRIAL CERAMICS}

MPUC, RSUC

HTML No. 93-078, "Effect of Alpha-Si $\mathrm{N}_{4}$ Content on the Creep/Fatigue Behavior of HIPed Silicon Nitride," Russ L. Yeckley

This effort examined the effect of the residual alpha- $\mathrm{Si}_{3} \mathrm{~N}_{4}$ content on the creep/fatigue behavior of HIPed silicon nitride. Recent work at ORNL has shown that during creep, the residual alpha- $\mathrm{Si}_{3} \mathrm{~N}_{4}$ may be dissolved in the intergranular phase, increasing its thickness and thus the extent of multigrain junction cavitation. Norton's current commercial materials (NT-154 and NT-164) have $20-40 \%$ alpha- $\mathrm{Si}_{3} \mathrm{~N}_{4}$. To study the effect of residual alpha- $\mathrm{Si}_{3} \mathrm{~N}_{4}$ on creep/fatigue behavior, NT-164 with two levels of a silicon nitride were tested.

SOLAR TURBINES

MPUC

HTML No. 93-087, "Long-Term Durability Testing of CFCCs for Combustor Liner Applications," Jane Simpson

Investigation of the long-term behavior of CFCC materials is needed to assess the durability of these materials and ultimately to predict their lifetimes in combustor applications. In current Solar ceramic combustor designs, thermal gradients will induce the majority of the stress in the combustor liner. Therefore, tests at constant stress with cyclic temperature are needed on these materials.

Loading will be applied to specimens in tension of a level of $10-15 \mathrm{ksi}$. The temperature will be cycled from $650^{\circ} \mathrm{F}$ to $2200^{\circ} \mathrm{F}$, with 2 minutes at each extreme. Test length will be up to at least 100 hours. The materials under investigation are DuPont Lanxide CVI's $\mathrm{SiC} / \mathrm{SiC}$ material and B\&W's oxide /oxide material. Work on this project will begin in the latter part of FY 1995.

\section{SUNDSTRAND AEROSPACE}

MPUC

HTML No. 93-025, "Silicon Carbide Room-Temperature Fatigue and Strength," Jong-Yeong Yung

In this project, the room-temperature cyclic fatigue behavior of a silicon carbide ceramic was evaluated using four-point flexure specimens. Results revealed the existence of a threshold stress above which fatigue effects were observed. Below the stress threshold, a million cycles were accumulated without failure. Subsequent room-temperature fourpoint flexure tests indicated that the strengths of the cycled specimens had increased significantly compared with the as-received value. The mechanism responsible for this strength enhancement is currently under investigation. 
ULTRAMET

MPUC, PPUC

HTML No. 93-059, "Mechanical and Thermal Characterizations of Foams, $\mathrm{C}_{\mathrm{f}} / \mathrm{H}_{\mathrm{f}} \mathrm{C}$, and $\mathrm{C}_{\mathrm{f}} / \mathrm{H}_{\mathrm{f}} \mathrm{C}-\mathrm{SiC}$ Materials," $V$. Heng and E. Litu

Ultramet, in collaboration with the MPUC, was able to generate high-temperature engineering compressive strength data on $\mathrm{SiC}$ - and C-reticulated ceramic foams. The carbon foams required testing tin an inert environment at elevated temperatures; the MPUC facilities were able to meet this requirement.

Researchers from Ultramet also investigated the thermal diffusivity of materials to be used as heat shields on reentry vehicles. Materials examined included carbon foams, $\mathrm{H}_{\mathrm{f}} \mathrm{C} / \mathrm{SiC}$ carbon felt composites, and electroplated and CVD-deposited $\mathrm{Ni}$ and $\mathrm{Cr}$ films on OFHC copper substrates. This is the first time the thermal properties of materials of this nature have been characterized. Ultramet is investigating applications for these materials in commercial markets.

\section{VALENITE CORPORATION}

MAUC

HTML No. 94-028, "Analysis of Structure of Composite $\mathrm{Al}_{2} \mathrm{O}_{3}-\mathrm{ZrO}_{2} \mathrm{CVD}$ Coatings," D. G. Bhat and W. Russell

Researchers are studying the effects of adding $\mathrm{ZrO}_{2}$ as a second-phase toughener to $\mathrm{Al}_{2} \mathrm{O}_{3}$ coatings deposited by chemical vapor deposition (CVD) processes onto the surfaces of cutting tools. The presence of the $\mathrm{ZrO}_{2}$ enhances the resistance of the $\mathrm{Al}_{2} \mathrm{O}_{3}$ coating to cracking and to grain growth due to thermal effects generated during machining.

Processing these coatings has resulted in a nanostructure composite phase developing in the coating; this phase is being investigated by high-resolution imaging and $X$-ray analysis on the Hitachi HF-2000 FE-TEM. Probing the elemental compositions of this nanostructure at the 1-nm level of spatial resolution is yielding information on the nature of the structure and is allowing this nanostructure to be correlated to physical behavior during use.

VALENITE CORPORATION

MAUC

HTML No. 94-018, "Process-Property Correlation of Diamond and DLC Films on Cutting Tools: Development of an Industrial Process for Superhard Coatings," D. G. Bhat

Microstructures of diamond and diamond-like carbon (DLC) films on cemented carbide cutting tools and other substrates are being studied by TEM, SEM, and electron microprobe methods. The goal is to correlate microstructural characteristics with deposition parameters and parameters of surface chemical treatment of the substrate for improving film adhesion. Microstructures will also be correlated to physical and thermal properties of the films. Researchers will therefore be able to isolate factors that influence processing parameters so that the manufacture of cutting tools with superhard surface coatings can be improved. 


\title{
A.2 UNIVERSITY USER PROJECTS
}

\author{
ALABAMA A\&M UNIVERSITY
}

MPUC

HTML No. 93-080, "Investigation into the Influence of Microcleanliness on Creep Properties of Alloy 718 ," S. Mysore and C. Ruiz

Alabama A\&M University and Teledyne Allvac, in collaboration with the MPUC, conducted high-temperature creep tests on a developmental nickel-based superalloy. The generation of engineering creep data was required to survey its development.

\section{ARIZONA STATE UNIVERSITY}

MAUC

HTML No. 94-035, "Electron Holographic Imaging of Potential Distributions in Semiconductors," M. McCartney

Electron holography on the Hitachi HF-2000 FE-TEM is being used for quantitative twodimensional mapping of the electric potential distributions at $\mathrm{p} / \mathrm{n}$ junctions. This project uses the unique capabilities of electron holography to characterize phase changes in the electron image wave that result from effects such as electric charge buildup. The results of these studies in this developing technique will be useful in determinations of the effects of charge on dislocation motion, which is important in understanding fundamentals of mechanical deformation processes in materials.

\section{CARNEGIE MELLON}

RSUC, XRDUC

HTML No. 94-080, "Structural Characterization of Chemically Synthesized Cubic Spinel Phase of $\mathrm{LiMn}_{2} \mathrm{O}_{4}$ " P. Kumta and R. Sriram

Lithium manganese oxide belongs to the family of ternary transition metal oxides in the $\mathrm{MnO}-\mathrm{Li}_{2} \mathrm{O}$ system. The material exhibits several defect structures, of which the cubic spinel structure is the one that is relevant to the proposed research. Previous studies have shown that the cubic spinel phase can be synthesized at temperatures as low as $400^{\circ} \mathrm{C}$ using sol-gel routes. This approach is radically different from the conventional route; the performance of this material as a cathode will strongly depend on the cation distribution in the cubic cell.

To characterize the structure and identify the exact distribution of $\mathrm{Li}$ and $\mathrm{Mn}$ atoms in the chemically synthesized cubic structure, RSUC/XRDUC researchers initiated a systematic, high-temperature $X$-ray and neutron diffraction study, combined with Rietveld analysis. This study provided extremely beneficial information for understanding the formation of such spinel phase. The project was supported by the Eveready Battery Company.

HTML No. 94-010, "Effect of Ca Substitution on the Physical Properties of $\mathrm{YBa}_{2} \mathrm{CuO}_{6+d}$ " T. Leventouri

In conventional $\mathrm{Ca}$ substitution of $\mathrm{Y}-\mathrm{Ba}-\mathrm{Cu}-\mathrm{O}$ system, $\mathrm{Ca}$ replaces $\mathrm{Y}$ but not $\mathrm{Ba}$. In a systematic study of the role of $\mathrm{Ca}$ substitution on the physical properties of the Y-Ba-Ca- 
$\mathrm{Cu}-\mathrm{O}$ compounds, a sample series with starting composition $\mathrm{YBa}_{2-x} \mathrm{Ca}_{\mathrm{x}} \mathrm{Cu}_{3} \mathrm{O}_{6+d}$, with $0 \leq x \leq 2.00$ was prepared.

Preliminary $X$-ray experiments show that the samples consist of the known superconducting phase $\mathrm{Y}_{1-2} \mathrm{Ca}_{2} \mathrm{Ba}_{2} \mathrm{Cu}_{3} \mathrm{O}_{G+d}$ with transition temperature $73 \leq \mathrm{T}_{c} \leq 92 \mathrm{~K}$, depending on $\mathrm{z}$. However, in addition to that, a new non-superconducting phase appears in amounts that increase with $x$. Using the state-of-the-art HTML X-ray diffraction facility, researchers from Florida Atlantic University have successfully identified this unknown phase as $\mathrm{Ca}_{2+\mathrm{x}} \mathrm{Y}_{2-\mathrm{x}} \mathrm{Cu}_{5} \mathrm{O}_{10}$. A detailed study on the crystal structure of this compound is planned.

\section{FLORIDA SOLAR ENERGY}

RSUC, XRDUC

HTML No. 93-007, "Residual Stress Minimization in Mo Thin Films Used as Back Contact in CuInSe ${ }_{2}$ Solar Cells," N. Dhere, M. Wollam, and S. Kuttath

The objective of this study was to measure the residual stresses in Mo thin films and to determine the effect of deposition conditions on the residual stress state in these films. The residual stress in Mo coatings may be changed by moderating the energy of the incident argon ions used in sputtering. Reduction of residual stress is desired and can potentially be achieved by (1) increasing the sputtering-gas pressure, which increases the number of collisions of the back-scattered atoms, (2) reducing the sputtering power, which reduces the energy of incident argon ions, and (3) increasing the angle of incidence, which provides mobility to deposited species for diffusion on the surface and reduces the energy at normal incidence responsible for peening.

The films examined were deposited at various sputtering-gas pressures $(8.0,12.5,18.8$ $\mathrm{m}$ Torr) and sputtering powers $(50,100,150 \mathrm{~W})$. The isotropic, in-plane residual stresses were found to peak at sputtering-gas pressure of $12.5 \mathrm{mT}$ orr and to increase with sputtering power. The maximum residual stresses were determined to be -550 and -1200 MPa for the $18.8 / 150$ and $12.5 / 100$ conditions, respectively. $X$-ray diffraction pole figures revealed that the samples were textured.

Since Mo is cubic and only slightly elastically anisotropic, the influence of the texture on the stresses was assumed to be negligible. The peaks were broad, which was attributed to the small particle /crystallite size in these films $(<100 \mathrm{~nm})$. The cause of the residual stresses was attributed wholly to the processing of the films (i.e., intrinsic or growth stresses). Grain-to-grain residual stresses due to anisotropic thermal expansion are zero since Mo is cubic. The stresses due to thermal expansion mismatch between the film and substrate were negligible because the deposition temperature was $\sim 60^{\circ} \mathrm{C}$.

The impact of this work was an increased understanding of the relationship between processing conditions and residual stresses. Thus, the results of this study will guide future Mo thin film deposition. 
HTML No. 93-052, "Composition Effects on the Texture and Epitaxy of YSZ Thin Films," W. B. Carter and A. T. Hunt

The objective of this study was to use pole figures of $\mathrm{Y}_{2} \mathrm{O}_{3}$ stabilized $\mathrm{ZrO}_{2}$ (YSZ) deposited via combustion chemical vapor deposition (CCVD) onto sapphire substrates to determine how the $\mathrm{Y}_{2} \mathrm{O}_{3}$ content and deposition temperature of $\mathrm{YSZ}$ films affects the epitaxial relationship between film and substrate and also film texture. The films appear to possess two or three groups of grains; each group oriented along a different pole. In the $2.5 \mathrm{~mol} \% \mathrm{Y}_{2} \mathrm{O}_{3}-\mathrm{ZrO}_{2}$ film (tetragonal) deposited at $1200^{\circ} \mathrm{C},\{001\},\{511\}$, and $\{321$ or 211\} fiber textures were observed, assuming the material is cubic.

As the deposition temperature increased to $1400^{\circ} \mathrm{C}$, this texture was found to be sharper, showing only $\{001\}$ and $\{211\}$ fiber textures. In the $8 \mathrm{~mol} \% \mathrm{Y}_{2} \mathrm{O}_{3}-\mathrm{ZrO}_{2}$ film (cubic) deposited at $1200^{\circ} \mathrm{C}$, strong $\{100\}$ and $\{531\}$ fiber textures were observed. The impact of this study was an increased understanding of CCVD processing temperatures and the resulting coating texture. Thus, coatings with more or less texture can be deposited predictably.

GEORGIA INSTITUTE OF TECHNOLOGY

RSUC, XRDUC

HTML No. 93-053, "Processing Variable Effects on the Composition and Texture of CCVD YBCO Thin Films," W. B. Carter and G. W. Book

The objective of this study was to investigate the texture and epitaxy of $\mathrm{YBa}_{2} \mathrm{Cu}_{3} \mathrm{O}_{x}$ superconducting thin films deposited via combustion chemical vapor deposition (CCVD) on single crystal $\mathrm{MgO}$ and polycrystalline silver substrates. As deposited films on singlecrystal (100) $\mathrm{MgO}$, substrates showed highly oriented c-axis up-growth and displayed the onset of a superconducting transition at $84^{\circ} \mathrm{K}$, with zero resistance obtained at $78^{\circ} \mathrm{K}$ after annealing in pure oxygen. Pole figures showed two in-plane alignment orientations of the film with respect to the substrate.

The YBCO [100] and [010] were aligned with the MgO substrate. YBCO films deposited on roll-textured polycrystalline silver at temperatures between $850^{\circ} \mathrm{C}-950^{\circ} \mathrm{C}$ displayed $c$-axis up-growth. The rolling texture of silver was not strong enough to induce detectable in-plane preferential growth of the $\mathrm{YBCO}$. These results will be used to select the process variables for producing single-phase, epitaxial $\mathrm{YBa}_{2} \mathrm{Cu}_{3} \mathrm{O}_{\mathrm{x}}$ superconducting thin films.

\section{GEORGIA INSTITUTE OF TECHNOLOGY}

MPUC

HTML No. 94-046, "Mechanical Properties of Metastable Thin-Film Materials," Canan Uslu, Deok-Hyung Lee, and Byungwoo Park

Georgia Tech researchers sought to characterize ion-implanted superhard structural materials - as well as NiTi materials implanted with boron - designed for endodontic 
applications. The nanoindenter was used to obtain hardness and Young's modulus measurements on samples of some of these materials.

GEORGIA INSTITUTE OF TECHNOLOGY

MAUC

HTML No. 94-079, "Microstructural Characterization of Carbon-Carbon Composites Produced by FCVI," W. J. Lackey, G. B. Freeman, and S. Vaidyaraman

Chemical vapor infiltration (CVI) increasingly is being used to fabricate fiber-reinforced ceramic and carbon matrix composites. In this process, a solid is chemically vapordeposited onto a porous preform to form the matrix of the composite. Of the six types of CVI processes, the forced-flow thermal gradient (FCVI) process is the fastest and therefore potentially the most economical.

Prior work at ORNL and Georgia Tech has shown that the FCVI process is applicable to the fabrication of $\mathrm{SiC}$ matrix composites. Recently, at Georgia Tech, the FCVI process has been shown to be very useful in fabricating carbon matrix composites. The purpose of the proposed HTML research is to examine, via TEM, the microstructure of the FCVI carbon matrix and to correlate the microstructure with processing conditions. This will assist in the selection of the preferred processing conditions.

IOWA STATE UNIVERSITY

XRDUC

HTML No. 94-038 "Thermal Expansion Anisotropy of $\mathrm{Ti}_{5} \mathrm{Si}_{3} \mathrm{Z}_{\mathrm{x}}$ " M. Akinc and A. Thom

$\mathrm{Ti}_{5} \mathrm{Si}_{3} \mathrm{Z}_{x}$ was investigated as a potential high-temperature structural material. The inherent thermal expansion anisotropy of the $\mathrm{Ti}_{3} \mathrm{Si}_{3}$ hexagonal material contributes to significant microcracking in consolidated material. Grain size must be reduced to about $1 \mu \mathrm{m}$ to eliminate the microcracking. Previous research at HTML by the investigators has shown that addition of carbon to $\mathrm{Ti}_{5} \mathrm{Si}_{3}$ significantly decreases the thermal expansion anisotropy.

This project studied the lattice expansion of B-, C-, N-, and O-doped titanium silicide with $x=0.25,0.50$, and 0.75 from room temperature to $1000^{\circ} \mathrm{C}$. Single-crystal structure analysis is being conducted at lowa State on a couple of the doped materials. Those data will be correlated with the reductions in anisotropy in the lattice thermal expansion.

MASSACHUSETTS INSTITUTE OF TECHNOLOGY

MPUC

HTML No. 93-082, "Fatigue of Micromechanical Devices," Will Van Arsdell

The nanoindenter was used to investigate small-scale material processes, such as slow crack growth and defect creation and correlate the response to changes in the beam material structure. 
NEW MEXICO INSTITUTE OF MINING AND TECHNOLOGY

MPUC

HTML No. 92-075, "The Effect of Tin Dioxide Interlayer in Alumina/Glass Composites," K. Chawla

Tin dioxide can be used as a fiber coating in alumina fiber-reinforced, silica-based glass ceramic composites. However, mechanical property data such elastic properties are lacking. The objective of this study was to determine the elastic properties of polycrystalline tin dioxide using a resonant ultrasound spectroscopic (RUS) technique. The HTML RUS facility allowed accurate measurements on the small specimens that were available. The elastic constants were measured, then the elastic constants of a fully dense polycrystalline tin dioxide were extrapolated from these measurements and the porosity.

NORTH CAROLINA STATE UNIVERSITY

MAUC

HTML No. 91-056, "Transmission Electron Microscopy and Scanning Auger Microprobe Spectroscopy of AlN/GaN and AlN/SiC Solid Solutions and Multilayer Heterostructures," S. Aliey-Trent

Single-crystal films of $\mathrm{SiC}, \mathrm{AlN}$, and GaN now are internationally considered as the materials that will fill the electronic niches for high-temperature, high-power, and highfrequency semiconductors and violet to ultraviolet optoelectronics and detectors. Ongoing research at NCSU has proved that these materials can be grown at very low temperatures and in several different phases.

$\mathrm{SiC}$ and AlN, as well as AIN and GaN, form solid solutions that allow the bandgap to be "engineered" throughout the solution and the interfaces between these materials. NCSU has conducted high-resolution and analytical transmissions electron microscopy to investigate the defect microstructure in the bulk of the materials and the microstructure and chemistry of the interface regions of these materials.

NORTH CAROLINA STATE UNIVERSITY

MAUC, MPUC

HTML No. 94-037, "Analysis of Adhesion at Metal-Ceramic Interfaces," Robert James and Robert Davis

In order to prevent erosion and corrosion of metallic parts, ceramic coatings are often applied to the surface of the metal. These ceramic coatings resist erosion and corrosion and can greatly prolong the life of a metallic part. However, the greatest problem in applying such a coating is often one of adhesion, as the chemistry of the metal-ceramic interface determines the adhesion of the coating. The object of this proposal was to make detailed chemical and microstructural analyses of metal-ceramic interfaces.

Because the tensile strength of a coating-substrate interface can now be measured quantitatively, this information can then be related to experimentally determined values of adhesion strength. The two applications of interest in this proposal were erosionresistant ceramic coatings for turbine compressor blades and corrosion-resistant ceramic coatings for use as liner materials in vessels containing radioactive waste. Metals of interest as compressor blades are $\mathrm{Ti} 6 \mathrm{Al} / 4 \mathrm{~V}$, Inconel 718 , and $17 \mathrm{Cr} / 4 \mathrm{Ni}$ stainless steel. 
Erosion-resistant ceramic coatings of TiN, TiAlN, and $\mathrm{Al} 2 \mathrm{O} 3$ have been applied to all of these metals for adhesion investigations. Candidate materials for radioactive waste containment are $\mathrm{Ti}$, Incoloy 825 , and Hastelloy $\mathrm{C} 4$. Coatings of $\mathrm{SiC}, \mathrm{Al}_{2} \mathrm{O}_{3}$, and $\mathrm{ZrN}$ have been applied to each of these metals.

In addition, these coatings were characterized using the nanoindenter. Nanoindentations were made on cross-sections of these 2 to $5 \mu \mathrm{m}$-thick coatings. Hardness and Young's moduli were determined.

NORTH CAROLINE STATE UNIVERSITY

MAUC

HTML No. 94-062, "Electron Holography and Atom Probe Study of $\mathrm{CoSi}_{2}$-Coated and Diamond-Coated Si Field Emitters," J. Hren

High-resolution imaging and electron holography on the HitachiHF-2000 FE-TEM are being used to characterize the structure of silicon field emitter needles coated with materials such as $\mathrm{Co}, \mathrm{CoSi}_{2}$ and diamond, as well as the effects of charging at the tip as related to the structure and composition of the coating material. This work has application both to military and commercial development of flat-panel video display systems.

\section{NORTHWESTERN UNIVERSITY}

PPUC, XRDUC

HTML No. 93-044, "Investigation of the Thermal Expansion and Heat Capacity of $(\mathrm{Mo}, \mathrm{Cr})_{2} \mathrm{C}$," G. Olson and $\mathrm{C}$. Knepfler

The lattice thermal expansion behavior of $\mathrm{M}_{2} \mathrm{C}(\mathrm{M}=\mathrm{Mo}, \mathrm{Cr})$ is important for understanding the nucleation and strengthening behavior of these carbides within secondary hardening steels. Investigations of the carbide composition as a function of aging time suggests that the system minimizes the lattice mismatch of the nucleating particles by nucleating particles of one composition (i.e.; $\mathrm{Mo} / \mathrm{Cr}-0.66$ ); as the particles grow, the carbide composition slowly changes $(\mathrm{Mo} / \mathrm{Cr}=1.5)$.

Lattice thermal expansion behavior was obtained to test this model of minimization of lattice mismatch. The heat capacity of $(\mathrm{Mo}, \mathrm{Cr}){ }_{2} \mathrm{C}$ was collected to provide data on the free energy of carbide systems. The results of this study were presented at the American Ceramic Society meeting and were included as part of C. Knepfler's Ph.D. dissertation.

NORTHWESTERN UNIVERSITY

MAUC

HTML No. 94-003, "Electron Interferometry and Holography of Internal Interfaces," V. Dravid

In this study, electron holography and interferometry techniques are being used to study space charge effects at grain boundaries in eutectic and electroceramic materials. In these predominantly ionic systems, there is considerable evidence for formation of an interfacial space-charge region, caused by the segregation of certain solute ions to defects and grain boundaries. The presence, extent and sign of the space charge region is 
believed to be the key to understanding interface properties, including cohesion energy and strength.

\section{NORTHWESTERN UNIVERSITY}

\section{MPUC}

HTML No. 94-008, "Nanoindentation and Compressive Strength Testing of Nanophase Iron," Gretchen Fougere and Julia Weertman

The objective of this study was to examine the effects of porosity on the elastic modulus on nanophase iron with average grain sizes of approximately 4 to $20 \mathrm{~nm}$. The specimens were made by inert gas condensation and warm compaction at temperatures ranging from $25^{\circ} \mathrm{C}$ to $294^{\circ} \mathrm{C}$. Measured porosity varied from $6 \%$ to $30 \%$. The elastic response was measured using the mechanical properties microprobe. The resulting elastic modulus values agreed with trends for other nanocrystalline metals. The porosity dependence of elastic modulus was best described by theories incorporating the effect of pores alone (i.e., neglecting cracks).

\section{NORTHWESTERN UNIVERSITY}

HTML No. 94-014, "Investigation of the Elastic Moduli of $\left(\mathrm{Mo}_{\mathrm{x}} \mathrm{Cr}_{1-\mathrm{x}}\right)_{2} \mathrm{C}$," C. Knepfler and K. T. Faber

The objective of this study was to investigate the elastic properties as a function of composition. These properties are important for understanding the strengthening behavior of carbides within secondary hardening steels. The resonant ultrasound spectroscopic technique was used to measure the elastic properties. Measurements have been made on selected compositions. This project will be continued in FY 1995, once the other needed specimens are available.

HTML No. 93-013, "Residual Stress Measurement in UNS G93106 Steel," C. Paliani and R. A. Queeney

Researchers from Penn State completed a series of tests on marquenched and ausrolled UNS G93106 gears steel samples carburized to $1 \%$ carbon. The objective of those tests was to characterize the surface and subsurface conditions (residual stress gradients, retained austenite content, carbon profile) in order to determine the appropriate testing conditions for XRD residual stress depth profiling. XRD and magnetic measurements showed an unexpectedly high content of retained austenite (approximately $40 \%$ ) as opposed to the expected $6 \%$. This observation could result in the necessity of measuring residual stresses in both phases; i.e., martensite and austenite.

It was also shown that the use of CrK-alpha radiation penetrating $\sim 5 \mu \mathrm{m}$ beneath the surface was not appropriate to depth-profile residual stresses with high gradients. The use of less penetrating CuK-alpha ( $2 \mu \mathrm{m}$ penetration) in the parallel beam optics and omega geometry was shown to be the proper way of measuring residual stresses on 
cylindrical surfaces in quenched carbon steels. The study will continue and will help to develop the gear processing technology for industrial and commercial applications.

PENNSYLVANIA STATE UNIVERSITY

XRDUC, RSUC

HTML No. 93-037, "The Role of Residual Stresses on Microcracking in $\mathrm{TiB}_{2} / \mathrm{SiC}$ Composites," M. J. Pan and D. J. Green

The objective of this study was to measure the residual microstrains (microstresses) in $\mathrm{TiB}_{2}$ particulate-reinforced $\mathrm{SiC}$ composites as a function of volume fraction of $\mathrm{TiB}_{2}$ and to determine the role of the residual stresses on spontaneous microcracking. Several composites were examined and found to possess at least three polytypes of $\mathrm{SiC}$, as well as $\mathrm{TiB}_{2}$ and another unknown phase.

The existence of several $\mathrm{SiC}$ polymorphism and an unknown phase (which accompanies the $\mathrm{TiB}_{2}$ ) made determination of the individual peak positions difficult. Several "models" were employed (consisting of different numbers of peaks and their locations), but none of the models chosen were able to produce sensible $2 Q$ vs $\sin ^{2} Y$ plots. These plots showed lots of scatter and were therefore unsatisfactory.

After this effort it became clear that successful completion of this project will require new experimental approaches, such as the location of "stand-alone" $\mathrm{SiC}$ and $\mathrm{TiB}_{2}$ reflections in the $>130^{\circ} 2 \mathrm{Q}$ region, samples with only one of $\mathrm{SiC}$, etc. It may not be possible to do by applying diffraction methods due to the complexity of the diffraction pattern.

PENNSYLVANIA STATE UNIVERSITY

RSUC

HTML No. 93-058, "Texture Analysis in Alloy 600 and 690 Steam Generator Tubing," C. O. Ruud and D. B. Haartz

This project was a part of a study supported by the Electric Power Research Institute at Penn State University. The objective was to examine the effects of microstructure on the susceptibility of Alloys 600 and 690 to intergranular stress corrosion cracking (IGSCC) in high-temperature aqueous environments typical of nuclear power plants.

The preferred orientation (crystallographic texture) is believed to have an effect on IGSCC by affecting the distribution of grain boundary disorientation angles. The differences in crystallographic texture in Alloys 600 and 690 tubing having different susceptibility to IGSCC were studied by X-ray diffraction. The variations of texture throughout the tube thickness (ID, OD, mid-thickness) were determined and explained in terms of the processing operations (mechanical and heat treatment).

PENNSYLVANIA STATE UNIVERSITY

MAUC

HTML No. 94-015, "FE-TEM Applications in Ceramics: Particle Shapes and Grain Boundary Segregation," A. Carim

In an effort to understand consolidation behavior by coalescence during sintering, electron holography on the Hitachi HF-2000 FE-TEM and image simulation are being 
used to characterize shapes, surfaces, and internal defect structures in nanocrystalline ceramic powders such as $\mathrm{ZrO}_{2}, \mathrm{TiO}_{2}$, and $\mathrm{SrTiO}_{3}$. The high spatial resolution X-ray analysis capabilities of the HF-2000 are also being used to study impurity or dopant segregation at grain boundaries in alumina as part of a large effort to understand the controlling mechanisms for anisotropic grain growth in ceramics.

In work to date, we have been able to unambiguously determine that a $5 \mathrm{~nm}$-diameter particle of $\mathrm{ZrO}_{2}$ is, in fact, not a cuboctahedron as previously suspected, but instead has a prismatic morphology. This is the first time such information has been reported for crystals of this size range.

\section{PENNSYLVANIA STATE UNIVERSITY}

RSUC, XRDUC

HTML No. 94-022, "Investigate Post-Annealing Lattice Parameter Recovery in a YImplanted Sapphire Substrate Using Glancing Angle X-ray Analysis," M. A. Stough and J. R. Hellmann

The objective of this study was to determine whether ion implantation of $\mathrm{Y}$ and $\mathrm{Zr}$ into single-crystal sapphire caused amorphization. The next objective was to determine whether or not ion implantation damage could be removed by annealing (via recrystallization) using grazing incidence X-ray diffraction (GIXD). Unfortunately, the nature of the single crystal sapphire precluded using GIXD. This study may continue by using $X$-ray reflectometry to measure the surface layer densities.

\section{UNIVERSITY OF ALABAMA}

RSUC

HTML No. 93-054, "Determination of the Texture and Residual Stress Distribution in AlLi-Cu Alloy 2095 (Weldalite) and Associated Weldment," G. O. Rading and J. T. Berry

The objective of this study, funded by NASA at the University of Alabama, was to investigate the texture and residual stress effects on fatigue crack propagation in aluminum lithium-welded structures. Preliminary modeling results indicated that the fatigue crack growth characteristics were greatly influenced by the residual stress distribution in the weld metal and heat-affected zone and by the rolling texture in the base metal. The material under investigation, which was supplied by Martin Marietta Astronautics Group, is a candidate material for the fabrication of lightweight external fuel tanks for the space shuttle.

The combination of X-ray and neutron mapping capabilities at HTML was a critical component in this study in that residual stresses on the surface, as well as in the bulk of the weldment, could be determined. The residual stress data throughout the weldment, obtained using the Neutron Residual Stress Facilities, were found consistent with the theoretical predictions. X-ray residual stress measurements allowed separation of the effects of machining and surface finish from those arising from welding.

$X$-ray texture measurements provided useful information for explaining the change of the fatigue crack propagation mode. Solution of the residual stress-induced cracking in 
repair welds would lead to savings of over 8000 pounds in the fuel tank, and thus significantly increase the payload.

UNIVERSITY OF ALABAMA/BIRMINGHAM

RSUC, XRDUC

HTML No. 94-053, "Crystallization of Ion-Beam Sputter Deposited Hydroxyapatite," D. Rigney and A. M. Bock

A graduate student and her faculty completed high-temperature $X$-ray diffraction (HTXRD) measurements on crystallization of plasma spray-deposited amorphous thin films of fluoroapatite (FA), $\mathrm{Ca}_{5}\left(\mathrm{PO}_{4}\right)_{3} \mathrm{~F}$, on Ti substrates. Preliminary studies indicate that lower-temperature processing is advantageous to bond strength; however, crystallization is required for good bone adhesion. The objective of this study was to understand the crystallization behavior of FA in order to fabricate bone implants with a high fluoroapatite-to-Ti bond strength. The HTXRD measurements showed an unexpectedly rapid crystallization at a low temperature $\left(300^{\circ} \mathrm{C}\right)$, as well as a significant influence of atmospheric humidity. Subsequent measurements will determine the thermal expansion behavior of both hydroxyapatite and fluoroapatite, then correlate that data with loss of bond strength versus processing temperature of conventionally coated implants.

UNIVERSITY OF DAYTON

MAUC

HTML No. 93-033, "An Investigation into the Sources of Instability of NTC Thermistors When Exposed to Elevated Temperature for Extended Periods of Time," N. Osborne

After exposure to temperatures of $100^{\circ} \mathrm{C}$ to $150^{\circ} \mathrm{C}$ for extended times, the initial resistance of thermistors $(\mathrm{Mn}, \mathrm{Ni}$, Fe cubic spinel materials) begins to shift to higher values. No information gathered so far by "conventional" means has been definitively correlated to this behavior. The literature suggests that diffusion of one or more multivalent ions in the material is the most likely cause of the phenomenon. Thermistors for this study will be made from co-precipitated powders supplied by Yellow Springs Instruments, Inc. (YSI)

The resistance of newly made thermistors was measured by YSI. These materials were then examined using (1) the mechanical properties microprobe to establish distribution of $\mathrm{Fe}, \mathrm{Mn}$, and $\mathrm{Ni}$ in the grains and grain boundaries, (2) AEM for accurate quantification of phase compositions across grains and grain boundaries, and (3) TEM to investigate the atomic structure and composition of the materials at the grain/grain boundary interface. This will establish the baseline information on the nature of the grains and grain boundaries of thermistor material. 
UNIVERSITY OF DELAWARE

MAUC

HTML No. 94-021, "High-Resolution Transmission Electron Microscopy (HRTEM) of Molybdenum-Promoted Rhodium on Gamma-Alumina: Correlation of Metal Aggregate Properties with Activity, Selectivity, and High-Temperature Carbon Monoxide Exposure Peak Broadening in X-Ray Asymmetric Diffraction Resulting from Chi Tilts," H. Foley, Mure Te, and Eric Lowenthal

A series of alumina-supported nonmetallic Rh and bimetallic Rh-Mo catalysts are being studied on the Hitachi HF-2000 FE-TEM to determine the size, distribution, exposed crystal facets, and relative metal content of the metallic aggregates present on these catalysts. These characteristics will be correlated to the reactive behavior of the catalysts in CO hydrogenation reactions, which were conducted at the University of Delaware. The ability of Mo species present at atomic level dispersions to stabilize the catalytically active $\mathrm{Rh}$ clusters during reactions will be investigated.

\section{UNIVERSITY OF DENVER}

XRDUC, RSUC

HTML No. 92-081, "Peak Broadening in X-Ray Asymmetric Diffraction Resulting from Chi Tilts," D. Dragoi

The objective of this study was to measure the peak broadening inherent in chi (c) tilting and compare that to a geometrical model proposed by D. Dragoi. The (012) and (300) reflections from a NIST $\mathrm{Al}_{2} \mathrm{O}_{3}$ plate were each scanned every $10^{\circ} \mathrm{C}$ from -70 to $+70^{\circ} \mathrm{C}(15$ tilts/reflection) to examine the influence of low and high $2 \theta$, respectively. The experimental and calculated relative broadening values were plotted as a function of $\mathrm{c}$ for low and high $2 \theta\left(38^{\circ}\right.$ and $\left.112^{\circ} 2 \theta\right)$, respectively.

The agreement between the experimental data and the model is excellent for the high $2 \theta$ region. Although the agreement is poorer in the low $2 \theta$ region, the model appears to be "functionally correct," suggesting that only minor adjustments need to be made to the model (e.g., a factor of $\mathrm{c}^{2}$ ). Also, certain approximations used in the calculations may not be valid in the low $2 \theta$ region and can be adjusted. This work qualitatively validates an existing model, thus providing researchers with a useful tool to predict and correct for broadening due to chi tilting.

HTML No. 93-024, "Determination of Depth Profiles of Residual Stress in Thin Films and Composites," P. Predecki and B. Ballard

The objective of this study was to determine the stress gradient in Mo thin films on borosilicate glass substrates using grazing incidence $X$-ray diffraction (GIXD). Strain was measured on a sample as a function of rotation angle, $f$, at constant angle of incidence, $a$, for various angles of incidence. The phi integral method can be used to calculate the residual stresses for a constant effective $X$-ray penetration depth, $t$.

Validation scans were performed with a standard Si powder on the Mo thin film and showed negligible changes in the interplanar spacing of the $\mathrm{Si}(533)$ reflections. The interplanar spacing of the Mo (321) reflection was found to vary sinusoidally with $f$ when 
a $>0.4^{\circ}(\mathrm{t}>4 \mathrm{~nm})$ indicating a nonisotropic in plane stress state due to deposition conditions. When $a<0.3^{\circ}(t<2 \mathrm{~nm})$, the variation of the interplanar spacing was approximate, suggesting an effect due to strain relief and/or surface roughness.

Researchers subsequently increased their understanding of the near-surface stress state in these films that resulted from deposition conditions. Additionally, this study demonstrated that near-surface stress gradients can be measured. Thus, GIXD should be an excellent technique to characterize the subsurface residual stresses in structural ceramics due to machining.

\section{UNIVERSITY OF DENVER}

RSUC

HTML No. 93-049, "High Resolution X-Ray Crystallographic Measurements," D. Dragoi

The objectives of this study were to measure the angle of misorientation between a set of planes of a single crystal and the surface of the crystal and compare that to an analytical model proposed by D. Dragoi. This measurement would then allow researchers to accurately determine the lattice parameter to 8 or 9 decimal places. Omega (W) scans of the $(400)$ reflection from a single crystal $\mathrm{Si}$ wafer were performed as a function of phi $(\mathrm{F})$, while chi $(\mathrm{c})$ and $2 \mathrm{Q}$ were fixed at $0^{\circ}$ and $69^{\circ}$, respectively.

The observed sine or cosine function was predicted by the model. Results indicate that the misorientation angle and the Bragg angle can be determined with the desired high accuracy. The experimental portion of this study is complete, and a manuscript has been submitted for publication.

UNIVERSITY OF FLORIDA

RSUC

HTML No. 92-043, "X-Ray Analysis of Residual Stress in Metals and Ceramics," P. H. Holloway and F. Baldwin

This HTML study with University of Florida users determined the residual stresses and stress relaxation rates in thin films of an $\mathrm{Al}-\mathrm{Si}-\mathrm{Cu}$ alloy on $\mathrm{Si}$ substrates in order to predict the mechanisms and times of failure. These films were found to possess an extreme $\{111\}$ texture. The samples were unpatterned or patterned. The patterned samples possessed alloy line widths of 2.5 and $1.5 \mu \mathrm{m}$.

The stress states were found to be biaxial, and as the line width decreased, the tensile residual stress in the alloy increased from 90 to $160 \mathrm{MPa}$ for the unpatterned and $1.5 \mu \mathrm{m}$ patterned samples, respectively. The residual stresses in the samples containing voids in the lines were $20 \%$ less than those without voids, linking high residual stresses to void formation.

UNIVERSITY OF ILLINOIS

MPUC

HTML No. 92-037, "High-Temperature Mechanical Properties of Ceramic and Ceramic Composites," J. F. Stubbins and S. Raghuraman

In this work, a series of stress-oxidation flexure tests of a $\mathrm{SiC}$ fiber-reinforced $\mathrm{SiC}$ 
composite were initiated. Flexure specimens were held under constant stress at $950^{\circ} \mathrm{C}$ for fixed periods of time. If the specimen survived the exposure, it was rapidly loaded to fracture to determine the retained strength. In the absence of applied stress, the strength did not change appreciably. However, above a critical stress threshold, extensive timedependent strength reduction was observed. This behavior was attributed to the stress activated degradation of the interface layers used to ensure fiber debonding and sliding.

UNIVERSITY OF ILLINOIS

MPUC, PPUC

HTML No. 93-003, "Investigation of Interfacial Shear Strengths of Fiber-Reinforced Boron Nitride Composites," James Economy and Cameron Cofer

Interfacial shear strength testing was performed on a series of boron nitride composites fabricated with carbon and other inorganic fibers. These fibers included PAN T300, Pitch K1100X, Nicalon, c-Nicalon, Nextel 440, Sumica, and FP Alumina. Both the nanoindenter and the interfacial testing system (ITS) were used to perform push-in tests on at least 10 fibers in each system. Fiber sliding, indicative of weak interfacial strengths, was observed for the carbon fiber specimens.

Additional investigations are planned for the boron nitride matrix composites. Interfacial testing will be performed on a several fibers that have been coated with a series of carbon or boron nitride coatings. Wedge-shaped samples will also be prepared in order to complete push-out testing of these composite systems. Further mechanical testing will then be performed to correlate first matrix cracking of the systems.

Researchers also used the scanning thermal conductivity microscope (STCM) to study carbon fiber-reinforced boron nitride composites. Thermal conductivity maps, 50 by 50 $\mu \mathrm{m}$, were obtained and analyzed using the STCM. Preliminary results suggest that the BN matrix has a higher thermal conductivity than either P-55 or K1100 carbon fibers. As expected, the K1100 fibers were found to have a higher thermal conductivity than the P-55 fibers. This information will be used to help model and understand the bulk thermal conductivity data acquired earlier using the xenon flash thermal diffusivity system.

\section{UNIVERSITY OF ILLINOIS}

RSUC, XRDUC

HTML No. 93-101, "Residual Stress in Ferroelectric Thin Layers," C. D. E. Lakeman and D. A. Payne

The objective of this study was to determine the residual stresses in $\mathrm{Pb}(\mathrm{Zr}, \mathrm{Ti}) \mathrm{O}_{3}$ (PZT) coatings which effect the mechanical, electrical, and electromechanical properties and to compare the measured values to those predicted theoretically due to thermal expansion mismatch. The samples exhibited a $\{111\}$ fiber texture. The highest occurring reflection for CuKa radiation from the PZT coating was at $\sim 80^{\circ} 2 \theta$.

The PZT reflections were broad because the coatings were pseudo-cubic and possessed a small crystallite size. Also, useful PZT reflections were often superimposed onto the more intense substrate reflections. Consequently, these factors prohibited theoretically sound residual stress measurements. Alternative analysis techniques are being pursued. 
HTML No. 94-012, "Characterization of the High-Temperature Phase Transformation in $\mathrm{Y}_{4} \mathrm{Al}_{2} \mathrm{O}_{9}, \mathrm{Dy}_{4} \mathrm{Al}_{2} \mathrm{O}_{9}$, and $\mathrm{Gd}_{4} \mathrm{Al}_{2} \mathrm{O}_{9}$," W. Kriven and J. Shull

University of Illinois researchers investigated the high-temperature phase transitions in rare earth aluminate compounds of the type $\operatorname{Re}_{4} \mathrm{Al}_{2} \mathrm{O}_{9}$. The study was performed to determine the feasibility of using this type of ceramic compound as an interface layer in yttrium aluminum garnet (YAG) fiber-YAG matrix composites. It is anticipated that the phase transformation will crack the interface layer, thus weakening the fiber/matrix bond strength. This should yield a desirable increase in fiber pullout during fracture.

$\mathrm{Y}_{4} \mathrm{Al}_{2} \mathrm{O}_{9}, \mathrm{Dy}_{4} \mathrm{Al}_{2} \mathrm{O}_{9}$, and $\mathrm{Gd}_{4} \mathrm{Al}_{2} \mathrm{O}_{9}$ samples of varying grain size were evaluated using differential scanning calorimetry (DSC) and dilatometry. Transformation temperatures were determined and a grain size dependence of the transformation temperature was demonstrated. These results will be used in conjunction with those determined using high-temperature $X$-ray diffraction (HTXRD) in order to determine the strains associated with the high-temperature phase transformation in these materials.

UNIVERSITY OF KENTUCKY

PPUC, XRDUC

HTML No. 92-061, "Crystal Structure Identification of $\mathrm{Pt}-\mathrm{Al}_{2} \mathrm{O}_{3}$ Catalysts Using HTXRD," R. Srinivasan, and B. H. Davis

The objective of this study was to determine, using high-temperature $\mathrm{X}$-ray diffraction, whether alloy formation between $\mathrm{Pt}$ and $\mathrm{Re}$ occurs on an amorphous $\mathrm{SiO}_{2}$ catalytic support. Since these materials are currently being employed as catalysts, this study will increase understanding of the catalytic activity of these materials in reforming reactions.

The $\mathrm{Pt}$ and Re precursors deposited on the support were placed in the furnace on the diffractometer and were heated to $500^{\circ} \mathrm{C}-550^{\circ} \mathrm{C}$ in flowing $\mathrm{H}_{2}$. Neither alloy formation nor metallic Re were observed on the catalysts containing both $\mathrm{Pt}$ and $\mathrm{Re}$; only metallic platinum was detected. Additional experiments were carried out on similar powders with $\mathrm{Pt}$ and /or $\mathrm{Re}$ on $\mathrm{Al}_{2} \mathrm{O}_{3}$ catalytic support and on powders with $\mathrm{Pt}_{-} \mathrm{SO}_{4}$ on $\mathrm{ZrO}_{2}$. The experimental portion of this study is complete, and a manuscript has been prepared on this work.

\section{UNIVERSITY OF MICHIGAN}

HTML No. 94-011, "Residual Stress and Fracture Toughness of Silicon Nitride," I. M. Peterson and T. Y. Tien

$X$-ray and neutron diffraction methods were used to measure the residual stresses in silicon nitride sintered with different sintering aids. Earlier studies suggest that fracture toughness of sintered silicon nitride ceramics is related to the residual stresses arising from the incorporation of sintering aids. Theoretical calculations show that the thermal expansion mismatch between the grain boundary phases and the silicon nitride resulted in stresses as large as $600 \mathrm{MPa}$. In the X-ray and neutron diffraction experiments, a welldefined high-angle reflection (323) from silicon nitride was used for strain measurements. 
The experimental data showed a compressive stress for the silicon nitride phase, consistent with the thermal expansion mismatch between silicon nitride and the sintering aids used. The measured stress values increased as the amount of grain boundary phase increased. The stress also increased as the thermal expansion mismatch increased. The stress values obtained from the $X$-ray data were smaller ( 110 MPa) than those from the neutron data, which indicates some degree of stress relaxation at the surface. In both cases, the experimentally determined stress values were lower than the predicted stresses.

\section{UNIVERSITY OF MISSOURI}

RSUC

HTML No. 90-062, "Measurement of Residual Stress Distribution of Stainless Steel Workpieces Machined by CNC Turning Center," D. Y. Jang

The objective of this study was to determine the effect of various turning parameters (i.e., machining speed, feed rate, depth of cut, tool geometry, and tool coating) on the resulting residual stresses in 304-type stainless steel, and thereby enhance the understanding of the relationships between the turning operation and "surface integrity." As-machined cylinders were examined during two visits to the HTML and found to possess predominantly compressive and tensile residual stresses in the axial and hoop directions.

The radial stresses appear to be slightly compressive $(\approx-50 \mathrm{MPa})$. Preliminary results indicate that machining speed $(180,310$, and $580 \mathrm{rpm})$ has the largest effect on the hoop residual stress $(260,360$, and $600 \mathrm{MPa}$, respectively). The experimental portion of this study is complete, and a manuscript is in preparation.

\section{UNIVERSITY OF NEW MEXICO}

MAUC

HTML No. 94-052, "Electron Holography of Catalytic Materials," A. Datye

Electron holography on the Hitachi HF-2000 FE-TEM is being used to study the morphology of model heterogeneous catalyst materials, such as $\mathrm{Pd}$ nanocrystals on $\mathrm{SiO}_{2}$ microspheres. The objective is to determine the nature of active sites in these materials. The ability of electron holography to recover the shapes of nanometer-size crystals by proper interpretation of pure phase images is being investigated.

Information on the three-dimensional shapes of nanocrystals as related to the crystal facets exposed on the surface will be invaluable in determining which structures at the atomic level are active in controlling catalytic reactions. Structure studies at the HTML will be correlated to reaction studies at the University of New Mexico.

HTML No. 92-065, "Laser-Enhanced Adhesion of Metallic Films to Ceramic Substrates," A. Pedraza

High-resolution electron microscopy and analytical electron microscopy studies are nearing completion in a project to understand a process to produce strongly adherent metallic films on ceramic substrates. Both magnetron sputter deposition and pulsed laser 
irradiation are used to deposit films of gold, nickel, or copper onto substrates such as sapphire, alumina, aluminum nitride, and fused silica. Changes in the structure and chemistry of the films and the film/substrate interface as characterized by electron microscopy methods are being correlated to adhesion properties so researchers can understand the mechanism of adhesion.

UNIVERSITY OF TENNESSEE

MAUC

HTML No. 93-029, "Studies of Sapphire-Containing Nanometer-Size Particles of Iron," C. McHargue

Nanocomposites of iron in sapphire, prepared by ion implantation, are being used as models to establish the potential of such materials for application in high-technology areas. These include improved friction and wear of ceramic surfaces, improved corrosion resistance, and control of electrical properties of ceramics that could lead to "smart" electrical insulators. High-resolution TEM imaging and high-spatial-resolution $X$-ray analysis of particle compositions has led to an understanding of the systematic effects of implantation parameters on the structures and behavior of the implanted surfaces.

UNIVERSITY OF TENNESSEE

MAUC

HTML No. 93-038, "Characterization of Healing Films Formed During Pitting Corrosion of Tungsten-Implanted Aluminum 1100," R. A. Buchanan and P. P. Smith

The surface topography of corrosion pits on the surfaces of the W-implanted 1100 aluminum has been imaged by AFM. Oxide blisters that form on the implanted surfaces prevent the loss of solute during pitting corrosion, as shown by AES. Both techniques confirm that blisters nucleate at the pitting electrical potential.

VANDERBILT UNIVERSITY

HTML No. 93-090, "The Incorporation of Texture into the Constitutive Modeling of Materials Through the Use of Internal Variables," P. C. Bastias and K-Y. Kim

This HTML user project with Vanderbilt University studied the evolution of crystallographic texture in plastically deformed 301-type stainless steel sheets. The study, which was a part of a larger project supported by TRW Safety Systems, was aimed at incorporating material anisotropy in modeling the plastic deformation of gas generators for automotive air bag systems.

The surface and bulk textures of both the transformed martensite and austenite were determined by $X$-ray diffraction on approximately 20 samples representing different conditions of plastically deformed 301-type metastable stainless steel. Researchers determined the effects of deformation temperature strain rate, initial cold work, and applied stress state on the texture evolution in both phases. The studies on the bulk material were carried out after removing the surface layers by electropolishing. 
Additionally, the transformed martensite content was determined by eddy current measurements. The results from this study are the foundation for a constitutive model suitable for implementation in a commercially available finite element package.

VIRGINIA POLYTECHNIC INSTITUTE AND STATE UNIVERSITY PPUC

HTML No. 93-102, "Thermal Shock Cycling of Combustion Chamber Materials," $D$. Hirschfeld and B. Russ

Researchers from the Virginia Polytechnic Institute are investigating the effects of cyclic thermal shock on the thermal conductivity and thermal expansion of silicon nitride, silicon carbide, partially stabilized zirconia, and calcium magnesium zirconia phosphate. The study is being performed to determine the effect of harsh thermal shock cycling under simulated combustion heat and gas flow on the thermal properties of advanced ceramics, and the feasibility of using these types of ceramics in combustion chambers of liquid propellant guns.

Comparison of the thermal conductivity measurements indicate no difference between virgin samples and those samples that underwent 1000 thermal shock cycles using an acetylene torch. The results of the thermal expansion measurements are currently being evaluated.

WEST VIRGINIA UNIVERSITY

MAUC

HTML No. 94-016, "Characterization and Mechanical Evaluation of Plasma-Enhanced CVD Silicon Nitride-Coated SCS-6 SiC Fibers," R. K. Gupta and D. Collazos

The composition of the outer surfaces of uncoated and $\mathrm{Si}_{3} \mathrm{~N}_{4}$-coated $\mathrm{SiC}$ filaments was analyzed by AES. Compositions were also measured across the fiber cross-sections that were exposed by fracturing the fibers in situ. Oxygen was found throughout the $\mathrm{SiC}$ filaments, regardless of their condition, but was never detected in their pure carbon cores. 


\section{APPENDIX B: PUBLICATIONS AND PRESENTATIONS}

Note: Asterisk indicates HTML staff member.

\section{B.1 PUBLICATIONS}

Alexander, K. B., P. F. Becher, X.-L. Wang, ${ }^{*}$ C. H. Hsueh. "Internal Stresses and the Martensitic Start Temperature in Alumina-Zirconia Composites: Effects of Composition and Microstructure," submitted to J. Amer. Ceram. Soc.

Allard, L. F.* and E. Völkl*. Report of Foreign Travel by L. F. Allard and E. Völkl, October 29November 6, 1993, ORNL Report No. FTR-4850, Oak Ridge National Laboratory, Oak Ridge, TN, 1993.

Allard, L. F.* and E. Völkl*. Report of Foreign Travel by L. F. Allard and E. Völkl, July 8-23, 1994, ORNL Report No. FTR-5097, Oak Ridge National Laboratory, Oak Ridge, TN, 1994.

Baldwin, F., P. H. Holloway, M. Bordelon, and T. R. Watkins*. "The Effect of Ultra-Low Temperature Treatments on the Stress in Aluminum Metallization on Silicon Wafers," published in the Proceedings of the Spring Meeting of the Materials Research Society, $V .338$, April 5-8, 1994, San Francisco, CA, Materials Research Society, Pittsburgh, PA, 1994.

Bandyopadhay, A., P. B. Aswath, W. D. Porter, and O. B. Cavin*."The LowTemperature Hexagonal to Orthorhombic Transformation in $\mathrm{Si}_{3} \mathrm{~N}_{4}$-Reinforced BAS Matrix Composites," to be submitted to J. Mater. Research, (1994).

Beecher, S. C., R. B. Dinwiddie, ${ }^{*}$ A. M. Abeel, and R. A. Lowden. "The Thermal Conductivity of Silicon Nitride with Molybdenum Disilicide Additions," Thermal Conductivity 22, ed. T. W. Tong, Technomic Publishing Co., Inc., pp. 859-67 (1994).

Beecher, S. C.,* R. B. Dinwiddie, ${ }^{*}$ R. A. Lowden. "The Thermal Conductivity of Carbon Coated Silicon Carbide Fibers Embedded in a Silicon Carbide Matrix," Thermal Conductivity 22, ed. T. W. Tong, Technomic Publishing Co., Inc., p324-34 (1994).

Bowers, D. A., J. W. Davis, and R. B. Dinwiddie*. "Development of 1-D Carbon Composites for Plasma-Facing Components," Journal of Nuclear Materials, 212-215 p11637 (1994).

Braski, D. N.* and K. B. Alexander. "AES Analysis of SiC-Whisker Surfaces and SiCWhisker /Alumina Interfaces," submitted to J. Mater. Research.

Breder, $K^{*}$. "Time-Dependent Strength Degradation of a Siliconized Silicon Carbide Determined by Dynamic Fatigue," submitted to Journal of American Ceramic Society.

Breder, K.* and V. J. Tennery*. "Comparison of the Dynamic Fatigue Behavior of Two Monolithic SiC Ceramics and an Al (Sub 2) 0 (Sub 3)/SiC Composite," submitted to the Proceedings of the 18th Annual Conference on Composites and Advanced Ceramics, Cocoa Beach, FL January 9-14, 1994.

Breder, K.* and V. J. Tennery*. "Materials Support for the Development of HighTemperature Advanced Furnaces (HITAF) - A Comparison of Selected Mechanical Properties for Three SiC-Based Ceramics," submitted to Proceedings of the 10th Annual 
Coal Preparation, Utilization, and Environmental Control Contractors Conference, Pittsburgh, July 18-21, 1994.

Chawla, K. K., M. K. Ferber, ${ }^{*}$ Z. R. Xu, and R. Venkatesh. "Interface Engineering in Alumina/Glass Composites," Materials Science Engineering Series, A126, 35-44 (1993).

Chawla, N., P. K. Liaw, E. Lara-Curzio,* R. A. Lowden, and M. K. Ferber*. "Effect of Fiber Orientation on the Monotonic and Fatigue Behavior of a Continuous Fiber Ceramic Composite," High-Performance Composites, ed. K. K. Chawla, P. K. Liaw, and S. G. Fishman, The Minerals, Metals, and Materials Society, pp. 291-303, 1994.

Cofer, C. G., J. Economy, M. K. Ferber, ${ }^{*}$ and E. Lara-Curzio*. "Evaluation of the Interfacial Mechanical Properties of Fiber Reinforced Boron Nitride Matrix Composites," to be published in Proceedings of the 18th Annual Conference on Composites and Advanced Ceramics, Cocoa Beach, FL January 9-14, 1994.

Dinwiddie, R. B., S. C. Beecher, ${ }^{*}$ P. V. Arya, and J. C. Withers, "The Thermal Conductivity of Carbon-Fiber Reinforced Metal Matrix Composites," Thermal Conductivity 22, ed. T. W. Tong, Technomic Publishing Co., Inc., pp. 868-77 (1994).

Dinwiddie, R. B., R. J. Pylkki, and P. E. West. "Thermal Conductivity Contrast Imaging with a Scanning Thermal Microscope," Thernal Conductivity 22, ed. T. W. Tong, Technomic Publishing Co., Inc., pp. 668-77 (1994).

Eaton, H. E., J. R. Linsey, and R. B. Dinwiddie*. "The Effect of Thermal Aging on the Thermal Conductivity of Plasma Sprayed Fully Stabilized Zirconia," Thermal Conductivity 22, ed. T. W. Tong, Technomic Publishing Co., Inc., pp. 289-300 (1994).

Ferber, M. K., M. G. Jenkins, T. A. Nolan, ${ }^{*}$ and R. Yeckley. "Comparison of the Creep and Creep Rupture Performance of Two HIPed Silicon Nitride Ceramics," J. Amer. Ceram. Soc. , 77 (3) 657-65, (1994).

Ferber, M. K., ${ }^{*}$ A. A. Wereszczak, ${ }^{*}$ L. Riester, ${ }^{*}$ R. A. Lowden, and K. K. Chawla. "Evaluation of the Interfacial Mechanical Properties in Fiber-Reinforced Ceramic Composites," pp. 168-79 in Proceedings of the 17th Annual Conference on Composites and Advanced Ceramic Materials, Westerville, $\mathrm{OH}$ (1993).

Hubbard, C. R., ${ }^{*}$ S. A. David, and S. Spooner. "Residual Stresses in Weldments and Their Mapping by Neutron and X-Ray Methods," EWI Insights 8 (1), pp. 6-7, 1994.

Hubbard, C. R., ${ }^{*}$ T. R. Watkins, ${ }^{*}$ K. J. Kozaczek, X-L. Wang, ${ }^{*}$ and S. Spooner. "Research Opportunities and Facilities at ORNL's Residual Stress User Center"; pp. 15662 in Proceedings of the Fourth International Conference on Residual Stresses. Society for Experimental Mechanics, Inc., 1994.

Jackson, T. B., S. Y. Limaye, and W. D. Porter*. "The Effects of Thermal Cycling on the Physical and Mechanical Properties of [NZP]-Type Ceramics," Book of Abstracts, 96th Annual Meeting of the American Ceramic Society, Indianapolis, IN, April 24-28, 1994.

Jo, J., X-L. Wang, * M. J. Kleinosky, R. S. Green, C. R. Hubbard, * and S. Spooner. "Evaluation of Stress Relief Treatment by Neutron and X-ray Diffraction Methods," pp. 1230-7 in Proceedings of the 4th International Conference on Residual Stresses, Baltimore, June 
8-10, 1994.

Joy, D. C.* and L. F. Allard*. "Optimizing Detector Resolution and Efficiency in CCD Arrays," Proceedings of the 52nd Annual Meeting of the Microscopy Society, New Orleans, July 31-August 5, 1994, San Francisco Press, San Francisco.

Kopp, O. C., E. L. Fuller, Jr., and O. B. Cavin*. "Oxidized Residues from 2020 Graphite," submitted to J. Nucl. Mater., 1994.

Kozaczek, K. J., ${ }^{*}$ C. O. Ruud, and J. D. Fitting. "Measurement of Residual Stresses on Ceramic Materials with High Spatial Resolution," Proceedings of the 6th International Symposium on Nondestructive Characterization of Materials

Kozaczek, K. J., * T. R. Watkins, ${ }^{*}$ C. R. Hubbard, X-L. Wang, and S. Spooner.

"Residual Stresses in Material Processing"; pp. 149-55 in Determining Material

Characterization: Residual Stress and Integrity with NDE, PVP-V. 276, NDE V. 12, ed. by J. C. Spanner, Jr., ASME, New York, 1994.

Kozaczek, K. J., ${ }^{*}$ T. R. Watkins, ${ }^{*}$ C. R. Hubbard, ${ }^{*}$ X-L. Wang, ${ }^{*}$ and S. Spooner. "Residual Stresses in Material Processing," Proceedings of the Am. Soc. Mech. Eng. Pressure Vessel and Piping Conference, Minneapolis, MN, June 19-24, 1994, ASME.

Liu, E., A. A. Wereszczak, , T. P. Kirkland, and M. K. Ferber". "High-Temperature Compressive Strength of Non-Oxide Ceramic Foams," to be submitted to Scripta Met.

Loboda, M. J. and M. K. Ferber* "Characterization of the Mechanical Properties of aSiC:H Films," J. Mater. Res., 8 (11) 2908-2915 (1993).

Menon, M. N., H. T. Fang, D. C. Wu, M. G. Jenkins, M. K. Ferber, K. L. More, ${ }^{*}$ C. R. Hubbard,* and T. A. Nolan*. "Creep and Stress Rupture Behavior of an Advanced Silicon Nitride: Part I, Experimental Observations," J. Amer. Ceram. Soc. , 77 (5) 1217-1227, 1994.

Menon, M. N., H. T. Fang, D. C. Wu, M. G. Jenkins, and M. K. Ferber* . "Creep and Stress Rupture Behavior of an Advanced Silicon Nitride: Part II, Creep Rate Behavior," J. Amer. Ceram. Soc. , 77 (5) 1228-1234, 1994.

Menon, M. N., H. T. Fang, D. C. Wu, M. G. Jenkins, and M. K. Ferber*. “Creep and Stress Rupture Behavior of an Advanced Silicon Nitride: Part III, Stress Rupture and Monkman-Grant Relationship," J. Amer. Ceram. Soc. , 77 (5) 1234-1241, 1994.

Menon, M. N., H. T. Fang, D. C. Wu, M. G. Jenkins, and M. K. Ferber* . Creep Rate and Stress Rupture Properties of NT154 $\mathrm{Si}_{3} \mathrm{~N}_{4}$, to be published in the Proceedings of Silicon Nitride 93, October 4-6, 1993, Stuttgart, Germany.

More, K. L., E. Lara-Curzio, * and R. A. Lowden. "Surface Roughness Characterization of Various Ceramic Fibers Using AFM and Low-Voltage SEM," Proceedings of the 52nd Annual Meeting of the Microscopy Society, Nezw Orleans, July 31-August 5, 1994, San Francisco Press, San Francisco.

More, K. L., R. A. Lowden, and T. M. Besmann. "Low-Temperature Mo-Catalyzed Growth of Crystalline $\mathrm{Si}_{3} \mathrm{~N}_{4}$ by CVD," pp. 918-19, Proceedings of the 51st Annual Meeting of the Microsc. Soc. Am. Cincinnati, Aug. 1-6, 1993, San Francisco Press, Inc., 1993. 
Park, D. G., J. M. Burlitch, M. H. E. Martin, C. K. Ober, O. B. Cavin, W. D. Porter, and C. R. Hubbard*. "Crystallization of Precursors of Forsterite and Chromium-Doped Forsterite,"J. Am. Cer. Soc. 77 (1), 33-40, 1994.

Pasto, A. E., B. L. Cox, M. K. Ferber, C. R. Hubbard, M. L. Santella, W. A. Simpson, Jr., and T. R. Watkins*. "Effect of Surface Condition on Strength and Fatigue Behavior of Alumina," Technical Document 2584, Oak Ridge National Laboratory, P.O. Box 2008, Oak Ridge, TN, 37831, November 1993.

Rabin, B. H., R. L. Williamson, T. R. Watkins, ${ }^{*}$ X-L. Wang, ${ }^{*}$ C. R. Hubbard, ${ }^{*}$ and S. Spooner. "Characterization of Residual Stresses in Graded Ceramic-Metal Structures: A Comparison of Diffraction Experiments and FEM Calculations," to be published in Proc. 3rd Int. Symp. on FGM, held in Lausanne, Switzerland, Oct. 10-12, 1994.

Raguraman, S., M. K. Ferber, J. F. Stubbins, and A. A. Wereszczak*. "Stress Oxidation Tests in SiCf/SiC Composites," to be published in the Proceedings of the Ceramic Matrix Composites Sympositum, held at the 96th Annual Meeting of the American Ceramic Society.

Raguraman, S., J. F. Stubbins, M. K. Ferber, and A. A. Wereszczak". "Crack Propagation in SiCf/SiC Ceramic Matrix Composite Under Static and Cyclic Loading Conditions," submitted to Journal of Nuclear Materials (Accepted).

Raguraman, S., J. F. Stubbins, M. K. Ferber, and A. A. Wereszczak". "Crack Growth Behavior of $\mathrm{SiCf} / \mathrm{SiC}$ Composite at Room and High Temperatures," to be published in the Proceedings of the 18th Annual Conference on Composites and Advanced Ceramic Materials.

Ruud, C. O. and K. J. Kozaczek*. "Errors Induced in Triaxial Stress Calculations Using Incorrect Lattice Parameters," in Proceedings of the 1994 SEM Spring Conference on Experimental Mechanics and Exhibit, Baltimore, MD, June 6-8, 1994 _(Bethel, CT: SEM, Inc., 1994), p.8.

Scanlon, M. R., M. K. Ferber, and R. C. Cammarata. "Indentation Study of the Mechanical Properties of Granular Thin Films," pages 555-8 in Mat. Res. Soc. Symp. Proc., 308, Materials Research Society, 1993.

Shanmugham, S., K. L. More, ${ }^{*}$ D. P. Stinton, C. R. Hubbard, O. B. Cavin, W. D. Porter, ${ }^{*}$ and M. K. Ferber. "Thermal and Mechanical Behavior of $\mathrm{Ba}_{1+x} \mathrm{Zr}_{4} \mathrm{P}_{6-2 x} \mathrm{Si}_{2 x} \mathrm{O}_{24}$ " to be published in Proceedings of the American Ceramic Society, (1994).

Shanmugham, S., D. P. Stinton, C. R. Hubbard, * and S. Y. Limaye. "Synthesis and Cell Refinement of $\mathrm{Ba}_{0.5+\times / 2} \mathrm{Zr}_{2} \mathrm{P}_{3-x} \mathrm{Si}_{x} \mathrm{O}_{12}$ with $\mathrm{x}=0.25$ and 0.375 ," submitted to J. Mater. Sci. Lett.

Spooner, S., S. A. David, X-L. Wang, C. R. Hubbard, T. M. Holden, and J. Root. "Residual Stresses in Weldments - Effect of Vibration on Stresses," to be published in Proceedings of the International Conference on Modeling and Control of Joining Processes, Orlando, Florida, December 6-8, 1993.

Spooner, S., J. A. Fernandez-Baca, S. A. David, C. R. Hubbard, T. M. Holden, and J. H. Root. "Investigation of Residual Stresses in a Multipass Weld in One-Inch Stainless Steel Plate," pp. 1205-9, Proceedings of the 4th International Conference on Residual Stresses, Baltimore, June 8-10, 1994, (1994). 
Spooner, S., X-L. Wang, and C. R. Hubbard*. "User Facility Available for Residual Stress Measurements," submitted to Mater. Technol., 1994.

Spooner, S., X-L. Wang, ${ }^{*}$ C. R. Hubbard, ${ }^{*}$ and S. A. David. "Residual Stresses in a Multi-Pass Weld in an Austenitic Stainless Steel Plate Before and After Thermal Stress Relief," pp. 964-9 in Proceedings of the 4th International Conference on Residual Stresses, Baltimore, June 8-10, 1994.

Subramanian, S., K. L. More, D. P. Stinton, C. R. Hubbard, O. B. Cavin, O. Porter, M. K. Ferber, S. Y. Limaye, and B. T. Jackson. "Thermal and Mechanical Behavior of $\mathrm{Ba}_{1+x} \mathrm{Zr}_{4} \mathrm{P}_{6-2 x} \mathrm{Si}_{2 \times} \mathrm{O}_{24}$ " Proceedings of the 96th Annual Meeting of the American Ceramic Society, Indianapolis, IN, American Ceramic Society, April 24-28, 1994.

Surrett, A. D., K. L. More, and R. A. Lowden. "Evaluation of Matrix and Interface Properties in SiC /SiC Composites," pp. 922-23, Proceedings of the 51st Annual Meeting of the Microsc. Soc. Am. , Cincinnati, Aug. 1-6, 1993, San Francisco Press, Inc., 1993.

Tennery, V. J.* and F. M. Foust*. "High Temperature Materials Laboratory Sixth Annual Report (October 1992 through September 1993)," ORNL Report.

Tennery, V. J.* and T. O. Morris*. "The Ceramic Manufacturability Center - A New Partnership with U.S. Industry," ORNL Report No. ORNL/M-3649.

Vasudev, A., K. L. More,* K. S. Ailey-Trent, and R. F. Davis. "Kinetics and Mechanisms of High-Temperature Creep in Polycrystalline Aluminum Nitride, J. Mater. Res. 8(5), 1101-8, 1993.

Völkl, E.* and L. F. Allard*. "Digital Processing of High-Resolution Electron Holograms," pp. 1066-76, Proceedings of the 51st Annual Meeting of the Microsc. Soc. Am., Cincinnati, Aug. 1-6, 1993, San Francisco Press, Inc., 1993.

Wang, X-L., * P. F. Becher, K. B. Alexander, J. A. Fernandez-Baca, and C. R. Hubbard*. "Residual Stress in $\mathrm{Al}_{2} \mathrm{O}_{3}-\mathrm{ZrO}_{2}$ Ceramic Composites," pp. 1172-77 in Proceedings of the 4th International Conference on Residual Stresses, Baltimore, June 8-10, 1994.

Wang, X-L., ${ }^{*}$ J. A. Fernandez-Baca, C. R. Hubbard, ${ }^{*}$ K. B. Alexander, and P. F. Becher. "Transformation Behavior in $\mathrm{AL}_{2} \mathrm{O}_{3}-\mathrm{ZrO}_{2}$ Ceramic Composites," submitted to the Proceedings of the International Conference on Neutron Scattering, Sendai, Japan, November 11-14, 1994.

Wang, X-L., ${ }^{*}$ J. A. Fernandez-Baca, C. R. Hubbard, ${ }^{*}$ K. B. Alexander, and P. F. Becher. "Transformation Behavior in $\mathrm{Al}_{2} \mathrm{O}_{3}-\mathrm{ZrO}_{2}$ Ceramic Composites," to appear in Physica $B$.

Wang, X-L., J. A. Fernandez-Baca, Z. R. Wang, D. Vaknin, and D. C. Johnston. "Neutron Diffraction Study of the Magnetic Ordering of $\mathrm{BaCuO}_{2+x}$, to appear in Physica $B$.

Wang, X-L., J. A. Fernandez-Baca, Z. R. Wang, D. Vaknin, and D. C. Johnston. "Neutron Diffraction Study of the Magnetic Ordering of $\mathrm{BaCuO}_{2+x}$," Bull. American Physics Society 39, p. 126, 1994.

Wang, X-L.* , C. R. Hubbard, ${ }^{*}$ K. B. Alexander, P. F. Becher, J. A. Fernandez-Baca, and S. Spooner. "Neutron Diffraction Measurements of the Residual Stresses in $\mathrm{Al}_{2} \mathrm{O}_{3}-\mathrm{ZrO}_{2}$ 
Ceramic Composites," J. Amer. Ceram. Soc. 77, 1569-75 (1994).

Wang, X-L., * C. R. Hubbard, * S. Spooner, S. A. David, B. H. Rabin, and R. L. Williamson. "Mapping of the Residual Stress Distribution within a Brazed Zirconia-Iron Joint," submitted to Acta Metall. Mat.

Wang, Z. R., D. Vaknin, D. C. Johnston, X-L. Wang, and J. A. Fernandez-Baca. "Magnetization Measurements of Ferromagnetic $\mathrm{Cu}_{6}$ and $\mathrm{Cu}_{18}$ Clusters in $\mathrm{BaCuO}_{2+\times}, B u l l$. American Physics Society 39, p. 588, 1994.

Watkins, T. R., C. R. Hubbard, and J. L. Bjerke. "Measurement of Elastic Constants in Plasma-Sprayed Zirconia Coatings Using X-Ray Diffraction," Proceedings of the 96 th Annual Meeting of the American Ceramic Society, Indianapolis, IN, April 24-28, 1994, American Ceramic Society, 1994.

Watkins, T. R., ${ }^{*}$ K. J. Kozaczek, * and C. R. Hubbard, "Depth Profiles of Residual Stresses Due to Machining with Grazing Incidence X-Ray Diffraction," to be given at the 19th Annual Conference/Expo, American Ceramic Society, Cocoa Beach, FL, January 812, 1995.

Watkins, T. R., X-L. Wang, ${ }^{*}$ C. R. Hubbard, ${ }^{*}$ B. H. Rabin, P. Zschach, and M. Nelson. "Residual Stress Distribution in Graded Ceramic-to-Metal Joints," published in the Brookhaven National Laboratory Annual Report for 1993, Upton, NY.

Watkins, T. R., X.-L. Wang, ${ }^{*}$ S. Spooner, C. R. Hubbard, ${ }^{*}$ S. J. Vance, B. H. Rabin, and R. L. Williamson. "Mapping of Residual Strains of a Ceramic-to-Metal Joint Using X-Ray Diffraction," pp. 672-8 in Proceedings of the 4th International Conference on Residual Stresses, Baltimore, June 8-10, 1994.

Wereszczak, A. A., ${ }^{*}$ K. Breder, ${ }^{*}$ M. K. Ferber, ${ }^{*}$ T. P. Kirkland, ${ }^{*}$ and P. K. Khandelwal. "Environmental Effects on the Flexure Strength of HIPed Silicon Nitride at Elevated Temperatures," Fall Meeting of the Electrochemical Society, pp 686-7, Electrochemical Society, Pennington, NJ., 1993.

Wereszczak, A. A., M. K. Ferber ${ }^{*}$ K. Breder, ${ }^{*}$ T. P. Kirkland, ${ }^{*}$ and P. Khandelwal. "High Temperature Dynamic Fatigue Performance of a Hot Isostatically Pressed Silicon Nitride," In press; Materials Science and Engineering.

Wereszczak, A. A., ${ }^{*}$ M. K. Ferber, ${ }^{*}$ T. P. Kirkland, ${ }^{*}$ M. R. Foley, and R. L. Yeckley. "Evolution of Stress Failure Resulting from Stress /Oxidation Damage in a Hot Isostatically Pressed Silicon Nitride at Elevated Temperatures," In review, Journal of the American Ceramic Society.

Wereszczak, A. A., ${ }^{*}$ M. K. Ferber, ${ }^{*}$ T. P. Kirkland, ${ }^{*}$ and K. L. More* ."Evolution of Oxidation and Creep Damage Mechanisms in HIPed Silicon Nitride Materials," Plastic Deformation of Ceramics, Plenum Press.

Wereszczak, A. A., ${ }^{*}$ M. K. Ferber, ${ }^{*}$ R. R. Sanders, M. G. Jenkins, and P. Khandelwal. "Fracture Toughness of a HIPed $\mathrm{Si}_{3} \mathrm{~N}_{4}$ at Elevated Temperatures," pp. 101-112 in Proceedings of the 17th Anmul Conference on Composites and Advanced Ceramic Materials, American Ceramic Society, Westerville, $\mathrm{OH}$ (1993). 
Wereszczak, A. A., ${ }^{*}$ T. P. Kirkland, ${ }^{*}$ K. Breder, ${ }^{*}$ M. K. Ferber ${ }^{*}$ and P. Khandelwal. "High Temperature Dynamic Fatigue Performance of a Hot Isostatically Pressed Silicon Nitride," to appear in Material Science and Engineering.

Wolf, J. S. and O. B. Cavin*. "The Effective Thermal Expansion of Nickel and Nickel Oxide During High-Temperature Oxidation," Adv. X-Ray Anal. Vol. 37, 449-56, 1994.

Zutshi, A., R. A. Haber, D. E. Niesz, J. W. Adams, J. B. Wachtman, M. K. Ferber,* and S. M. Hsu. "Processing, Microstructure, and Wear Behavior of Silicon Nitride Hot Pressed with Alumina and Yttria," J. Amer. Ceram. Soc. ,77 [4] 883-90, 1994.

\section{B.2 PRESENTATIONS}

Alexander, K. B., P. F. Becher, C. H. Hsueh, and X-L. Wang*. "The Role of Microstructure on the Martensitic Transformation in Zirconia-Toughened Alumina," 96th Annual Meeting of the American Ceramic Society, Indianapolis, IN, April 24-28, 1994.

Allard, L. F.* and T. A. Nolan*. "Electron Holography in Materials Science Research at the High Temperature Materials Laboratory," technical seminar given at DuPont Company, Wilmington, DE, December 14, 1993.

Allard, L. F.* and E. Völkl*. "Techniques and Applications of Electron Holography," Appalachian Regional Electron Microscopy Society (AREMS), Knoxville, TN, March 24$25,1994$.

Allard, L. F., E. Völkl,* and T. A. Nolan*. "Application of a New Convergent Beam/Electron Holography Method to Grain Boundary Characterization in $\mathrm{Si}_{3} \mathrm{~N}_{4}$ Ceramics," 96th Annual Meeting of the American Ceramic Society, Indianapolis, IN, April 24-28, 1994.

Bandyopadhay, A., P. B. Aswath, W. D. Porter, and O. B. Cavin*. "A Phase Transformation Study in Barium Aluminosilicate (BAS)-Silicon Nitride Ceramic Composites," 96th Annual Meeting of the American Ceramic Society, Indianapolis, IN, April 24-28, 1994.

Beecher, S. C.* and R. B. Dinwiddie*. "The Effect of Oxidation on the Thermal Diffusivity of Continuous Fiber Reinforced Ceramic Matrix Composites," Fall Meeting of Materials Research Society, Boston, MA, November 28 - December 2, 1994.

Beecher, S. C., ${ }^{*}$ R. B. Dinwiddie, ${ }^{*}$ and B. A. Nagaraj. "The Thermal Conductivity of Zirconia Thermal Barrier Coatings," to be given at the 19th Annual Conference/Expo, American Ceramic Society, Cocoa Beach, FL, January 8-12, 1995.

Braski, D. N., * N. R. Osborne, and J. M. Zurbechen. "XPS Study of Ni-Mn-Fe Spinel Thermistor Material," Fall meeting of the Material Research Society, Boston, MA, November 28-December 2, 1994.

Breder, K, T. M. Strobel, J. P. Hurley, and J. E. Holowczak. "Strength Measurements of Monolithic SiC Ceramics and $\mathrm{Al}_{2} \mathrm{O}_{3} / \mathrm{SiC}$ Composites After Exposure to Coal Slag," 96th Annual Meeting of the American Ceramic Society, Indianapolis, IN, April 24-28, 1994.

Breder, K* and V.J. Tennery* "Comparison of the High-Temperature Strength and Slow Crack Growth Properties of Two Monolithic $\mathrm{SiC}$ Ceramics and an $\mathrm{Al}_{2} \mathrm{O}_{3} / \mathrm{SiC}$ 
Composite," 96th Annual Meeting of the American Ceramic Society, Indianapolis, ID, April 24-28, 1994.

Chawla, N. and P. K. Liaw, University of Tennessee, Knoxville, TN; and E. LaraCurzio, ${ }^{*}$ R. A. Lowden, and M. K. Ferber*. "Cyclic Fatigue and Monotonic Behavior of a Laminated Continuous Fiber Ceramic Composite (CFCC)," Oak Ridge National Laboratory, Oak Ridge, TN.

Chawla, K. K., Z. R. Xu, and J-S. Ha, New Mexico Tech, Socorro, NM; and E. LaraCurzio,* M. K. Ferber, and S. Russ. "Interfacial Characteristics in Mullite Fiber/BN Coating/Mullite Matrix Composites," Oak Ridge National Laboratory, Oak Ridge, TN. Article in preparation.

Dinwiddie, R. B., and S. C. Beecher *. "Scanning Thermal Conductivity Microscopy," Fall Meeting of Materials Research Society, Boston, MA, November 28 - December 2, 1994.

Dinwiddie, R. B.,* S. C. Beecher, and B. A. Nagaraj. "Influence of Microstructure on the Thermal Conductivity of Zirconia Thermal Barrier Coatings," 96th Annual Meeting of the American Ceramic Society, Indianapolis, IN, American Ceramic Society, April 24-28, 1994.

Dinwiddie, R. B.* S. C. Beecher, ${ }^{*}$ R. J. Pylkki, and P. E. West. "Scanning Thermal Conductivity Microscopy," 96th Annual Meeting of the American Ceramic Society, Indianapolis, IN, April 24-28, 1994.

Ferber, M. K.* and A. A. Wereszczak*. "A Simple Explanation for Stratification of Monkman-Grant Curves for HIPed Silicon Nitrides," Oak Ridge National Laboratory, Oak Ridge, TN.

Hubbard, C. A.* "High Temperature X-Ray Powder Diffraction Studies at a National User Facility," W. B. Pearson International Symposium, Royal Military College of Canada, Kingston, Ontario, June 20-21, 1994.

Hubbard, C. R., E. Lara-Curzio, X-L. Wang, and S. Spooner. "Phase-Sensitive Mechanical Properties of Ceramic Matrix Composites," to be given at the 19th Annual Conference/Expo, American Ceramic Society, Cocoa Beach, FL, January 8-12, 1995.

Hubbard, C. R., ${ }^{*}$ X-L. Wang, ${ }^{*}$ and S. Spooner. "Residual Stress Measurements Within Components by Neutron Diffraction Methods," 96th Annual Meeting of the American Ceramic Society, Indianapolis, IN, April 24-28, 1994.

Hubbard, C. A., ${ }^{*}$ T. R. Watkins, X-L. Wang, and S. Spooner. "Determination of Residual Stresses in Ceramic Materials by Diffraction Methods," American Ceramic Society Pacific Coast Regional Meeting, Los Angeles, CA, October 19-22, 1994.

Jackson, T. B. and W. D. Porter*. "Environmental Microcracking of [NZP] Type Ceramics," 96th Annual Meeting of the American Ceramic Society, Indianapolis, IN, April 24-28, 1994.

Jenkins, M. G., K. Breder,* J. A. Salem, and V. J. Tennery*. "Elevated-Temperature Macro-Flaw Fracture and Tensile Creep/Creep Rupture Behaviors of a Self-Reinforced 
Silicon Nitride," Pacific Rim Meeting of the American Ceramic Society, Honolulu, HA, November 7 - 11, 1993.

Jo, J., X-L. Wang, * M. J. Kleinosky, C. R. Hubbard, * and S. Spooner. "Thermal Stress Relief Evaluation Using Neutron Diffraction," Fall Meeting of the Metallurgical Society, Rosemont, IL, October 2-6, 1994.

Knepfler, C. A., K. T. Faber, G. B. Olson, J. Weertman, C. R. Hubbard, ${ }^{*}$ O. B. Cavin, and W. D. Porter* "An Investigation of the Dependence of the Properties of $(\mathrm{Mo}, \mathrm{Cr})_{2} \mathrm{C}$ on Composition," 96th Annual Meeting of the American Ceramic Society, Indianapolis, IN, April 24-28, 1994.

Kozaczek, K. J., T. R. Watkins, * C. R. Hubbard, and D. Y. Jang. "Surface Residual Stresses in Machined Austenitic Stainless Steel," Materials Week, Rosemont, IL, October 3-7, 1994.

Lara-Curzio, E., ${ }^{*}$ K. L. More, ${ }^{*}$ M. K. Ferber, and R. A. Lowden. "A Quantitative Study of the Effect of Fiber Roughness in the Interfacial Properties of Continuous Fiber Ceramic Composites," Oak Ridge National Laboratory, Oak Ridge, TN.

Love, M. S., J. R. Dick, K. L. More, ${ }^{*}$ T. J. Henson, T. S. Geer, and T. A. Nolan*. "Identification of Processing Defects in Ceramic Tile to Improve Manufacturing Yield," 96th Annual Meeting of the American Ceramic Society, Indianapolis, IN, April 24-28, 1994.

More, K. L., * E. Lara-Curzio, * and R. A. Lowden. "Characterization of the Surface Roughness of a Variety of Ceramic Fibers Using High-Resolution SEM and Atomic Force Microscopy," 96th Annual Meeting of the American Ceramic Society, Indianapolis, IN, April 24-28, 1994.

More, K. L. ${ }^{*}$ and R. A. Lowden. "Microstructural Characterization of Interfaces in FiberReinforced Ceramic Matrix Composites," Frontiers of Electron Microscopy in Materials Science, Oakland, CA, June 21-24, 1994.

More, K. L., A. A. Wereszczak, ${ }^{*}$ M. K. Ferber, and R. Yeckley. "A Kinetic Study of the Formation of Voids in a Silicon Nitride Ceramic During High Temperature Creep Deformation," 96th Annual Meeting of the American Ceramic Society, Indianapolis, IN, April 24-28, 1994.

More, K. L., A. A. Wereszczak, ${ }^{*}$ M. K. Ferber, ${ }^{*}$ and R. Yeckley. "A Kinetic Study of the Formation of Voids in a Silicon Nitride Ceramic During High Temperature Creep Deformation," Oak Ridge National Laboratory, Oak Ridge, TN; Russ Yeckley, Saint Gobain/Norton Industrial Ceramics, Northboro, MA.

Mroz, T. J., R. B. Dinwiddie, ${ }^{*}$ W. D. Porter, ${ }^{*}$ and S. C. Beecher*. "High Temperature Thermal Conductivity of Aluminum Nitride," 96th Annual Meeting of the American Ceramic Society, Indianapolis, IN, April 24-28, 1994.

Nolan, T. A., ${ }^{*}$ K. L. More, ${ }^{*}$ L. F. Allard, ${ }^{*}$ M. K. Ferber, ${ }^{*}$ and D. W. Coffey*. "Microstructural Characterization of $\mathrm{Si}_{3} \mathrm{~N}_{4}$ Ceramics Intended for Use in Reciprocating Engines," 96th Annual Meeting of the American Ceramic Society, Indianapolis, IN, April 24-28, 1994. 
Nolan, T. A., ${ }^{*}$ K. L. More, ${ }^{*}$ L. F. Allard, $*$ M. K. Ferber, ${ }^{*}$ and D. W. Coffey*

"Microstructural Characterization of $\mathrm{Si}_{3} \mathrm{~N}_{4}$ Ceramics Intended for Use in Reciprocating Engines," Oak Ridge National Laboratory, Oak Ridge, TN

Porter, W. D. , and T. B. Jackson "Thermal Expansion Behavior of (NZP) Type Ceramics," Meeting of the North American Thermal Analysis Society, Toronto, Canada, September 25-28, 1994.

Raguraman, S. and J. F. Stubbins, University of Illinois, Urbana, IL; and M. K. Ferber* and A. A. Wereszczak*. "Stress-Rupture Tests in SiCf/SiC Composites," Oak Ridge National Laboratory, Oak Ridge, TN.

Ruud, C. O., A. R. McIlree, and K. J. Kozaczek*. "The Residual Stresses in RollerExpanded Iconel 600 Steam Generator Tubing," American Society of Mechanical Engineering Pressure Vessels and Piping Conference, Minneapolis, MN, June 19-24, 1994.

Spooner, S. , S. A. David, X-L. Wang, ${ }^{*}$ C. R. Hubbard, ${ }^{*}$ T. M. Holden, and J. H. Root. "Effect of Vibratory Stress Relief During Welding of Thick Stainless Steel Plate," International Conference on Modeling and Control of Joining Processes, Orlando, FL, December 6-8, 1993.

Spooner, S., C. R. Hubbard, X-L. Wang, and S. A. David. "Residual Stress Patterns in Ferritic and Austenitic Steel Welds," Fall Meeting of Materials Research Society, Boston, MA, November 28 -December 2, 1994.

Tennery, V. J.* and K. Breder* "Research at ORNL Related to High-Performance Materials in Coal Conversion/Utilization," University of Tennessee Space Institute, Tullahoma, TN, November 2, 1993.

Tortorelli, P. F., L. Riester, ${ }^{*}$ E. Lara-Curzio, ${ }^{*}$ and M. K. Ferber*. "Use of Push-in Tests to Examine Oxidation Effects on Fiber-Reinforced SiC Composites," Oak Ridge National Laboratory, Oak Ridge, TN.

Wang, X-L., * C. R. Hubbard, ${ }^{*}$ S. Spooner, S. A. David, B. H. Rabin, and R. L. Williamson. "Measurement and Modeling of Residual Stress Distribution in a Brazed Zirconia-Cast Iron Joint," Fall Meeting of the Materials Research Society, Boston, MA, November 28-December 2, 1994.

Wang, X-L, J. A. Fernandez-Baca, K. B. Alexander, B. F. Becher, and C. R. Hubbard*. "Residual Stress and Transformation Behavior in $\mathrm{Al}_{2} \mathrm{O}_{3}-\mathrm{ZrO}_{2}$ Ceramic Composites," Fall Meeting of Materials Research Society, Boston, MA, November 28-December 2, 1994.

Wang, X-L, J. A. Fernandez-Baca, Z. R. Wang, D. Vaknin, and D. C. Johnston.

"Neutron Diffraction Study of the Magnetic Ordering of $\mathrm{BaCuO}_{2+x}$," International Conference on Neutron Scattering (ICNS '94), Sendai, Japan, October 11-14, 1994.

Wang, X-L., J. A. Fernandez-Baca, Z. R. Wang, D. Vaknin, and D. C. Johnston. "Neutron Diffraction Study of the Magnetic Ordering of $\mathrm{BaCuO}_{2+\times}$," March Meeting of the American Physics Society, Pittsburgh, PA, March 21-25, 1994.

Wang, H. Y., R. N. Singh, S. C. Beecher, and R. B. Dinwiddie*. "Thermal Shock Behavior of Fiber-Reinforced Composites," 96th Annual Meeting of the American 
Ceramic Society, Indianapolis, IN, April 24-28, 1994.

Wang, Z. R., D. Vaknin, D. C. Johnston, X-L. Wang, ${ }^{*}$ and J. A. Fernandez-Baca.

"Magnetization Measurements of Ferromagnetic $\mathrm{Cu}_{6}$ and $\mathrm{Cu}_{18}$ Clusters in $\mathrm{BaCuO}_{2+\times}$,

March Meeting of the American Physics Society, Pittsburgh, PA, March 21-25, 1994.

Watkins, T. R., X-L. Wang, ${ }^{*}$ C. R. Hubbard, B. H. Rabin, P. Zschack, and M. Nelson. "Residual Stress Distribution in Graded Ceramic-to-Metal Joints," 96th Annual Meeting of the American Ceramic Society, Indianapolis, IN, April 24-28, 1994.

Wereszczak, A. A., ${ }^{*}$ M. K. Ferber, ${ }^{*}$ and T. P. Kirkland*. "Fracture Evolution in HIPed Silicon Nitride at Elevated Temperatures," Oak Ridge National Laboratory, Oak Ridge, TN. 


\section{APPENDIX C: FY 1994 HTML ADVISORY COMMITTEES}

FY 1994 HTML ADVISORY COMMITTEE

Dr. Ronald H. Chand (1992)

Chand Kare Technical Ceramics

Worcester, MA

Mr. Al A. Chesnes (1992)

Department of Energy Headquarters (retired)

Washington, DC

Mr. Bryan J. McEntire (1992)

Saint Gobain /Norton Industrial Ceramics Corp.

East Granby, CT
Dr. James W. Patten (1991)

Cummins Engine Co.

Columbus, IN

Dr. Maxine L. Savitz (1990)

AlliedSignal Ceramic Components

Torrance, CA

Dr. William T. Snyder (1993);

University of Tennessee

Knoxville, TN

FY 1994 HTML USER ADVISORY (PROPOSAL REVIEW) COMMITTEE

Mr. Lance Groseclose (1991)

Allison Gas Turbine Operations

General Motors Corporation

Indianapolis, IN

Dr. Linda Horton (1987)

Oak Ridge National Laboratory

Metals \& Ceramics Division

Oak Ridge, TN

Ms. Mary Rawlins (1991)

Department of Energy

Oak Ridge National Laboratory

Oak Ridge, TN
Dr. V. J. Tennery, Chair

Oak Ridge National Laboratory

High Temperature Materials Laboratory

Oak Ridge, TN

Dr. Wendell S. Williams (1993);

Dept. of Materials Science and Engineering

Case Western Reserve University

Cleveland, $\mathrm{OH}$

Dr. Thomas J. Whalen (1991)

Ford Motor Company

Dearborn Heights, MI 



\section{APPENDIX D: STANDARD NONPROPRIETARY USER AGREEMENTS IN PLACE (CUMULATIVE) J ULY 1987-SEPTEMBER 1994 INDUSTRIES - 91}

Note: Multiple listings indicate user organizations with facilities in more than one state

\section{ALABAMA}

Monarch Tile, Inc. (Florence)

ARIZONA

AlliedSignal (Phoenix)

\section{CALIFORNIA}

AlliedSignal EMRC (Los Angeles)

Alzeta Corp. (Santa Clara)

Amercom Inc. (Chatsworth)

Applied Materials, Inc. (Santa Clara)

CERCOM, Inc. (Vista)

Guidance \& Control Systems - Litton Ind. (Woodland Hills)

IBM Almaden Research Center (San Jose)

Membrane Technology Research (Menlo Park)

Northrop Corporation (Pico Rivera)

Nuclear \& Aerospace Materials Corp. (Poway)

Rohr Industries, Inc. (Chula Vista)

Solar Turbines, Inc. (San Diego)

Sullivan Mining Corp. (San Diego)

Sundstrand Power Systems (San Diego)

Ultramet (Pacoma)

\section{COLORADO}

Coors Ceramics Company (Golden)

\section{CONNECTICUT}

Torrington $\mathrm{Co}$. (Torrington)

United Technologies (Pratt \& Whitney) (East Hartford)

\section{DELAWARE}

E. I. DuPont de Nemours (Wilmington)

FLORIDA

Pratt \& Whitney (West Palm Beach)

Westinghouse Electric Corporation (West Palm Beach)

$$
\text { GEORGIA }
$$

Ionic Atlanta, Inc. (Atlanta)

ILLINOIS

AlliedSignal (Des Plains)

Caterpiller Inc. - Tech Center (Peoria)

$$
\text { INDIANA }
$$

AlliedSignal (South Bend)

Allison Engine Co., Inc. (Indianapolis)

Cummins Engine Company (Columbus)

GM Corporation/Delco Remy (Andersonville)

\section{KENTUCKY}

Florida Tile Industries (Lawrenceburg)

\section{MASSACHUSETTS}

American Superconductor Corp. (Westborough)

Ceramics Process Systems Corp. (Cambridge)

Chand Kare Tech Ceramics (Worchester)

Foster-Miller, Inc. (Waltham)
GTE Laboratories, Inc. (Waltham)

Norton Company (Northboro)

Norton/TRW Ceramics (Northboro)

Refractory Testing Associates (Chestnut Hill)

Textron Specialty Materials (Lowell)

MICHIGAN

Chrysler Corporation (Highland Park)

Detroit Diesel Corporation (Detroit)

Dow Corning Corp./Midland

Eaton Corporation (Southfield)

Energy Conversion Devices, Inc. (Troy)

Ford Motor Company (Ann Arbor)

GM Research \& Development (Warren)

Valenite, Inc. (Troy)

\section{MINNESOTA}

FMC Naval Systems Division (Minneapolis)

MISSISSIPPI

Alpha Optical Systems (Ocean Springs)

MISSOURI

McDonnell Douglas Corp. (St. Louis) NEW HAMPSHIRE

Miniature Precision Bearings (Keene) NEW JERSEY

AlliedSignal (Morristown) AT\&T Bell Laboratories (Murrary Hill)

Ceramic Magnetics, Inc. (Fairfield)

Engelhard Corp. (Edison)

Exxon Research \& Eng. Co. (Annadell)

INRAD (Northvale)

\section{NEW YORK}

Advanced Refractory Tech, Inc. (Buffalo)

Carborundum Company (Niagara Falls)

Eastman Kodak Co. (Rochester)

ReMaxCo Technologies, Inc. (Kenmore)

\section{NORTH CAROLINA}

Selee Corporation (Hendersonville)

Teledyne Allvac (Monroe)

\section{OHIO}

Applied Sciences, Inc. (Yellow Springs)

Eaton Corporation (Willoughby Hills)

G.E. Aircraft Engines (Cincinnati)

Goodyear Tire \& Rubber Co. (Akron)

Procter \& Gamble (Cincinnati)

Tosoh SMD, Inc. (Grove City)

Universal Energy Systems, Inc. (Dayton)

PENNSYLVANIA

Alcoa Tech Center (Alcoa Center)

Certainteed Corporation (Valley Forge)

Concurrent Technologies Corp. (Johnstown)

Thermacore, Inc. (Lancaster)

Westinghouse Science \& Tech Center (Pittsburgh)

RHODE ISLAND

Quadrax Corporation (Portsmouth) 


\section{TENNESSEE}

American Matrix, Inc. (Knoxville)

CTI, Inc. (Knoxville)

Cavin Consulting Services (Knoxville)

Church \& Dwight Co., Inc. (Knoxville)

Coors Electronic Package (Chattanooga)

Coors Technical Center (Oak Ridge)

DG Trim Products (Alcoa)

Great Lakes Research (Elizabethton)

IMTech Company (Knoxville)

J. A. Martin (Knoxville)

Oxyrase (Knoxville)

ReMaxCo Technologies (Kingston)

Tennessee Center for R\&D (Knoxville)
Third Millennium Tech, Inc. (Knoxville)

TEXAS

CarboMedics, Inc. (Austin)

Exxon Corp. (Houston)

Southwest Research Institute (San Antonio)

UTAH

LoTEC, Inc. (Salt Lake City)

VIRGINIA

B\&W Nuclear Technologies (Lynchburg)

Babcock \& Wilcox (Lynchburg)

Institute for Defense Analyses (Alexandria)

Phillip Morris (Richmond)

\section{UNIVERSITIES - 102}

\section{AlabaMA}

Alabama A\&M Univ (Normal)

Auburn Univ (Auburn)

Tuskegee Univ (Tuskegee)

Univ of Alabama - Tuscaloosa

Univ of Alabama - Birmingham

\section{ARIZONA}

Arizona State (Tempe)

Univ of Arizona (Tucson)

\section{CALIFORNIA}

Stanford Univ (Stanford)

Univ of Calif, Irvine

Univ of Calif, Los Angeles

Univ of Calif, San Diego

Univ of Calif, Santa Cruz

Univ of Southern California

\section{COLORADO}

Univ of Denver

\section{CONNECTICUT}

Univ of Connecticut (Storrs)

Yale Univ (New Haven)

\section{DELAWARE}

Univ of Delaware (Newark)

\section{FLORIDA}

Florida Atlantic Univ (Boca Raton)

Florida International Univ (Miami)

Florida Solar Energy Center (Cape Canaveral)

Florida State Univ (Tallahassee)

Univ of Florida (Gainesville)

\section{GEORGIA}

Georgia Institute of Technology (Atlanta)

HAWAII

Univ of Hawaii (Honolulu)

ILLINOIS

Illinois Institute of Technology (Chicago)

Northwestern Univ (Evanston)
Southern Illinois Univ (Carbondale)

Univ of Illinois (Urbana)

INDIANA

Univ of Notre Dame (South Bend)

IOWA

Iowa State Univ (Ames)

\section{KENTUCK}

Berea College (Berea)

Univ of Kentucky (Lexington)

LOUISIANA

Louisiana State Univ and A\&M (Baton. Rouge)

Southern Univ (Baton Rouge)

MARYLAND

Johns Hopkins Univ (Baltimore)

Univ of Maryland (College Park)

\section{MASSACHUSETTS}

Harvard Univ (Cambridge)

Massachusetts Inst of Tech. (Cambridge)

Mount Holyoke College (South Hadley)

Univ of Massachusetts (Amherst)

\section{MICHIGAN}

Michigan State Univ (East Lansing)

Michigan Technological Univ (Houghton)

Univ of Michigan (Ann Arbor)

MINNESOTA

Univ of Minnesota (Minneapolis)

MISSISSIPPI

Mississippi College (Clinton)

Mississippi State Univ (Mississippi State)

\section{MISSOURI}

Univ of Missouri-Columbia

Univ of Missouri-Rolla

Washington Univ (St. Louis)

\section{NEW H AMPSHIRE}

Dartmouth College (Hanover) 
NEW JERSEY

New Jersey Inst of Tech (Newark)

Princeton Univ (Princeton)

Rutgers Univ (Piscataway)

Stevens Institute of Technology (Hoboken)

NEW MEXICO

NM Inst of Mining \& Tech (Socorro)

Univ of New Mexico (Albuquerque)

\section{NEW YORK}

Alfred Univ, Col of Ceramics (Alfred)

Clarkson Univ (Potsdam)

Cornell Univ (Ithaca)

Polytechnic Univ (Brookland)

Rensselaer Polytechnic Inst (Troy)

Rochester Institute of Tech (Rochester)

Univ of Rochester (Rochester)

\section{NORTH CAROLINA}

North Carolina A\&T State Univ (Greensboro)

North Carolina State Univ (Raleigh)

Univ of North Carolina (Chapel Hill)

\section{OHIO}

Case Western Reserve Univ (Cleveland)

John Carroll Univ (University Heights)

Kent State Univ (Kent)

Ohio State Univ (Columbus)

Univ of Cincinnati

Univ of Akron

Univ of Dayton

Wright State Univ

\section{OKLAHOMA}

Oklahoma State Univ (Stillwater)

Univ of Oklahoma (Oklahoma City)

\section{OREGON}

Oregon Graduate Institute (Portland)

Oregon State Univ (Corvallis)

PENNSYLVANIA

Carnegie Mellon Univ (Pittsburgh)
Lehigh Univ (Lehigh)

Pennsylvania State Univ (University Park)

Univ of Pennsylvania (Philadelphia)

Univ of Pittsburgh (Pittsburgh)

RHODE ISLAND

Brown Univ (Providence)

SOUTH CAROLINA

Clemson Univ (Clemson)

Univ of South Carolina (Columbia)

SOUTH DAKOTA

South Dakota State Univ (Brookings)

TENNESSEE

Maryville College (Maryville)

Tennessee Techrological Univ (Cookeville)

Univ of Tennessee (Knoxville)

Vanderbilt Univ (Nashville)

\section{TEXAS}

Rice Univ (Houston)

Texas A\&M Univ (College Station)

Univ of Houston

Univ of Texas-Arlington

UTAH

Univ of Utah (Salt Lake)

VIRGINIA

VPI \& State Univ (Blacksburg)

Washington \& Lee Univ (Lexington)

WASHINGTON

Washington State Univ (Pullman)

Univ of Washington (Seattle)

WEST VIRGINIA

West Virginia Univ (Morgantown)

WISCONSIN

Marquette Univ (Milwaukee)

Univ of Wisconsin (Madison)

\section{OTHER GOVERNMENT FACILITIES - 9}

Note: Multiple listings indicate user organizations with facilities in more than one state

\section{ALABAMA}

U.S. Bureau of Mines/Tuscaloosa

\section{CALIFORNIA}

Naval Post Graduate School

IDAHO

Idaho National Engineering Lab

MARYLAND

U.S. Naval Academy

\section{NEW MEXICO}

Los Alamos National Laboratory Sandia National Laboratory

\section{ОНIO}

EG\&G Mound Applied Tech NASA Research Ctr.

OREGON

U.S. Bureau of Mines/Albany VIRGINIA

NASA Langley Research Center WASHINGTON, DC

Naval Research Laboratory 

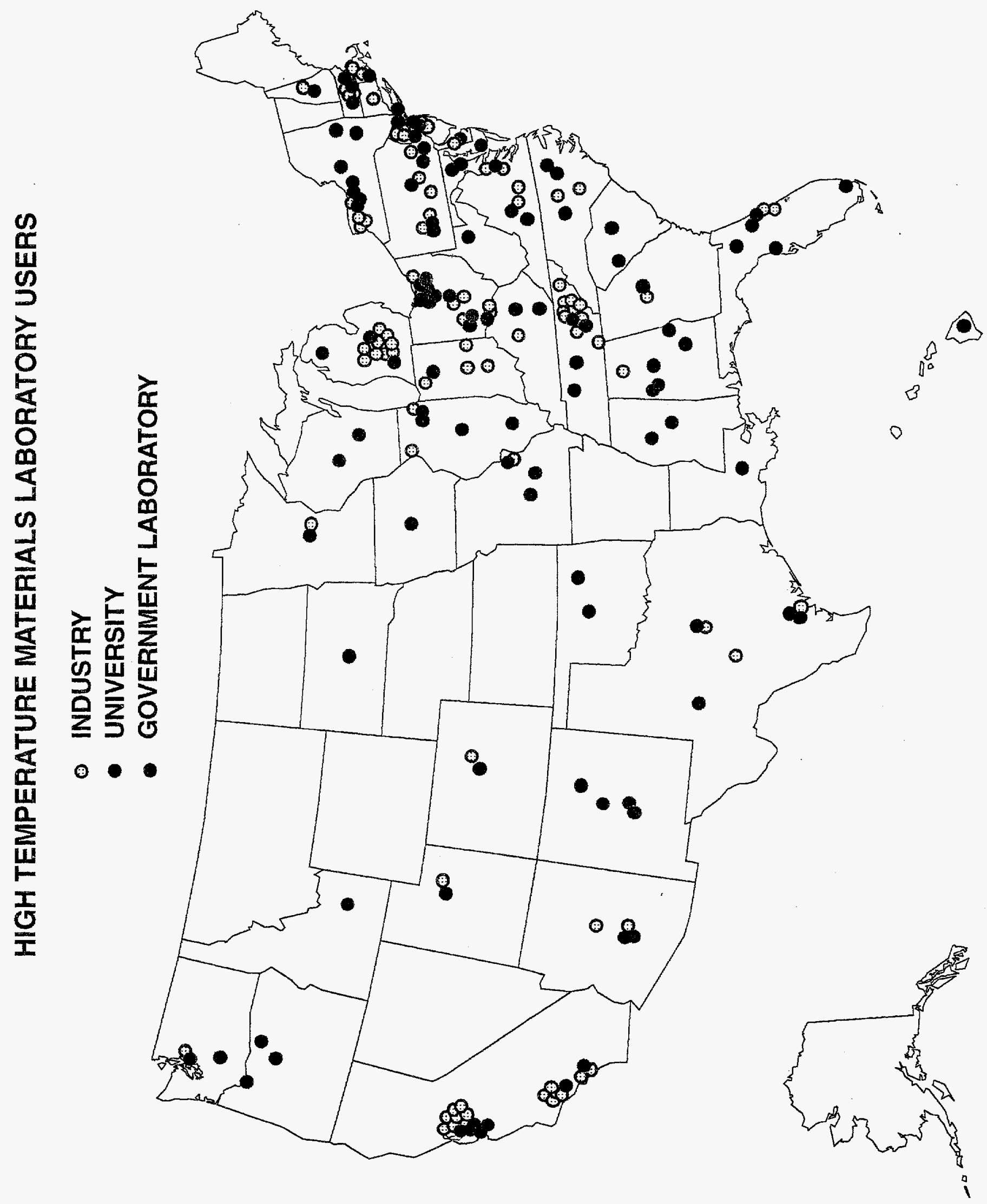


\section{APPENDIX E: FY 1994 NONPROPRIETARY RESEARCH PROPOSALS}

\begin{tabular}{|c|c|c|c|}
\hline \multicolumn{4}{|c|}{ IST QUARTER FY 1994 REVIEW MEETING } \\
\hline PROP \# & $\begin{array}{l}\text { INSTITUTION } \\
\text { (\# of proposals from institution) } \\
\text { TITLE OF PROPOSAL }\end{array}$ & USERS & $\begin{array}{l}\text { USER } \\
\text { CENTER(S) }\end{array}$ \\
\hline $93-081$ & $\begin{array}{l}\text { Clemson University (13) } \\
\text { "A Microstructural Analysis of High Thermal } \\
\text { Conductivity Carbon Fibers" }\end{array}$ & $\begin{array}{l}\text { Dan Edie } \\
\text { (spokesperson) } \\
\text { Kerry Robinson }\end{array}$ & MAUC \\
\hline $93-082$ & $\begin{array}{l}\text { Mass. Institute of Technology (2) } \\
\text { "Fatigue of Micromechanical Devices" }\end{array}$ & $\begin{array}{l}\text { Stuart Brown } \\
\text { (spokesperson) } \\
\text { Will Van Arsdell }\end{array}$ & MPUC \\
\hline $93-083$ & $\begin{array}{l}\text { LANL (1) } \\
\text { "Preliminary Assessment of Residual Stress in } \\
\text { Quenched Heat Treated and Carburized } \\
\text { Automobile Parts" }\end{array}$ & $\begin{array}{l}\text { Mark Bourke } \\
\text { (spokesperson) } \\
\text { Joyce Goldstone }\end{array}$ & RSUC \\
\hline $93-084$ & $\begin{array}{l}\text { Rensselaer Polytechnic Institute (3) } \\
\text { "Study Involving Signa Time/Tal } 21 \text { Composite } \\
\text { System" }\end{array}$ & $\begin{array}{l}\text { Himanshu Nigam } \\
\text { (spokesperson) } \\
\text { G. J. Dvorak } \\
\text { D. Buchanan }\end{array}$ & MPUC \\
\hline $93-085$ & $\begin{array}{l}\text { NASA Research Center (2) } \\
\text { "Understanding } \mathrm{MoSi}_{2} \mathrm{Accelerated} \mathrm{Oxidation} \mathrm{at} \\
500^{\circ "}\end{array}$ & $\begin{array}{l}\text { David R. Hull } \\
\text { (spokesperson) } \\
\text { R. Dickerson } \\
\text { Joy Doychak } \\
\text { Mohan Hebsur }\end{array}$ & MAUC \\
\hline $93-086$ & $\begin{array}{l}\text { GE Aircraft Engines (2) } \\
\text { "Residual Stress in MMCs" }\end{array}$ & P. K. Wright & RSUC \\
\hline $93-087$ & $\begin{array}{l}\text { Carnegie Mellon Univ. (1) } \\
\text { "Wave Function Retrieval in High-Resolution } \\
\text { Transmission Electron Microscopy" }\end{array}$ & Marc DeGraef & MAUC \\
\hline $93-088$ & $\begin{array}{l}\text { Sandia National Laboratories (1) } \\
\text { "Thermal Conductivity of Thermal-Battery } \\
\text { Materials" }\end{array}$ & Ronald A. Guidotti & PPUC \\
\hline $93-089$ & $\begin{array}{l}\text { Cummins Engine Company (7) } \\
\text { "Characterization of the Oil Balls and Their } \\
\text { Influence on Premature Overlay Removal of } \\
\text { Diesel Engine Bearings" }\end{array}$ & Magan J. Patel & $\begin{array}{l}\text { MAUC } \\
\text { MPUC }\end{array}$ \\
\hline $93-090$ & $\begin{array}{l}\text { Vanderbilt University (12) } \\
\text { "The Incorporation of Texture into the } \\
\text { Constitutive Modeling of Materials Through } \\
\text { the Use of Internal Variables" }\end{array}$ & $\begin{array}{l}\text { Pedro C. Bastias } \\
\text { (spokesperson) } \\
\text { K. Y. Kim }\end{array}$ & RSUC \\
\hline $93-091$ & $\begin{array}{l}\text { Advanced Refractory Technologies (6) } \\
\text { "Mechanical Properties of AIN-SiCw Composites } \\
\text { Exposed to a Corrosive Environment" }\end{array}$ & Thomas J. Mroz & $\begin{array}{l}\text { MAUC } \\
\text { MPUC }\end{array}$ \\
\hline $93-092$ & $\begin{array}{l}\text { AlliedSignal, Inc. (17) } \\
\text { "Effect of Room-and Elevated-Temperature } \\
\text { Proof Testing on the Elevated Temperature } \\
\text { Residual Strength of NT-154 Silicon Nitride" }\end{array}$ & $\begin{array}{l}\text { Nanu M. Menon } \\
\text { (spokesperson) } \\
\text { Ho T. Fang } \\
\text { David C. Wu } \\
\end{array}$ & MPUC \\
\hline $93-093$ & $\begin{array}{l}\text { AlliedSignal, Inc. (18) } \\
\text { "Effect of Surface Condition, Machined versus } \\
\text { As-Densified Surface, in Flexural Cyclic } \\
\text { Fatigue of NT-154 Silicon Nitride" }\end{array}$ & $\begin{array}{l}\text { Nanu M. Menon } \\
\text { (spokesperson) } \\
\text { Ho T. Fang } \\
\text { David C. Wu }\end{array}$ & MPUC \\
\hline $93-094$ & $\begin{array}{l}\text { Advanced Refractory Technologies (7) } \\
\text { "Characterization of Interfaces in AIN-SiCw } \\
\text { Composites" }\end{array}$ & Eric Groat & MAUC \\
\hline
\end{tabular}




\begin{tabular}{|c|c|c|c|}
\hline $93-095$ & $\begin{array}{l}\text { Advanced Refractory Technologies (8) } \\
\text { "Determination of the Physical and Chemical } \\
\text { Characteristics of M Grade SiCW" }\end{array}$ & Eric Groat & MAUC \\
\hline $93-096$ & $\begin{array}{l}\text { Georgia Tech (20) } \\
\text { "Texture Analysis and Nanoindentation of } \\
\text { Polycrystalline NiAl" }\end{array}$ & $\begin{array}{l}\text { Dave McDowell } \\
\text { (spokesperson) } \\
\text { Ritesh Shah }\end{array}$ & $\begin{array}{l}\text { MPUC } \\
\text { RSUC }\end{array}$ \\
\hline $93-097$ & $\begin{array}{l}\text { Solar Turbines (2) } \\
\text { "Long-Term Durability Testing of CFCCs for } \\
\text { Combustor Liner Applications" }\end{array}$ & Jane Simpson & MPUC \\
\hline $93-098$ & $\begin{array}{l}\text { Coors Electronic Packaging (13) } \\
\text { "Characterization of Gold Microstructure to Limit } \\
\text { Nickel Diffusion and Improve Functional } \\
\text { Performance" }\end{array}$ & $\begin{array}{l}\text { William K. Baxter } \\
\text { (spokesperson) } \\
\text { Earl Winters }\end{array}$ & $\begin{array}{l}\text { MAUC } \\
\text { MPUC } \\
\text { XRDUC }\end{array}$ \\
\hline $93-099$ & $\begin{array}{l}\text { Clemson University (14) } \\
\text { "High Thermal Conductivity Carbon/Carbon } \\
\text { Composites" }\end{array}$ & $\begin{array}{l}\text { Dan Edie } \\
\text { (spokesperson) } \\
\text { James W. Klett }\end{array}$ & PPUC \\
\hline $93-100$ & $\begin{array}{l}\text { General Motors - North American Operations } \\
\text { R\&D Center (1) } \\
\text { "TEM Investigation of Precipitation in Metal } \\
\text { Matrix Composites" }\end{array}$ & $\begin{array}{l}\text { Raja K. Mishra } \\
\text { (spokesperson) } \\
\text { V. Franetovitch }\end{array}$ & MAUC \\
\hline $93-101$ & $\begin{array}{l}\text { Univ. of llinois (10) } \\
\text { "Residual Stress in Ferroelectric Thin Layers" }\end{array}$ & $\begin{array}{l}\text { David A. Payne } \\
\text { (spokesperson) } \\
\text { C. Lakeman }\end{array}$ & RSUC \\
\hline $93-102$ & $\begin{array}{l}\text { VPI \& State Univ. (16) } \\
\text { "Thermal Shock Cycling of Combustion } \\
\text { Chamber Materials" }\end{array}$ & $\begin{array}{l}\text { Deidre Hirschfeld } \\
\text { (spokesperson) } \\
\text { S. Alexander }\end{array}$ & PPUC \\
\hline $93-103$ & $\begin{array}{l}\text { Ohio State University (2) } \\
\text { "Grain Boundary Composition Versus Bulk } \\
\text { Composition in Nonstoichiometric Nd123 } \\
\text { Superconducting Oxides" }\end{array}$ & $\begin{array}{l}\text { Ken Sandhage } \\
\text { (spokesperson) } \\
\text { Holly Miron }\end{array}$ & MAUC \\
\hline $93-105$ & $\begin{array}{l}\text { Carnegie Mellon Univ. (2) } \\
\text { "Structural Characterization of Chemically } \\
\text { Synthesized High-Pressure Cubic Spinel } \\
\text { Phase of } Z \mathrm{Zn}_{2} \mathrm{~S}_{4} \text { " }\end{array}$ & $\begin{array}{l}\text { Prashant N. Kunta } \\
\text { (spokesperson) } \\
\text { M. A. Sriram }\end{array}$ & XRDUC \\
\hline \multicolumn{4}{|c|}{ 2ND QUARTER FY 1994 REVIEW MEETING } \\
\hline $93-104$ & $\begin{array}{l}\text { University of Utah (5) } \\
\text { "Composition Analysis of the } \mathrm{Gd}_{2} \mathrm{O}_{3} \mathrm{Bi}_{2} \mathrm{O}_{3} \\
\text { System" }\end{array}$ & $\begin{array}{l}\text { A.V. Virkar } \\
\text { (spokesperson) } \\
\text { Pomin Su }\end{array}$ & MAUC \\
\hline $\begin{array}{l}94-002 \\
\text { Rev. } 1\end{array}$ & $\begin{array}{l}\text { University of Tennessee }(36) \\
\text { "Microanalysis for Life Prediction of High } \\
\text { Temperature Material HR } 160^{\text {" }}\end{array}$ & $\begin{array}{l}\text { Peter Liaw } \\
\text { (spokesperson) } \\
\text { Weiju Ren }\end{array}$ & MAUC \\
\hline $\begin{array}{l}\text { 94-003 } \\
\text { Rev. } 1\end{array}$ & $\begin{array}{l}\text { Northwestern University (3) } \\
\text { "Electron Interferometry and Holography of } \\
\text { Internal Interfaces" }\end{array}$ & $\begin{array}{l}\text { Vinayak P. Dravid } \\
\text { (spokesperson) } \\
\text { Nathan Wilcox } \\
\text { V. Ravikumar }\end{array}$ & MAUC \\
\hline $94-005$ & $\begin{array}{l}\text { University of Michigan (4) } \\
\text { "Effect of Grain Boundary Phase on } \\
\text { Microstructure and Fracture Toughness of } \\
\text { Silicon Nitride" }\end{array}$ & $\begin{array}{l}\text { T. Y. Tien } \\
\text { (spokesperson) } \\
\text { Irene M. Peterson }\end{array}$ & $\begin{array}{l}\text { MAUC } \\
\text { CMUC }\end{array}$ \\
\hline $94-006$ & $\begin{array}{l}\text { University of Rochester (1) } \\
\text { "Impression Creep of Tin Grain Boundaries and } \\
\text { Triple Points" }\end{array}$ & $\begin{array}{l}\text { J.C.M. Li } \\
\text { (spokesperson) } \\
\text { Fuquian Yand }\end{array}$ & MPUC \\
\hline $\begin{array}{l}\text { 94-007 } \\
\text { Rev. } 1\end{array}$ & $\begin{array}{l}\text { St. Gobain/Norton (9) } \\
\text { "Inert Environment Creep Performance of NCX- } \\
5102 \text { Silicon Nitride" }\end{array}$ & Michael Foley & MPUC \\
\hline $94-008$ & $\begin{array}{l}\text { Northwestern Universtiy (4) } \\
\text { "Nanoindention and Compressive Strength } \\
\text { Testing of Nanophase Iron" }\end{array}$ & $\begin{array}{l}\text { Julia R. Weertman } \\
\text { (spokesperson) } \\
\text { Gretchen Fougere }\end{array}$ & MPUC \\
\hline
\end{tabular}




\begin{tabular}{|c|c|c|c|}
\hline $94-010$ & $\begin{array}{l}\text { Florida Atlantic University (1) } \\
\text { "Effect of } \mathrm{Ca} \text { Substitutions on the Physical } \\
\text { Properties of } \mathrm{YBa}_{2} \mathrm{Cu}_{3} \mathrm{O}_{6+d} "\end{array}$ & Theodora Leventouri & $\begin{array}{l}\text { XRDUC } \\
\text { RSUC }\end{array}$ \\
\hline $\begin{array}{l}94-011 \\
\text { Rev. } 1\end{array}$ & $\begin{array}{l}\text { University of Michigan (5) } \\
\text { "Effect of Grain Boundary Phase on Residual } \\
\text { Stress and Fracture Toughness of Silicon } \\
\text { Nitride" }\end{array}$ & $\begin{array}{l}\text { T. Y. Tien } \\
\text { (spokesperson) } \\
\text { Irene M. Peterson }\end{array}$ & RSUC \\
\hline $94-012$ & $\begin{array}{l}\text { University of Illinois (11) } \\
\text { "Characterization of the High Temperature } \\
\text { Phase Transformation in } \mathrm{Y}_{4} \mathrm{Al}_{2} \mathrm{O}_{9}, \mathrm{Dy}_{4} \mathrm{Al}_{2} \mathrm{O}_{9} \text {. } \\
\text { and } \mathrm{Gd}_{4} \mathrm{Al}_{2} \mathrm{O}_{9}{ }^{n}\end{array}$ & $\begin{array}{l}\text { Waltraud M. Kriven } \\
\text { (spokesperson) } \\
\text { James L. Shull }\end{array}$ & $\begin{array}{l}\text { PPUC } \\
\text { XRDUC }\end{array}$ \\
\hline $\begin{array}{l}94-013 \\
\text { Rev. } 2\end{array}$ & $\begin{array}{l}\text { Penn State University (15) } \\
\text { "Residual Stress Measurement in UNS G93106 } \\
\text { Steel" }\end{array}$ & $\begin{array}{l}\text { Dr. Richard A. Queeney } \\
\text { (spokesperson) } \\
\text { Christopher Paliani }\end{array}$ & RSUC \\
\hline $94-014$ & $\begin{array}{l}\text { Northwestern University (5) } \\
\text { "Investigation of the Elastic Modulus of } \mathrm{M}_{2} \mathrm{C}(\mathrm{M} \square \\
\mathrm{Mo}, \mathrm{Dr}, \mathrm{Fe}, \mathrm{V})\end{array}$ & $\begin{array}{l}\text { Dr. Katherine T. Faber } \\
\text { (spokesperson) } \\
\text { Cheryi Knepfler }\end{array}$ & MPUC \\
\hline $94-015$ & $\begin{array}{l}\text { Penn State University (16) } \\
\text { "Field Emission TEM Applications in Ceramics: } \\
\text { Particle Shapes and Grain Boundary } \\
\text { Segregation" }\end{array}$ & Altaf H. Carim & MAUC \\
\hline $94-016$ & $\begin{array}{l}\text { West Virginia University (1) } \\
\text { "Characterization and Mechanical Evaluation of } \\
\text { Plasma-Enhanced CVD Silicon Nitride Coated } \\
\text { SCS-6 Fibers" }\end{array}$ & $\begin{array}{l}\text { Dr. R.K. Gupta } \\
\text { (spokesperson) } \\
\text { Daniel Collazos }\end{array}$ & $\begin{array}{l}\text { MAUC } \\
\text { MPUC }\end{array}$ \\
\hline $94-017$ & $\begin{array}{l}\text { University of Hawaii (1) } \\
\text { "High Temperature C Ring Flexure Testing and } \\
\text { Residual Stresses Determination of Filament- } \\
\text { Wound Ceramic Matrix Composites" }\end{array}$ & $\begin{array}{l}\text { Dr. Mehrdad Nejhad } \\
\text { (spokesperson) } \\
\text { Mahesh Chandramouli }\end{array}$ & $\begin{array}{l}\text { MAUC } \\
\text { MPUC } \\
\text { RSUC }\end{array}$ \\
\hline $\begin{array}{l}\text { 94-018 } \\
\text { Rev. } 1\end{array}$ & $\begin{array}{l}\text { Valenite, Inc. (1) } \\
\text { "Process-Property Correlation of Diamond and } \\
\text { DLC Films on Cutting Tools: Development of } \\
\text { an Industrial Process for Superhard Coatings" }\end{array}$ & Dr. Deepak G. Bhat & MAUC \\
\hline $\begin{array}{l}94-020 \\
\text { Rev. } 1\end{array}$ & $\begin{array}{l}\text { Ceramatec, Inc. (1) } \\
\text { "Determination of Residual Stress in Layered } \\
\text { WC Produced by Differential Creep" }\end{array}$ & $\begin{array}{l}\text { Raymond A. Cutler } \\
\text { (spokesperson) } \\
\text { T. Barrett Jackson }\end{array}$ & $\begin{array}{l}\text { PPUC } \\
\text { RSUC }\end{array}$ \\
\hline $\begin{array}{l}94-021 \\
\text { Rev. } 1\end{array}$ & $\begin{array}{l}\text { University of Delaware (4) } \\
\text { "HRTEM of Molybdenum-Promoted Rhodium on } \\
\text { Gamma-Alumina: Correlation of Metal } \\
\text { Aggregate Properties with Activity, Selectivity, } \\
\text { and High-Temperature Carbon Monoxide } \\
\text { Exposure" }\end{array}$ & $\begin{array}{l}\text { Dr. Henry C. Foley } \\
\text { (spokesperson) } \\
\text { Eric E. Lowenthal }\end{array}$ & MAUC \\
\hline $\begin{array}{l}94-022 \\
\text { Rev. } 2\end{array}$ & $\begin{array}{l}\text { Penn State University (17) } \\
\text { "Investigate Post-Annealing Lattice Recovery in } \\
\text { a Y-Implanted Sapphire Substrate Using } \\
\text { Glancing-Angle X-Ray Analysis" }\end{array}$ & $\begin{array}{l}\text { Dr. John R. Hellmann } \\
\text { (spokesperson) } \\
\text { Matthew A. Stough }\end{array}$ & XRDUC \\
\hline $\begin{array}{l}\text { 94-023 } \\
\text { Rev. } 1\end{array}$ & $\begin{array}{l}\text { Ford Research Laboratory (1) } \\
\text { "Residual Stress Analyses on Al } 319 \text { Thermally } \\
\text { Sprayed Coating Systems" }\end{array}$ & $\begin{array}{l}\text { Oludele O. Popoola } \\
\text { (spokesperson) } \\
\text { Matther J. Zaluzec } \\
\text { Robert C. McCune }\end{array}$ & RSUC \\
\hline $\begin{array}{l}94-025 \\
\text { Rev. } 1\end{array}$ & $\begin{array}{l}\text { St. Gobain/Norton (10) } \\
\text { "Tensile Creep Resistance of NT } 164 \text { Silicon } \\
\text { Nitride in Ambient and Inert Environments } \\
\text { ("As-HIPed" versus "Conventionally Machined" } \\
\text { Surfaces)" }\end{array}$ & Russell Yeckley & $\begin{array}{l}\text { MAUC } \\
\text { MPUC } \\
\text { XRDUC }\end{array}$ \\
\hline $94-026$ & $\begin{array}{l}\text { University of Michigan (6) } \\
\text { "Lateral Compressive Behavior of Crosslinkable } \\
\text { PPTA-co-XTA High-Performance Polymer } \\
\text { Fibers by Nanoindention" }\end{array}$ & $\begin{array}{l}\text { Prof. David C. Martin } \\
\text { (spokesperson) } \\
\text { Marie-Christine G. Jones }\end{array}$ & MPUC \\
\hline
\end{tabular}




\begin{tabular}{|c|c|c|c|}
\hline $94-027$ & $\begin{array}{l}\text { Naval Research Lab (1) } \\
\text { "Thermal Conductivity of Nanocomposite } \\
\text { Aluminum Nitride" }\end{array}$ & $\begin{array}{l}\text { Paul Schoen } \\
\text { (spokesperson) } \\
\text { Yung-Shou Ho }\end{array}$ & PPUC \\
\hline $94-028$ & $\begin{array}{l}\text { Valenite, Inc. (2) } \\
\text { "Analysis of Structure of Composite } \mathrm{Al}_{2} \mathrm{O}_{3}-\mathrm{ZrO}_{2} \\
\text { CVD Coatings" }\end{array}$ & $\begin{array}{l}\text { Dr. William C. Russell } \\
\text { Dr. Deepak G. Bhat }\end{array}$ & MAUC \\
\hline $\begin{array}{l}\text { 94-029 } \\
\text { Rev. } 1\end{array}$ & $\begin{array}{l}\text { Cummins Engine Co., Inc. (1) } \\
\text { "Microstructural Characterization of } \\
\text { Electrochemical Celis" }\end{array}$ & Dr. Sivanandi Rajaduri & MAUC \\
\hline $\begin{array}{l}94-030 \\
\text { Rev. } 1\end{array}$ & $\begin{array}{l}\text { Cummins Engine Co., Inc. (2) } \\
\text { "Microstructural Characterization of Oxidation } \\
\text { Catalysts" }\end{array}$ & Dr. Suzanne Raebel & $\begin{array}{l}\text { MAUC } \\
\text { XRDUC }\end{array}$ \\
\hline $94-032$ & $\begin{array}{l}\text { Coors Electronic Package (14) } \\
\text { "Effect of Various Heat-Treatments and } \\
\text { Chemical Activation Steps on the Surface } \\
\text { Composition of Plated Ni-B Films" }\end{array}$ & $\begin{array}{l}\text { William K. Baxter } \\
\text { (spokesperson) } \\
\text { Dr. Earl D. Winters }\end{array}$ & MAUC \\
\hline $94-034$ & $\begin{array}{l}\text { Cercom, Inc. (1) } \\
\text { "Investigation of Sources of Mechanical Failure } \\
\text { of Sic Ceramics" }\end{array}$ & $\begin{array}{l}\text { Richard Policka } \\
\text { (spokesperson) } \\
\text { James Shih }\end{array}$ & $\begin{array}{l}\text { MAUC } \\
\text { MPUC }\end{array}$ \\
\hline $94-035$ & $\begin{array}{l}\text { Arizona State (1) } \\
\text { "Electron Holographic Imaging of Potential } \\
\text { Distributors in Semiconductors" }\end{array}$ & $\begin{array}{l}\text { Dr. Martha R. } \\
\text { McCartney }\end{array}$ & MAUC \\
\hline $94-036$ & $\begin{array}{l}\text { University of Arizona (3) } \\
\text { "Investigation of a Standard Reference Material } \\
\text { for the Nanoindenter" }\end{array}$ & $\begin{array}{l}\text { Dr. Brian Fabes } \\
\text { (spokesperson) } \\
\text { W. Howard Poisl }\end{array}$ & MPUC \\
\hline $94-037$ & $\begin{array}{l}\text { North Carolina State ( } 9 \text { ) } \\
\text { "Analysis of Adhesion at Metal-Ceramic } \\
\text { Interfaces" }\end{array}$ & $\begin{array}{l}\text { Robert F. Davis } \\
\text { (spokesperson) } \\
\text { Robert D. James } \\
\end{array}$ & $\begin{array}{l}\text { MAUC } \\
\text { MPUC }\end{array}$ \\
\hline \multicolumn{4}{|c|}{ 3RD QUARTER FY 1994 REVIEW MEETING } \\
\hline $94-009$ & $\begin{array}{l}\text { Ford Research Laboratory (2) } \\
\text { "Effect of Thermal Cycling on the Thermal } \\
\text { Conduction of HCC-MMCs (High Ceramic } \\
\text { Content Metal Matrix Composites)" }\end{array}$ & $\begin{array}{l}\text { Gary Crosbie } \\
\text { (spokesperson) }\end{array}$ & PPUC \\
\hline $\begin{array}{l}94-038 \\
\text { Rev. } 1\end{array}$ & $\begin{array}{l}\text { lowa State University (2) } \\
\text { "Thermal Expansion Anisotropy of } \mathrm{Ti}_{s} \mathrm{Si}_{3} \mathrm{Z}_{x} \text { " }\end{array}$ & $\begin{array}{l}\text { Dr. Mufit Akinc } \\
\text { (spokesperson) } \\
\text { Andrew Thom }\end{array}$ & $\begin{array}{l}\text { RSUC } \\
\text { XRDUC }\end{array}$ \\
\hline $\begin{array}{l}94-039 \\
\text { Rev. } 1\end{array}$ & $\begin{array}{l}\text { Purdue University (1) } \\
\text { "Elastic Properties of Single Crystal and } \\
\text { Textured Polycrystalline Ceramics" }\end{array}$ & $\begin{array}{l}\text { Keith J. Bowman } \\
\text { (spokesperson) } \\
\text { Peter Miller } \\
\text { David Collins }\end{array}$ & CMUC \\
\hline $94-040$ & $\begin{array}{l}\text { Oregon Graduate Institute of Science and } \\
\text { Technology (1) } \\
\text { "Effect of Weld Parameter and Groove } \\
\text { Configuration on Girth Weld Residual Stress } \\
\text { State" }\end{array}$ & $\begin{array}{l}\text { Dr. David G. Atteridge } \\
\text { (spokesperson) } \\
\text { Ming Li }\end{array}$ & RSUC \\
\hline $\begin{array}{l}\text { 94-042 } \\
\text { Rev. } 1\end{array}$ & $\begin{array}{l}\text { AlliedSignal Engines (19) } \\
\text { "Influence of Surface Condition on Creep } \\
\text { Rupture of NT-154 Silicon Nitride" }\end{array}$ & $\begin{array}{l}\text { M. Nanu Menon } \\
\text { (spokesperson) } \\
\text { Ho T. Fang } \\
\text { David C. Wu }\end{array}$ & MPUC \\
\hline $94-044$ & $\begin{array}{l}\text { EG\&G Idaho, Inc, (1) } \\
\text { "Residual Stress Mapping of Graded } \mathrm{Al}_{2} \mathrm{O}_{3}-\mathrm{Ni} \\
\text { Joints" }\end{array}$ & $\begin{array}{l}\text { Dr. B. H. Rabin } \\
\text { (spokesperson) }\end{array}$ & RSUC \\
\hline $\begin{array}{l}94-045 \\
\text { Rev. } 1\end{array}$ & $\begin{array}{l}\text { Texas A\&M (1) } \\
\text { "Map Retained Austenite. Dislocation Density } \\
\text { and Texture Difference in } 4140 \text { Steel Tube" }\end{array}$ & $\begin{array}{l}\text { Don E. Bray } \\
\text { (spokesperson) } \\
\text { Ron A. Pfluger }\end{array}$ & RSUC \\
\hline $\begin{array}{l}\text { 94-046 } \\
\text { Rev. } 1\end{array}$ & $\begin{array}{l}\text { Georgia Institute of Technology (21) } \\
\text { "Mechanical Properties of Metastable Thin-Film } \\
\text { Materials" }\end{array}$ & $\begin{array}{l}\text { Byungwoo Park } \\
\text { (spokesperson) } \\
\text { Canan Uslu } \\
\text { Deok-Hyung Lee }\end{array}$ & MPUC \\
\hline
\end{tabular}




\begin{tabular}{|c|c|c|c|}
\hline $94-047$ & $\begin{array}{l}\text { University of Tennessee (37) } \\
\text { "Characterization of Healing Films Formed } \\
\text { During Pitting Corrosion of Tungsten- } \\
\text { Implanted Aluminum" }\end{array}$ & $\begin{array}{l}\text { Raymond A. Buchanan } \\
\text { (spokesperson) } \\
\text { Preston P. Smith }\end{array}$ & $\begin{array}{l}\text { MAUC } \\
\text { CMUC }\end{array}$ \\
\hline $\begin{array}{l}\text { 94-048 } \\
\text { Rev. } 1\end{array}$ & $\begin{array}{l}\text { Rohr, Inc. (1) } \\
\text { "Simultaneous Thermal Analysis and Evolved } \\
\text { Gas Analysis During Pyrolysis of Preceramic } \\
\text { Polymers" }\end{array}$ & $\begin{array}{l}\text { Andrew S. Gurney } \\
\text { (spokesperson) }\end{array}$ & PPUC \\
\hline $\begin{array}{l}94-049 \\
\text { ReV. } 1\end{array}$ & $\begin{array}{l}\text { Boeing Commercial Airplane Group (1) } \\
\text { "Processing and Quenching Residual Stresses } \\
\text { in Aluminum Aircraft Components" }\end{array}$ & $\begin{array}{l}\text { Donna Walker } \\
\text { (spokesperson) }\end{array}$ & RSUC \\
\hline $94-050$ & $\begin{array}{l}\text { Eastman Kodak Company (1) } \\
\text { "Residual Stress Measurements of Coated } \\
\text { Photographic Product Using X-Ray Diffraction } \\
\text { Methods" }\end{array}$ & $\begin{array}{c}\text { Thomas N. Blanton } \\
\text { (spokesperson) }\end{array}$ & RSUC \\
\hline $94-051$ & $\begin{array}{l}\text { University of Dayton (3) } \\
\text { "An Investigation Into the Sources of instability } \\
\text { of NTC Thermistors When Exposed to } \\
\text { Elevated Temperatures for Extended Periods } \\
\text { of Time" }\end{array}$ & $\begin{array}{l}\text { Nora Osborne } \\
\text { (spokesperson) }\end{array}$ & $\begin{array}{l}\text { RSUC } \\
\text { XRDUC }\end{array}$ \\
\hline $94-052$ & $\begin{array}{l}\text { University of New Mexico (3) } \\
\text { "Electron Holography of Catalytic Materials" }\end{array}$ & $\begin{array}{l}\text { Abhaya Datye } \\
\text { (spokesperson) }\end{array}$ & MAUC \\
\hline $94-053$ & $\begin{array}{l}\text { University of Alabama/Birmingham (6) } \\
\text { "Crystallization of lon-Beam Sputter Deposited } \\
\text { Hydroxyapatite" }\end{array}$ & $\begin{array}{c}\text { E. Douglas Rigney } \\
\text { (spokesperson) }\end{array}$ & XRDUC \\
\hline $\begin{array}{l}94-054 \\
\text { Rev. } 1\end{array}$ & $\begin{array}{l}\text { Concurrent Technologies, Inc. (5) } \\
\text { "Thermophysical Properties Measurements of } \\
\text { HY-100 Steel and II-Ni Bronze Alloy" }\end{array}$ & $\begin{array}{l}\text { Jin-Myun Jo } \\
\text { (spokesperson) } \\
\text { Mary Jane Kleinosky } \\
\text { Ronald E. Smelser }\end{array}$ & PPUC \\
\hline $94-056$ & $\begin{array}{l}\text { Advanced Refractory Technologies, Inc. } \\
\text { "Characterization of Aluminum Nitride Whiskers" }\end{array}$ & $\begin{array}{l}\text { Eric A. Groat } \\
\text { (spokesperson) }\end{array}$ & MAUC \\
\hline $94-057$ & $\begin{array}{l}\text { G.E. Aircraft Engines } \\
\text { "Specific Heat Capacity of Physical Vapor } \\
\text { Deposited and Plasma Sprayed Thermal } \\
\text { Barrier Coatings" }\end{array}$ & $\begin{array}{l}\text { Bangalore A. Nagaraj } \\
\text { (spokesperson) }\end{array}$ & PPUC \\
\hline \multicolumn{4}{|c|}{ 4TH QUARTER FY 1994 REVIEW MEETING } \\
\hline $\begin{array}{l}\text { 94-055 } \\
\text { Rev. } 3\end{array}$ & $\begin{array}{l}\text { Rodel, Inc. (1) } \\
\text { "Effects of Chemical Mechanical Polishing } \\
\text { (CMP) on Metal Interconnect Structures" }\end{array}$ & $\begin{array}{l}\text { Anantha R. Sethuraman } \\
\text { (spokesperson) }\end{array}$ & $\begin{array}{l}\text { MAUC } \\
\text { XRDUC } \\
\text { RSUC }\end{array}$ \\
\hline $94-059$ & $\begin{array}{l}\text { McDonnell Douglas (5) } \\
\text { "Development of High Thermal Conductivity } \\
\text { Carbon Fiber Composities" }\end{array}$ & $\begin{array}{l}\text { David A. Bowers } \\
\text { (spokesperson) }\end{array}$ & MPUC \\
\hline $\begin{array}{l}\text { 94-060 } \\
\text { Rev. } 1\end{array}$ & $\begin{array}{l}\text { Westinghouse Electric Company (2) } \\
\text { "Materials Property Evaluation of Combustion } \\
\text { Turbine Overlay/Bond Coatings (MCrAlY's) } \\
\text { from Room Temperature to } 1650^{\circ} \mathrm{F}^{\prime}\end{array}$ & $\begin{array}{l}\text { Alfred A. Pallotta } \\
\text { (spokesperson) }\end{array}$ & MPUC \\
\hline $94-061$ & $\begin{array}{l}\text { PPG Industries (1) } \\
\text { "Compressive Creep Testing of Fusion Cast } \\
\text { Alpha-Beta Alumina Material (Carborundum } \\
\text { Monofrax M)" }\end{array}$ & $\begin{array}{l}\text { Dr. George A Pecoraro } \\
\text { (spokesperson) } \\
\text { Mr. Gary Hughes } \\
\text { Dr. Michael Tenhover }\end{array}$ & MPUC \\
\hline $94-062$ & $\begin{array}{l}\text { North Carolina State University (10) } \\
\text { "Electron Holography and Atom Probe Study of } \\
\text { CoSi }_{2}-\text { Coated and Diamond-Coated Si Field } \\
\text { Emitters" }\end{array}$ & $\begin{array}{l}\text { Dr. John Hren } \\
\text { (spokesperson) } \\
\text { Alline Frances Myers }\end{array}$ & MAUC \\
\hline $94-063$ & $\begin{array}{l}\text { Polytechnic University (1) } \\
\text { "High Resolution TEM Investigation of } \\
\text { Dislocations in Gamma Titanum Aluminides" }\end{array}$ & $\begin{array}{l}\text { Sung H. Whang } \\
\text { (spokesperson) } \\
\text { Zhong-Min Wang }\end{array}$ & MAUC \\
\hline
\end{tabular}




\begin{tabular}{|c|c|c|c|}
\hline $\begin{array}{l}\text { 94-065 } \\
\text { Rev. } 1\end{array}$ & $\begin{array}{l}\text { ART, Inc. (8) } \\
\text { "Investigation of the Thermal and Mechanical } \\
\text { Properties and Structural Characteristics of } \\
\text { Diamond-like Nanocomposite (DLN) Thin } \\
\text { Films" }\end{array}$ & $\begin{array}{l}\text { Arvind Goel } \\
\text { (spokesperson) }\end{array}$ & $\begin{array}{l}\text { MPUC } \\
\text { MAUC } \\
\text { XRDUC }\end{array}$ \\
\hline $94-066$ & $\begin{array}{l}\text { University of Washington (2) } \\
\text { "Characterization of the Effects of Manufacturing } \\
\text { Processes on the Elevated Temperature } \\
\text { Properties and Performance of Self- } \\
\text { Reinforced Silicon Nitrides" }\end{array}$ & $\begin{array}{c}\text { Michael G. Jenkins } \\
\text { (spokesperson) }\end{array}$ & $\begin{array}{l}\text { MPUC } \\
\text { MAUC } \\
\text { XRDUC }\end{array}$ \\
\hline $94-067$ & $\begin{array}{l}\text { ART, Inc. (9) } \\
\text { "Determination of the Physical and Chemical } \\
\text { Characteristics of Titanium Nitride Whiskers } \\
\text { Systhesized via a Novel Route" }\end{array}$ & $\begin{array}{l}\text { Arvind Goel } \\
\text { (spokesperson) } \\
\text { Eric Groat }\end{array}$ & MAUC \\
\hline $\begin{array}{l}\text { 94-068 } \\
\text { Rev. } 1\end{array}$ & $\begin{array}{l}\text { Corning Incorporated (1) } \\
\text { "Reliability, Fatigue, and Machining Damage } \\
\text { Tolerance of Mica-Containing Glass- } \\
\text { Ceramics" }\end{array}$ & $\begin{array}{c}\text { Dr. Kenneth Chyung } \\
\text { (spokesperson) }\end{array}$ & $\begin{array}{l}\text { MPUC } \\
\text { MAUC }\end{array}$ \\
\hline $\begin{array}{l}\text { 94-069 } \\
\text { Rev. } 1\end{array}$ & $\begin{array}{l}\text { University of Tennessee (38) } \\
\text { "Measurement of Stiffness and Hardness of } \\
\text { Multiple Phase Intermetallics" }\end{array}$ & $\begin{array}{l}\text { Peter K. Liaw } \\
\text { (spokesperson) } \\
\text { Jeffrey A. Cook }\end{array}$ & $\begin{array}{l}\text { MPUC } \\
\text { MAUC }\end{array}$ \\
\hline $\begin{array}{l}94-070 \\
\text { Rev. } 1\end{array}$ & $\begin{array}{l}\text { Golden Technologies Co. (1) } \\
\text { "Analysis of Residual Stresses in GTC's } \\
\text { Sintered Reaction Bonded Silicon Nitride } \\
\text { (SRBSN)" }\end{array}$ & $\begin{array}{l}\text { Garry J. Ganey } \\
\text { (spokesperson) }\end{array}$ & $\begin{array}{l}\text { RSUC } \\
\text { XRDUC } \\
\text { MPUC }\end{array}$ \\
\hline $\begin{array}{l}\text { 94-071 } \\
\text { Rev. } 1\end{array}$ & $\begin{array}{l}\text { Alabama A\&M University (2) } \\
\text { "Process Dependence of Orientation of Aromatic } \\
\text { Ribbons (Fibrils) and Storage of Lithium in } \\
\text { Glassy Carbon" }\end{array}$ & $\begin{array}{l}\text { Hossein Maleki } \\
\quad \text { (spokesperson) } \\
\text { D. lla } \\
\text { Gwyn M. Jenkins } \\
\text { Lawrence R. Holland }\end{array}$ & $\begin{array}{l}\text { XRDUC } \\
\text { MAUC } \\
\text { MPUC }\end{array}$ \\
\hline $\begin{array}{l}\text { 94-072 } \\
\text { Rev. } 1\end{array}$ & $\begin{array}{l}\text { U. S. Bureau of Mines (2) } \\
\text { "Characterization Microstructure of Mechanically } \\
\text { Alloyed Fe-N Powder" }\end{array}$ & $\begin{array}{c}\text { Dr. James C. Rawers } \\
\text { (spokesperson) }\end{array}$ & $\begin{array}{l}\text { RSUC } \\
\text { XRDUC } \\
\text { MAUC } \\
\text { MPUC }\end{array}$ \\
\hline $\begin{array}{l}\text { 94-073 } \\
\text { Rev. } 1\end{array}$ & $\begin{array}{l}\text { Rolls Royce, Inc. (1) } \\
\text { "Effect of Thermal Exposure on Residual } \\
\text { Stresses in TiAl" }\end{array}$ & $\begin{array}{l}\text { Jerry Allsman } \\
\text { (spokesperson) } \\
\text { Dr. Ash Thakker }\end{array}$ & $\begin{array}{l}\text { RSUC } \\
\text { MAUC }\end{array}$ \\
\hline $\begin{array}{l}\text { 94-074 } \\
\text { Rev. } 1\end{array}$ & $\begin{array}{l}\text { Martin Marietta Corporation (1) } \\
\text { "Thermal Diffusivity Evaluation of Iron-Nickel } \\
\text { Electroform" }\end{array}$ & $\begin{array}{l}\text { Dr. James J. Steppan } \\
\text { (spokesperson) } \\
\text { Brian E. McClure }\end{array}$ & PPUC \\
\hline $94-075$ & $\begin{array}{l}\text { University of Illinois at Urbana-Champaign (12) } \\
\text { "Oxygen Octahedra Distortion in Rhombohedra } \\
\text { PZT Solid Solution and Constriction on } \\
\text { Polarization" }\end{array}$ & $\begin{array}{l}\text { Dwight Viehland } \\
\text { (spokesperson) } \\
\text { Xunhu Dai }\end{array}$ & PPUC \\
\hline $\begin{array}{l}94-076 \\
\text { Rev. } 1\end{array}$ & $\begin{array}{l}\text { NASA Langley Research Center (3) } \\
\text { "Determination of Heat-Transfer Properties for } \\
\text { Glass-Ceramic Materials Used in } \\
\text { Aerothermodynamic Heating Studies" }\end{array}$ & $\begin{array}{l}\text { Gregory M. Buck } \\
\text { (spokesperson) }\end{array}$ & PPUC \\
\hline $\begin{array}{l}94-077 \\
\text { Rev. } 1\end{array}$ & $\begin{array}{l}\text { Ceradyne, Inc. (1) } \\
\text { "Evaluation of the Creepfeed Grinding Process } \\
\text { for Improved Material Rates of Selected } \\
\text { Ceramic Materials" }\end{array}$ & $\begin{array}{l}\text { Robert Roy Baker } \\
\text { (spokesperson) } \\
\text { Dave Parmenter } \\
\text { Bijana Mikijelj }\end{array}$ & $\begin{array}{l}\text { CMUC } \\
\text { MPUC }\end{array}$ \\
\hline $\begin{array}{l}94-078 \\
\text { Rev. } 1\end{array}$ & $\begin{array}{l}\text { Westinghouse Electric Company (3) } \\
\text { "Investigation of the Long-Term, High } \\
\text { Temperature Properties of a Commercially } \\
\text { Available Continuous Ceramic Fiber- } \\
\text { Reinforced Ceramic Matrix Composite" }\end{array}$ & $\begin{array}{c}\text { Evan M. Ludeman } \\
\text { (spokesperson) }\end{array}$ & MPUC \\
\hline
\end{tabular}




\begin{tabular}{|c|c|c|c|}
\hline $94-079$ & $\begin{array}{l}\text { Georgia Institute of Technology (22) } \\
\text { "Microstructural Characterization of Carbon- } \\
\text { Carbon Composites Produced by FCVI" }\end{array}$ & $\begin{array}{l}\text { W. J. Lackey } \\
\text { (spokesperson) } \\
\text { Garth B. Freeman } \\
\text { Sundar Vaidyaraman }\end{array}$ & MAUC \\
\hline $94-080$ & $\begin{array}{l}\text { Carnegie Mellon Universtiy (3) } \\
\text { "Structural Characterization of Chemically } \\
\text { Synthesized Cubic Spinel Phase of } \mathrm{LiMn}_{2} \mathrm{O}_{4} \text { " }\end{array}$ & $\begin{array}{l}\text { Prashant N. Kumta } \\
\text { (spokesperson) } \\
\text { Akshay Waghray }\end{array}$ & $\begin{array}{l}\text { XRDUC } \\
\text { RSUC }\end{array}$ \\
\hline $94-081$ & $\begin{array}{l}\text { Oak Ridge National Lab (1); Metals and } \\
\text { Ceramics Division } \\
\text { "Thermal Expansion Behavior of Ceria-Stabilized } \\
\text { Zirconia" }\end{array}$ & $\begin{array}{l}\text { K. B. Alexander } \\
\text { (spokesperson) } \\
\text { P. F. Becher } \\
\text { S. Spooner }\end{array}$ & RSUC \\
\hline $94-082$ & $\begin{array}{l}\text { Phillip Morris, USA (1) } \\
\text { "Reaction Synthesis of } \mathrm{FeSi}_{2}, \mathrm{Ni}_{3} \mathrm{Si}_{1} \mathrm{Ti}_{5} \mathrm{Si}_{3}, \mathrm{CoSi}_{2} \\
\text { and a Composite of Silicide and Silicon } \\
\text { Carbide" }\end{array}$ & $\begin{array}{l}\text { Dr. Seetharama C. } \\
\text { Deevi (spokesperson) }\end{array}$ & $\begin{array}{l}\text { PPUC } \\
\text { XRDUC }\end{array}$ \\
\hline $94-083$ & $\begin{array}{l}\text { Cree Research, Inc. (1) } \\
\text { "TEM Analysis fo Group III Nitrides on SiC } \\
\text { Substrates" }\end{array}$ & $\begin{array}{l}\text { John Edmond } \\
\text { (spokesperson) }\end{array}$ & MAUC \\
\hline $94-084$ & $\begin{array}{l}\text { Universal Energy Systems, Inc. (3) } \\
\text { "Surface Hardening of Polymeric Composites by } \\
\text { High Energy lon Irradiation" }\end{array}$ & $\begin{array}{l}\text { Rabi S. Bhattacharya } \\
\text { (spokesperson) }\end{array}$ & MPUC \\
\hline $94-085$ & $\begin{array}{l}\text { Golden Technologies Company, Inc. (2) } \\
\text { "Evaluation of Centerless Grinding: A Cost- } \\
\text { Effective Production Process for Selected TT2 } \\
\text { and SRBSN Components" }\end{array}$ & $\begin{array}{l}\text { Jack Sibold } \\
\text { (spokesperson) } \\
\text { Marc Ritland }\end{array}$ & $\begin{array}{l}\text { CMUC } \\
\text { CMC }\end{array}$ \\
\hline $94-086$ & $\begin{array}{l}\text { Golden Technologies Company, Inc. (3) } \\
\text { "Creepfeed Grinding with COMMEC Assist of } \\
\text { Selected Ceramic/Metal Composites" }\end{array}$ & $\begin{array}{l}\text { Jack Sibold } \\
\text { (spokesperson) } \\
\text { Marc Ritland }\end{array}$ & $\begin{array}{c}\text { CMUC } \\
\text { CMC }\end{array}$ \\
\hline $94-087$ & $\begin{array}{l}\text { Eaton Manufacturing Tech Center (3) } \\
\text { "Evaluation of Centerless Grinding a Cost } \\
\text { Effective Production Process for SRBSN } \pi T 2 \\
\text { Components" }\end{array}$ & $\begin{array}{l}\text { Joseph A. Kovach } \\
\text { (spokesperson) }\end{array}$ & $\begin{array}{l}\text { CMUC } \\
\text { CMC }\end{array}$ \\
\hline $94-088$ & $\begin{array}{l}\text { University of Massachusetts (2) } \\
\text { "Residual Stress Measurements in Residual } \\
\text { Stress Strengthened Ceramic Materials" }\end{array}$ & $\begin{array}{l}\text { Karl Jakus } \\
\text { (spokesperson). }\end{array}$ & RSUC \\
\hline
\end{tabular}



ORNL/TM-12902

\section{INTERNAL DISTRIBUTION}

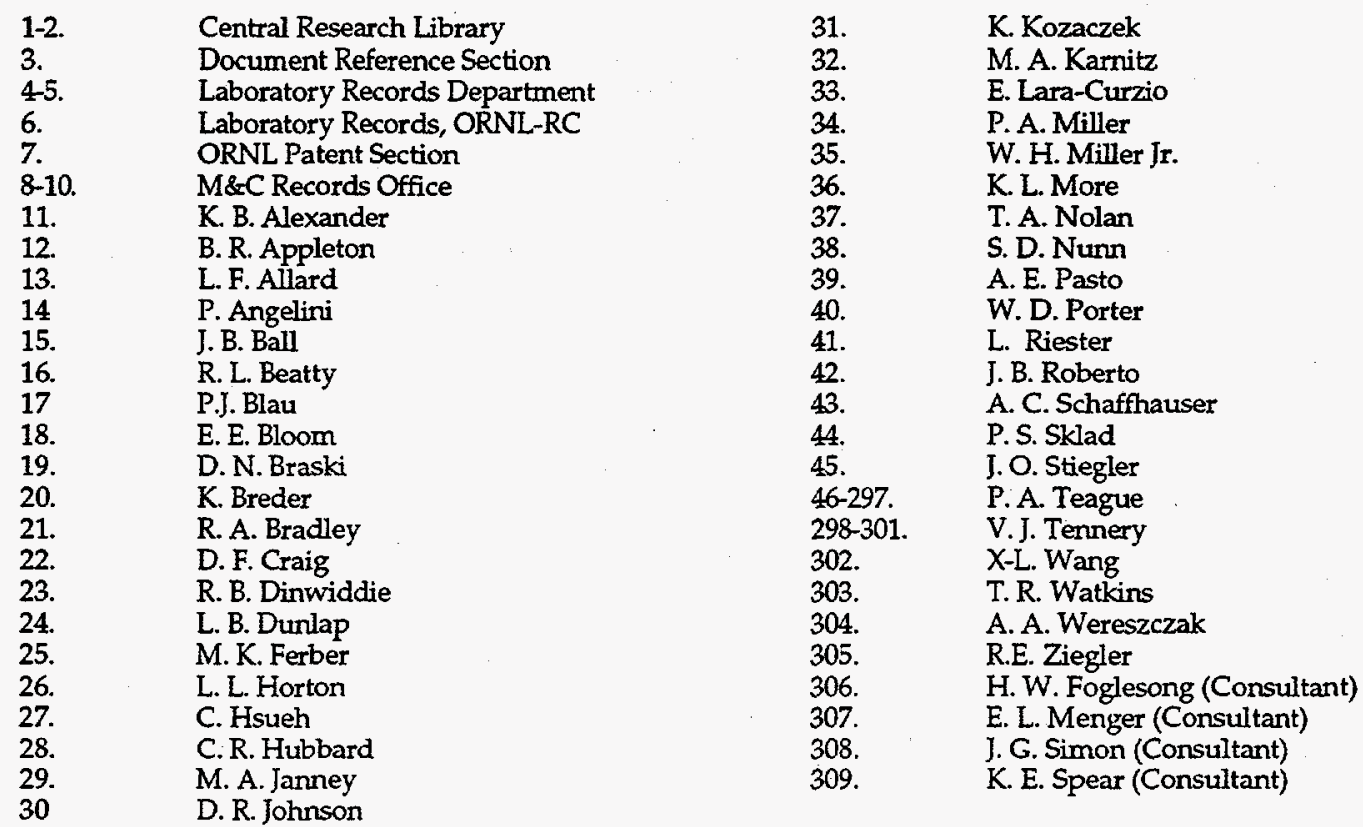

\section{EXTERNAL DISTRIBUTION}

310. AIR PRODUCTS, R\&D Lab No. 1, 7201 Hamilton Boulevard, Allentown, PA 18195

F. Kimock

311-313. ADVANCED REFRACTORY TECHNOLOGIES, INC., 699 Hertel Avenue, Buffalo, NY 14207
A. Goel
T. J. Mroz
E. Groat

314. ALABAMA A\&M UNIVERSITY, Department of Physics, Normal, AL 35762

H. Maleki

315-319. ALFRED UNIVERSITY, New York State College of Ceramics, P.O. Box 771, Alfred, NY 14802
T. Bell
D. Carnahan
R. L. Snyder
N. Ninos
J. Taylor

320. ALLIEDSIGNAL AEROSPACE COMPANY, 717 N. Bendix Drive, South Bend, IN 46620

R. Rateick

321-325. ALLIEDSIGNAL AEROSPACE COMPANY, Ceramic Components Division, 2525 W. 190th Street, MS:T52, Torrance, CA 90509

B. J. Busovne, Jr.

M. V. Mitchell

M. L. Savitz

J.P. Pollinger

H. C. Yeh

326-329. ALLIEDSIGNAL AEROSPACE COMPANY, Garrett Engine Division, MS 503-412, 111 S. 34th St., P.O. Box 52181, Phoenix, AZ 85034

H. T. Fang

M. N. Menon

J. Schienle

J. R. Smyth 
330-331. ALLIEDSIGNAL CORPORATE TECHNOLOGY, Box 1021, Morristown, NJ 07962-1021

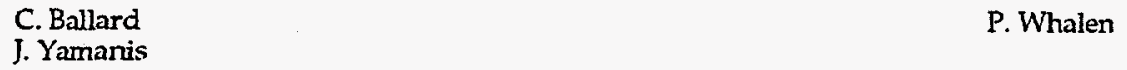

332-334. ALLIEDSIGNAL ENGINEERED MATERIALS RESEARCH CENTER, 50 East Algonquin Road, Box 5016, Des Plaines, IL 60017-5016

K. R. Karasek
R. Leung

335-339. ALLISON ENGINE COMPANY, P.O. Box 420, Indianapolis, IN 46206-54748

$\begin{array}{ll}\text { J. Chang } & \text { P. Khandelwal } \\ \text { L. E. Groseclose } & \text { R. D. Zordan } \\ \text { PJ. Haley } & \end{array}$

340-341. ALUMINUM COMPANY OF AMERICA, Alcoa Technical Center, Product of Design and Mechanics Division, Alcoa Center, PA 15069
R. A. Marra
H.F. Wu

342. ALZETA CORPORATION, 2343 Calle Del Mundo, Santa Clara, CA 95054

M. G. Carswell

343. AMERICAN SUPERCONDUCTOR, 149 Grove Street, Watertown, MA 02172

P. Gallien

344. APPLE COMPUTER COMPANY, INC.,20650 Valley Green Drive, MS: 26C, Cupertino, CA 95014

S. Myers

345. ARIZONA STATE UNIVERSITY, PSB234-CSSS, Tempe, AZ 85287-1704

M.R. McCartney

346. BOEING COMMERICAL AIRPLANE GROUP, P. O. Box 3703, MS 73-44, Seattle, WA 98124-2207

D. Walker

347-348. CASE WESTERN RESERVE UNIVERSITY, Department of Materials Science, 10900 Euclid Avenue, Cleveland, OH 44106
A. H. Heuer
W.S. Williams

349. CARBOMEDICS, INC., 1300 B East Anderson Lane, Austin, TX 78753

L. A. Beavan

350. THE CARBORUNDUM CO., P.O. Box 832, Bldg. 100, Niagara Falls, NY 14302

G. V. Srinivasan

351. CARNEGIE MELLON UNIVERSITY, 5000 Forbes Avenue, Pittsburgh, PA 15213

P. N. Kumpta

352-357. CATERPILLAR, INC., Technical Center, Bldg. E, P.O. Box 1875, Peoria, IL 61656-1875

C. J. Anderson

D. I. Biehler

M. H. Haselkom

J. L. Bjerke

H. D. Lawrence

E. Wolff

358. CERADYNE, INC. 3169 Redhill Avenue, Costa Mesa, CA 92626

R. R. Baker

359. CERCOM, Inc., 1960 Watson Way, Vista, CA 92083

R. Policka

360. CHAND KARE TECHNICAL CERAMICS, 2 Coppage Drive, Worchester, MA 01603

R. A. Chand

361. CHRYSLER CORPORATION, CIMS 418-17-09, 12000 Chrysler Drive, High Land Parks, MI 48288-1118

D. Wetzel

362-367. CLEMSON UNIVERSITY, College of Engineering, Department of Mechanical Engineering, 318 Riggs Hall, Clemson, SC 19634-0921
D. Brosnan
J. Jara-Almonte
T. D. Taylor
R. J. Diefendorf 
C. C. Fain

P. K. Wachtel

368-371. CONCURRENT TECHNOLOGIES CORPORATION, 1450 Scalp Ave., Johnston, PA 15904

$\begin{array}{ll}\text { R. Green } & \text { P. Khan } \\ \text { J. Jo } & \text { M. Kleinosky }\end{array}$

372-373. COORS CERAMICS CO., 17750 W 32nd Avenue, Golden, CO 80401

$\begin{array}{ll}\text { J. Coors } \quad \text { M. Readey } & \end{array}$

374-382. COORS ELECTRONIC PACKAGE CO., 511 Manufacturers Rd., Chattanooga, TN 37405

W. K. Baxter

W. Minehan

L. Dolhert

C. Schardt

K. Duchow

W. K. Weidner

C. Johnson

E. D. Winters

D. Horn

383-384. COORS TECHNICAL CERAMICS CO., 1100 Commerce Park Drive, Oak Ridge, TN 37830
J.M. Ghinazzi
W. Howe

385-387. CORNELL UNIVERSITY, Bard Hall, Ithaca, NY 14853-1501
H. Maring
C. K. Ober
L. R. Thompson

388-389. CORNING GLASS WORKS, Technical Ceramics, MP WX 01 05, Corning, NY 14831

\section{J. Henderson}

W. R. Prindle

390. CREE RESEARCH, INC., 2810 Meridian Parkway, Durham, NC 27713

J. Edmond

391-402. CUMMINS ENGINE CO., INC., Box 3005, MC 50183, Columbus, IN 47202
J. Bokelman
P. C. Becker
L. C. Broering
Y.C. Chen
J. E. Denton
M. Myers

M. J. Patel

J. W. Patten

S. Raebel

S. Rajadurai

B. E. Wilde

T. Yonushonis

403. CVC PRODUCTS, 6305 York Road, Suite 40, Baltimore, MD 21212

\section{F. Grunewald}

404-409. DETROIT DIESEL CORPORATION, World Headquarters, 13400 Outer Drive West, Detroit, MI 48239-4001
D. Giles
N. Hakim
J. Hyde
T. Kaushal
C. L. Hoberty
W. Lakso

410. DETROIT GASKET, Route 7, Box 7, Newport, TN 37821

$$
\text { M. L. Surbrook }
$$

411-412. THE DOW CHEMICAL CO., Analytical Science Laboratory, Midland, MI 48674
A. Pyzik
P. D. Stone

413-414. DOW CORNING CORPORATION, 3901 S. Saginaw Road, MS 43, Midland, MI 48640
W. H. Atwell
M. J. Loboda

415. EASTMAN KODAK COMPANY, Kodak Park B-49, Rochester, NY 14652-3712

T. N. Blanton

416-418. EATON CORPORATION, P. O. Box 766, Southfield, MI 48037

J. Barla

J. Edler

J. A. Kovach

419. EG\&G IDAHO, INC., P.O. Box 1625, Idaho Falls, ID 83415-2218

B. H. Rabin

420. EKZO CHEMICAL, INC., Livingston Avenue, Dobbs Ferry, NY 10522 
K. Kiss

421-422. ENERGY CONVERSION DEVICES, INC., 1675 West Maple Road, Troy, MI 48084

$\begin{array}{ll}\text { B. Chao } & \text { R. T. Young }\end{array}$

423-429. ENGELHARD CORPORATION, Menlo Park, P.O. Box 2900, Edison, NJ 08818-2900
F. M. Allen
R. J. Farrauto
T. A. Gegan
J. K. Lampert
T. W. Langner
J. St. Amand

M. Hamil

430. ETHEL CORPORATION, Ethyl Technical Center, P.O. Box 14799, Baton Rouge, LA 70898

M. Gluckstein

431-432. FIBER MATERIALS, INC., Biddeford Industrial Park, Biddeford, ME 04005

$\begin{array}{lll}\text { D. Dunn } & \text { M. K. Marshall }\end{array}$

433. FOSTER WHEELER DEVELOPMENT CORPORATION, 12 Peech Tree Hill Road, Livingston, NY 07039

J. Shenker

434. FLORIDA ATLANTIC UNIVERSITY, Physics Department, Boca Raton, FL: 33431

T. Leventori

435-436. FMC CORPORATION, Advanced Systems Center, 1300 South Second Street, P.O. Box 59043, Minneapolis, MI 55459-0043

M. J. Kneer J. Koo

437. FORD ELECTRONICS TECHNOLOGY CENTER, 17000 Rotunda Drive, Dearborn, MI 48121

K. Salisbury

438-441. FORD RESEARCH LAB, 2000 Rotunda Drive, P. O. Box 2053, MD 2313 SRL, Dearborn, MI 48121-2053
W. Donolon
O. A. Popoola
G. Crosbie
T. J. Whalen

442-443. FOSTER-MILLER, INC., 350 Second Avenue, Waltham, MA 02254

P. Stark

R. D. Tetrault

444. GBC CORPORATION, Monestary Drive, LaTrobe, PA 15650
E. R. Tostevin

445-450. GENERAL ELECTRIC AIRCRAFT ENGINES, 1 Neumann Way, Cincinnati, OH 45215
K. Bain
R. Harrison
B. A. Nagaraj
L. Lisiecki
P. K. Wright
J. Williams

451-452. GENERAL MOTORS - NORTH AMERICAN OPERATIONS, North American Operations R\&D Center, Warren, MI 48090
V. Franetovic
R.K. Mishra

453-455. THE GEORGIA INSTITUTE OF TECHNOLOGY, 110 Baker Building, Atlanta, GA 30332
G. B. Freeman
W. J. Lackey
T. L. Starr

456-457. GOLDEN TECHNOLOGIES COMPANY, 4545 Mcintyre Street, Golden, CO 80403

G. J. Garvey

J. Sibold

458. GTE LABS, Valenite, Materials Manufacturing, 1100 West 13th Mile Road, Madison Heights, MI 48071

K. Ostreicher

459. INSTRON, Corporate Technical Director, 100 Royall Street, Canton, MA 02021

J. Amaral 
460. INSTRON CORPORATION, 3781 N.E. Expressway, Suite 132, Atlanta, GA 30340

M. Mayer

461. IOWA STATE UNIVERSITY, 110 Engineering Annex, Amex, Iowa 50011

M. Akinc

462. ISCAR CERAMICS, INC., 36733 Amrhein, Livonia, MI 48150

J. Barta

463. THE JOHNS HOPKINS UNIVERSITY, Department of Materials Science and Engineering, 102 Maryland Hall, Baltimore, MD 21218

R. C. Cammarata

464. KANTHAL CORPORATION, 119 Wooster Street, Bethel, CN 06801

R. Watson

465. KEMET ELECTRONICS, P.O. Box 5928, Greenville, SC 29606

L. Mann

466. LANXIDE CORPORATION, Tralee Industrial Park, P. O. Box 6077, Newark, DE 19714-6077

J. Wang

467. LAWRENCE LIVERMORE LABORATORY, P.O. Box 808, MS L 566, Livermore, CA 94550

A. Tesar

468. LITTON INDUSTRIES, P.O. Box 87, 5500 Canoga Avenue, Woodland Hills, CA 91367

R. A. Hansen

469. LOS ALAMOS NATIONAL LABORATORY, Los Alamos, NM

M.A. Bourke

470. MARTIN MARIETTA AERO NAVAL SYSTEMS, 103 Cheasepeake Park Plaza, Baltimore, MD 21220

D. Trawinski

471. MARTIN MARIETTA CORPORATION, Advanced Manufacturing Technologies Department, P. O. Box 555837, M. P. 88, Orlando, FL 32885-5837

J. J. Steppan

472-473. MCDONNELL DOUGLAS CORPORATION, P.O. Box 516, St. Louis, MO 63166
D. A. Bowers
J. W. Sapp, Jr.

474-475. MEMBRANE TECH. \& RES., INC., 1360 Willow Rd., Menlo Park, CA 94025-1516
A. Athayde
P. Nguyen

476-477. MICHIGAN STATE UNIVERSITY, Engineering Research Facility, 2857 Jolly Road, Okemos, MI 48864
R. Schalek
H. Schock

478. MICHIGAN TECHNOLOGY UNIVERSITY, Houghton, MI 49931

C. White

479-481. MINIATURE PRECISION BEARINGS, Division of MPB Corporation, Precision Park, P.O. Box 547, Keene, NH 03431-0547
K. M. Gordon
R. L. Houghton

R. A. Hanson

482-483. MOBIL RESEARCH AND DEVELOPMENT CORPORATION, Central Research Laboratory, Pennington Rocky Hill Road, Pennington, NJ 08534
C. R. Aguinaldo
D. Olson

484-485. MONARCH TILE MANUFACTURING, INC., P.O. Box 999, Florence, AL 35630
D. Brosnan
J. Ranney

486. MONTANA TECHNOLOGY COMPANY, INC., Applied Testing Laboratory, 321 West Galena Street, Butte, MT 59701

F. Bradley 
487. MORGANTOWN ENERGY TECHNOLOGY CENTER, P. O. Box 880, Morgantown, PA 26507-0880

T. McMahon

488. MSE, INC., P.O. Box 3767, Butte, MT 59702

V. Griffiths

489-491. NASA LANGLEY RESEARCH CENTER, Mail Stop 194, Hampton, VA 23665
J. C. Rawers
K. E. Wiedeman

R. K. Clark

492. NATIONAL INSTITUTE OF STANDARDS AND TECHNOLOGY, Ceramics Division, Gaithersburg, MD 20899

\section{S. Freiman}

493. NEW MEXICO INSTITUTE OF MINING AND TECHNOLOGY, Department of Materials and Metallurgical Engineering, Socorro, NM 87801

K. Chawla

494-495. NORTH CAROLINA STATE UNIVERSITY, Department of Materials Engineering, Box 7907, Raleigh, NC 27695-7907
R. F. Davis
C. Koch

496-497. NORTHWESTERN UNIVERSITY, 2225 N. Campus Drive, Evanston IL 60208

K. T. Faber J. R. Weertman

498-508. NORTON COMPANY, High Performance Ceramics, Goddard Road, Northboro, MA 01532-1545
N. D. Corbin
B. J. McIntyre
M. Foley
J. N. Panzarino
S. D. Hartline
R. L. Yeckley

504. NUCLEAR \& AEROSPACE MATERIALS CORPORATION, 16716 Martincoit Road, Poway, CA 92064

G. B. Engle

505. OFFICE OF SCIENCE AND TECHNOLOGY POLICY, Old Executive Office Building, 175th Street and Pennsylvania Aventue, Washington, DC 20506

W. D. Phillips

506. OKLAHOMA STATE UNIVERSITY, Physics Department, Stillwater, OK 07478

C. Allison

507. OPTICAL COATING LABORATORY, 2789 Northpoint Parkway, Santa Rosa, CA 95407

J. Swab

508. OREGON GRADUATE INSTITUTE, P. O. Box 91000, Portland, OR 97291-1000

D. G. Atteridge

509. PCC AIRFOILS, 5105 Rex McLeod Road, Stanford, NC 27330

T. Crofts

510-517. THE PENNSYLVANIA STATE UNIVERSITY, 410 Walker Building, University Park, PA 16802
A. H. Carim
L. E. Cross
J. Hellmann
R. A. Queeney
D. J. Green
C. O. Ruud
K. Spear
R. Tressler

518. PPG INDUSTRIES, P. O. Box 11472, Pittsburgh, PA 15238-0472

G. A. Pecoraro

519. PHILIIP MORRIS, USA, Research and Development Center, 4201 Commerce Road, Richmond, VA 23234

S. C. Deevi

520. PITTSBURGH ENERGY TECHNOLOGY CENTER, P. O. Box 10940, Pittsburgh, PA 15236-0940

C. Smith

521. POLYTECHNIC UNIVERSIT, Six Metrotech Center, Brooklyn, NY 11201

S. H. Whang 
522-525. QUADRAX CORPORATION, 300 High Point Avenue, Portsmouth, RI 02871

A. Bailey

R. Florentine
R. Kierman

M. Mello

526-527. RENSSELAER POLYTECH INSTITUTE, Troy, NY 12180
S. S. Sternstein
R. D. Sarno

528-529. RICE UNIVERSITY, Department of Mechanical Engineering and Materials Science, P.O. Box 1892, Houston, TX77251

G. M. Pharr

W. Wilson

530. RODEL, INC., 451 Bellevue Road, Newark, DE 19713

A. R. Sethuraman

531. ROHR, INC, P. O. Box 878, MZ-107P, Chula Vista, CA 91912-0878

$$
\text { A.S. Gurney }
$$

532. ROLLS-ROYCE, INC., 2849 Paces Ferry Road, Suite 400, Atlanta, GA 30339-3769

J. Allsman

533-535. RUTGERS UNIVERSITY, Center for Ceramics Research, P.O. Box 909, Piscataway, NJ 08855-0909
S. C. Danforth
J. B. Wachtman
D. Niesz

536. SANDIA NATIONAL LABORATORY, Department 2522, P. O. Box 5800, Albuquerque, NM 87185-5800

R. A. Guidotti

537. SAN JOSE STATE UNIVERSITY, Department of Physics, San Jose, CA 95192-0106

F. Freund

538. SELEE CORPORATION, P.O. Box 747, Hendersonville, NC 38793

P. A. Bosomworth

539-541. SOLAR TURBINES INCORPORATED, P.O. Box 85376, San Diego, CA 92186
B. Harkins
M. Van Roode
V. Parthasarathy

542. SOUTHERN ILLINOIS UNIVERSITY, Rural Route 10, Box 99B, Carbondale, IL 62901

D. E. Wittmer

543. SOUTHERN UNIVERSITY, Mechanical Engineering Department, Baton Rouge, LA 70813

A. R. Mirshams

544. STANFORD UNIVERSIT, Peterson Building, Stanford, CA 94305

D. A. Stevenson

545-553. TELEDYNE ALLVAC, P.O. Box 5030, Monroe, NC 28110-0531
W. D. Cao
A. Gallagher
B. P. Hudson
L. Jackman
R. L. Kennedy
V. Lowery
J. Moyer
S. Taylor
S. Vallandingham

554555. TENNESSEE TECHNOLOGICAL UNIVERSITY, Center for Manufacturing Research, Brown Hall, Room 222 , Cookeville, TN 38505
T. Lundy
T. C. Ramaraj

556-557. TENNESSEE TECHNOLOGICAL UNIVERSITY, Chemical Engineering, Department, Cookeville, TN 38505
N. Faulk
D. Yarbrough

558. TEXAS A\&M UNIVERSITY, Department of Mechanical Engineering, College Station, TX 77843-3123

D. E. Bray

559. TEXTRON SPECIALTY MATERIALS, 2 Industrial Avenue, Lowell, MA 01851

T. Carroll 
560-563. THERMACORE, INC., 780 Eden Road, Lancaster, PA 17601
G. Y. Eastman
J. R. Hartenstine
D. M. Ernst
R. Keller

564. THERMO CERAMICS, INC., Box 923, Augusta, GA 30903

M. Katagiri

565. THIRD MILLENIUM TECHNOLOGIES, INC., 408 Cedar Bluff Road, Suite 383, Knoxville, TN 37923

S. C. Weaver

566-568. TOSOH SMD, INC., 3515 Grove City Road, Grove City, OH 43123
P. Frausto
C. E. Wickersham

C. McKeehan

569-574. TUSKEGEE UNIVERSITY, Tuskegee, AL 36088
H. A. Aglan
A. Haque
S. Jeelani
F. Wilks
M. Huq
D. Zadoo

575. UNITED TECHNOLOGIES RESEARCH CENTER, MS 129-30, East Hartford, CT 06108

D. Seery

576. UNIVERSAL ENERGY SYSTEMS, INC., 4401 Dayton-Xenia Road, Dayton, OH 45432-1894

R.S. Bhattacharya

577-580. UNIVERSITY OF ALABAMA-BIRMINGHAM, Materials Science and Engineering, BEC 360, Birmingham, AL 35294-4461
J. A. Haynes
R. D. Ott
E. D. Rigney
M. Rigsbee

581-586. THE UNIVERSITY OF ALABAMA-TUSCALOOSA, School of Mines and Energy Development, P.O. Box 870204, Tuscaloosa, AL 35487-0204
J. B. Gantenburg
C. R. Johnson
J. R. Levine
W. R. Lacefield
L. Lucas
J. L. Ong

587-589. UNIVERSITY OF ARIZONA, Departm ent of Materials Science and Engineering, Tucson, AZ 85712
B. Fabes
D. R. Uhleman
D. Taylor

590. UNIVERSITY OF CALIFORNIA-DAVIS, Department of Mechanical Engineering, Davis, CA 95616

J. C. Gibeling

591. UNIVERSITY OF CALIFORNIA-LOS ANGELES, Department of Earth and Space Sciences, 405 Hilgard Avenue, Los Angeles, CA 90024

P. Bird

592-593. THE UNIVERSITY OF DAYTON RESEARCH INSTITUTE, 300 College Park, Dayton, OH 45469-0001
N. L. Hecht
N. Osborne

594-597. UNIVERSITY OF DELAWARE, Department of Mechanical Engineering, Newark, DE 19716
H. C. Foley
A. Parvizi-Majdi
I. Hall
P. Pluvinage

598. UNIVERSITY OF DENVER, Engineering Department, University Park, Denver, CO 80208 P. K. Predecki

599-601. UNIVERSITY OF FLORIDA, Department of Materials Science and Engineering, Gainesville, FL 32611
D. E. Clark A. Cozzi
J. Mecholsky

602. UNIVERSITY OF HAWAII, 2540 Dole Street Holmes 302, Honolulu, HI 96822

M. Nejhad 
603-605. UNIVERSITY OF ILLINOIS, Department of Materials Science and Engineering, 105 South Goodwin Avenue, Room 212A, Urbana, IL 61801
S. D. Brown
W. Kriven
J. Economy

606-611. UNIVERSITY OF KENTUCKY, Center for Applied Energy Research, 3572 Iron Works Pike, Lexington, KY 40511-8433
B. H. Davis
P. Eklund
Y.Q. Fei
R. Gonzalez
R. Srinivasan
J. Stencel

612-613. THE UNIVERSITY OF MASSACHUSETTS, Amherst, MA 01003
K. Jackus
T. J. McCarthy

614-615. THE UNIVERSITY OF MICHIGAN, Materials Science and Engineering, $2201 \mathrm{H}$. H. Dow Building, Ann Arbor, MI 48109-2136
W. C. Bigelow
T. Y. Tien

616. UNIVERSITY OF MINNESOTA, Department of Chemical Engineering and Materials Science, 421 Washington Avenue SE, Minneapolis, MN 55455

M. L. McCartney

617. THE UNIVERSITY OF NEW MEXICO, Department of Chemical and Nuclear Engineering, Albuquerque, NM 87131

618. THE UNIVERSITY OF NORTH DAKOTA, Energy and Environmental Research Center, P. O. Box 8213, Grand Forks, ND 58202

J. Hurley

619. UNIVERSITY OF ROCHESTER, Department of Mechanical Engineering, 233 Hopeman Building, Rochester, NY 14627

J. C. M. Li

620-630. THE UNIVERSITY OF TENNESSEE, College of Engineering, Knoxville, TN 37996
C. R. Brooks
R. A. Buchanan
C. D. Lundin
S. Cao
J. F. Fellers
G. G. Geesey
T. T. Meek
J. Park
A. J. Pedraza
J. E. Spruiell

P. K. Liaw

631. THE UNIVERSITY OF TENNESSEE, Center for Materials Processing, 101 Perkins Hall, Knoxville, TN $37996-$ 2000

C. G. McHargue

632. UNIVERSITY OF UTAH, Department of Materials Science and Engineering, Salt Lake City, UT 84112

A. V. Virkar

633-634. U.S. BUREAU OF MINES, Tuscaloosa Research Center, P.O. Box L, Tuscaloosa, AL 35486

J. C. Rawers

L. Sadler

635-636. VALENITE, INC., 1711 Thunderbird Street, Troy, MI 48084
D. Bhat
W. C. Russell

637-638. VANDERBILT UNIVERSITY, Box 6309 Station B, Nashville, TN 37235
P. C. Bastias
J. J. Wert

639-644. VIRGINIA POLYTECHNIC INSTITUTE AND STATE UNIVERSITY, Materials Engineering Department, 301 Burruss Hall, Blacksburg, VA 24061
J. J. Brown
R. Hendricks
S. Desu
D. Hirshfeld
R. Gordon
K. Reifsnider

645. WEST VIRGINIA UNIVERSITY, P. O. Box 6101, Morgantown, WV 26505

R. K. Gupta 
646-647. WESTINGHOUSE ELECTRIC COMPANY, 4400 Alafaya Trial, MC 303, Orlando, FL 32826
E. M. Ludeman
A. A. Pallotta

648. DOE, OFFICE OF ASSISTANT SECRTETARY FOR DEFENSE PROGRAMS, Forrestal Building, 1000 Independence Avenue, Washington, DC 20585

D. Byrd

649-656. DOE, OFFICE OF ASSISTANT SECRETARY FOR ENERGY EFFICIENCY AND RENEWABLE ENERGY, Office of Transportation Technologies, Forrestal Building, 1000 Independence Avenue, Washington, DC 20585
S. Diamond
D. Haught
J. J. Eberhardt
P.Patterson
T. J. Gross
P. G. Patil
A. Hegnauer
R.B. Schulz

657. DOE, OFFICE OF ASSISTANT SECRETARY FOR ENERGY RESEARCH, Forrestal Building, 1000 Independence Avenue, Washington, DC 20585

T. Vojnovich

658-659. DOE, OAK RIDGE OPERATIONS OFFICE, P.O. Box 2008, Oak Ridge, TN 37831-6269

R. O. Hultgren

M. H. Rawlins

660-669. DOE, OFFICE OF SCIENTIFIC AND TECHNICAL INFORMATION, P.O. Box 62, Oak Ridge, TN 37831

For distribution by microfiche as shown in DOE /OSTI-4500, Distribution Categories UC-322

(Ceramics /Advanced Materials) and UC-365 (High-Temperature Materials). 